Prepared for the U.S. Department of Energy

Under Contract DE-AC05-76RL01830

\title{
Optimization of Rhodium-Based Catalysts for Mixed Alcohol Synthesis - 2009 Progress Report
}
MA Gerber
JF White
MJ Gray
BL Thompson
DJ Stevens

December 2010 


\title{
DISCLAIMER
}

This report was prepared as an account of work sponsored by an agency of the United States Government. Neither the United States Government nor any agency thereof, nor Battelle Memorial Institute, nor any of their employees, makes any warranty, express or implied, or assumes any legal liability or responsibility for the accuracy, completeness, or usefulness of any information, apparatus, product, or process disclosed, or represents that its use would not infringe privately owned rights. Reference herein to any specific commercial product, process, or service by trade name, trademark, manufacturer, or otherwise does not necessarily constitute or imply its endorsement, recommendation, or favoring by the United States Government or any agency thereof, or Battelle Memorial Institute. The views and opinions of authors expressed herein do not necessarily state or reflect those of the United States Government or any agency thereof.

\author{
PACIFIC NORTHWEST NATIONAL LABORATORY \\ operated by \\ BATTELLE \\ for the \\ UNITED STATES DEPARTMENT OF ENERGY \\ under Contract DE-AC05-76RL01830 \\ Printed in the United States of America \\ Available to DOE and DOE contractors from the \\ Office of Scientific and Technical Information, \\ P.O. Box 62, Oak Ridge, TN 37831-0062; \\ ph: (865) 576-8401 \\ fax: (865) 576-5728 \\ email: reports@adonis.osti.gov

\begin{abstract}
Available to the public from the National Technical Information Service, U.S. Department of Commerce, 5285 Port Royal Rd., Springfield, VA 22161 ph: (800) 553-6847 fax: (703) 605-6900 email: orders@ntis.fedworld.gov

online ordering: http://www.ntis.gov/ordering.htm
\end{abstract}




\title{
Evaluation of Promoters for Rhodium- Based Catalysts for Mixed Alcohol Synthesis - 2009 Progress Report
}

\author{
MA Gerber JF White \\ MJ Gray \\ BL Thompson \\ DJ Stevens
}

December 2010

Prepared for

the U.S. Department of Energy

under Contract DE-AC05-76RL01830

Pacific Northwest National Laboratory

Richland, Washington 99352 



\section{Executive Summary}

The U.S. Department of Energy's (DOE) Pacific Northwest National Laboratory (PNNL) and National Renewable Energy Laboratory (NREL) are conducting research to investigate the feasibility of producing mixed alcohols from biomass-derived synthesis gas (syngas). PNNL is tasked with screening promising mixed alcohol catalysts in a laboratory-scale reactor system. The most promising catalysts are provided to NREL for testing using a slipstream from a pilot-scale biomass gasifier.

After a review of the literature in 2006 and conversations at that time with companies that produce catalysts, we concluded that commercial catalysts for synthesizing mixed alcohols were not publically available. One catalyst manufacturer did supply a modified methanol catalyst (MeOH-X) that was tested in the PNNL laboratory-scale system and then provided to NREL for further testing. PNNL also prepared and tested the behavior of 10 other catalysts that represented the distinct catalyst classes that are used to synthesize mixed alcohols. The catalyst with the best combination of $\mathrm{C}_{2}+$ oxygenates space time yield (STY) and selectivity was a silica-supported catalyst containing rhodium (Rh) and manganese (Mn). These results of these tests were reported by Gerber and co-workers (Gerber et al. 2007).

Based on the catalyst screening test results, subsequent testing during 2007 and 2008 focused on the performance of the Rh-based catalyst to determine the effects of adding metals to Rh catalysts in addition to the Mn promoter already being used. A total of 28 tests were conducted to evaluate 22 different metals as well as the modified catalyst. These tests were described by Gerber and co-workers (Gerber et al. 2008).

The catalyst modified with iridium (Ir) significantly improved the STY of oxygenates with an observed maximum STY of approximately $810 \mathrm{~g} / \mathrm{L}_{\text {cat }} / \mathrm{hr}$. Platinum (Pt) followed with an observed maximum STY of $660 \mathrm{~g} / \mathrm{L}_{\mathrm{cat}} / \mathrm{hr}$. The catalysts modified with gold (Au), lithium (Li), nickel (Ni), molybdenum (Mo), and ruthenium $(\mathrm{Ru})$ also had observed maximum STYs that were higher than that achieved for the unmodified $\mathrm{RhMn} / \mathrm{SiO}_{2}$ catalyst ( $440 \mathrm{~g} / \mathrm{L}_{\text {cat }} / \mathrm{hr} \mathrm{C}_{2}+$ oxygenates STY), although the $\mathrm{Ru}-$ and Mo-modified catalysts rapidly deactivated during testing, and are considered unsuitable.

Of all of the catalysts evaluated, Li-modified catalysts had the highest carbon selectivity to $\mathrm{C}_{2}+$ oxygenates (47\%) under the conditions at which the maximum $\mathrm{C}_{2}+$ oxygenates STYs were obtained. The catalysts modified with Ir, Pt, and Au had carbon selectivity to $\mathrm{C}_{2}+$ oxygenates at maximum $\mathrm{C}_{2}+$ oxygenates STYs, of 39, 39, and 37\%, respectively, which were better than the unpromoted catalyst (with a carbon selectivity of 32\%). All of the modified catalysts with $\mathrm{C}_{2}+$ oxygenates STYs greater than the baseline catalyst mostly produced oxygenates other than $\mathrm{C}_{2}+$ alcohols. Only the gallium (Ga)- and indium (In)-modified catalysts had reasonably high $\mathrm{C}_{2}+$ oxygenates STYs (albeit lower than the unmodified catalyst) had very high ratios of $\mathrm{C}_{2}+$ alcohols to total $\mathrm{C}_{2}+$ oxygenates ratios, with ratios of 0.67 and 0.71 , respectively. These same catalysts had total alcohol:oxygenates ratios of 0.87 and 0.89 , respectively.

In During 2009, the main goal of the testing program shifted to optimizing selected RhMn- based catalysts. Optimization involved examining different total concentrations and atomic ratios of Rh and Mn as well as that of the more promising promoters ( $\mathrm{Ir}$ and $\mathrm{Li}$ ) identified in the earlier screening studies. Optimization primarily involved catalyst performance improvements with respect to the STY and 
converted carbon selectivity to $\mathrm{C}_{2}+$ oxygenates, with additional consideration given to the fraction of the oxygenates that were $\mathrm{C}_{2}+$ alcohols.

Based on the results obtained to date, it appears that the optimum Rh concentration is about $5.56 \mathrm{wt} \%$ (1X the baseline concentration used in promoter screening tests) when used in combination with Mn in which the $\mathrm{Mn}: \mathrm{Rh}$ atomic ratio was $0.57(1.69 \% \mathrm{Mn})$. It may be possible to get further improvements at slightly higher Rh concentrations, but in a test at 1.5X the baseline concentration, the combination of high hydrocarbon concentrations in the product gas and heat management problems at temperatures as low as $271^{\circ} \mathrm{C}$ made evaluation very difficult.

It also appears that the optimum manganese concentration is about $1.13 \mathrm{wt} \%$ (2/3X the baseline concentration used in promoter screening tests) when $\mathrm{Rh}$ is at the baseline concentration of $5.56 \mathrm{wt} \%$. This concentration provides the highest $\mathrm{C}_{2}+$ oxygenates STY, while not significantly compromising the converted carbon selectivity to $\mathrm{C}_{2}+$ oxygenates. The selectivity of the $\mathrm{C}_{2}+$ oxygenates to alcohols does not appear to be affected significantly by Mn concentrations above $0.55 \%$.

The optimum Ir concentration is between $0.34 \%$ and $1.03 \%$ (1/3X and $1 \mathrm{X}$ the baseline concentration), at which the RhMn concentrations are at their baseline concentration (5.56wt\% Rh and $1.69 \mathrm{wt} \% \mathrm{Mn}$ ). This concentration range provides high $\mathrm{C}_{2}+$ oxygenates STYs accompanied by a favorable converted carbon selectivity of about $45 \%$ to $52 \%$ to $\mathrm{C}_{2}+$ oxygenates. The selectivity of the $\mathrm{C}_{2}+$ oxygenates to alcohols is relatively low over this concentration range, but none of the conditions achieved a very good selectivity. The selectivity ranged from about $15 \%$ to $35 \%$ over the range of temperatures and Ir concentrations evaluated.

The addition of Li to the RhMn catalyst improves the converted carbon selectivity to both the $\mathrm{C}_{2}+$ oxygenates and ethanol; however, the STYs of both decrease significantly. Consequently, it is not possible to specify an optimum Li concentration. Instead, it becomes an issue as to which parameter is more important—STY or selectivity—-within the constraint that a catalyst temperature that is too high will cause the catalyst to deactivate.

The combination of Ir and Li modifiers on the same RhMn catalyst did not improve $\mathrm{C}_{2}+$ oxygenates STYs over that when only Li was present in the catalyst. However, it does appear to modestly improve the converted carbon selectivity to both $\mathrm{C}_{2}+$ oxygenates and ethanol. There also was evidence that heating catalysts containing both metals to higher temperatures (up to $345^{\circ} \mathrm{C}$ ) resulted in increased catalytic activity, but the carbon selectivity to $\mathrm{C}_{2}+$ oxygenates decreased. This behavior has not been fully studied.

In addition, limited catalyst screening continued to examine some additional promoters (magnesium [Mg], vanadium [V], lanthanum [La], cerium [Ce], boron [B], tungsten [W], and sodium [Na]) that were not previously tested. These tests also were conducted using the baseline $\mathrm{RhMn} / \mathrm{SiO}_{2}$ catalyst composition of $5.56 \mathrm{wt} \% \mathrm{Rh}$ and $1.69 \mathrm{wt} \% \mathrm{Mn}$ on Davisil 645 silica. The promoters were added at concentrations corresponding to a Rh:M atomic ratio of 1.0:0.1, where M was Mg, V, La, Ce, B, or W, and a Rh:M atomic ratio of 1.0:0.30 for Na. The latter atomic ratio was selected so it could be compared to that used to evaluate $\mathrm{Li}$ in previous tests (Gerber et al. 2008). All catalysts were prepared using a single impregnation to add the $\mathrm{Rh}, \mathrm{Mn}$, and additional promoter $\mathrm{M}$ to the catalyst support. This approach differs from the procedure previously reported for catalyst promoter screening in the earlier tests. None of these catalysts was more active than the $\mathrm{RhMn} / \mathrm{SiO}_{2}$ catalyst. However, the B-, Mg-, and La-promoted 
catalysts did achieve comparable or better converted carbon selectivity to $\mathrm{C}_{2}+$ oxygenates at both the conditions where they achieved their maximum $\mathrm{C}_{2}+$ oxygenates STYs and at the common testing temperature of $300^{\circ} \mathrm{C}$, with the Mg- and La-promoted catalysts achieving significantly greater selectivity to alcohols. In that case, there is merit in retesting these three catalysts using two impregnations (as was done in the earlier tests) to determine if this method of adding the promoters further improved their performance.

Further testing is continuing, primarily to examine the effects of catalyst preparation and activation methods as well as the effects of alternative catalyst support on catalyst performance. Examination of the effects of selected additional operating parameters such as pressure and the $\mathrm{H}_{2}$ :CO ratio also will be conducted on the more promising catalyst formulations. 



\section{Acronyms and Abbreviations}

$\begin{array}{ll}\mathrm{Au} & \text { gold } \\ \mathrm{B} & \text { boron } \\ \mathrm{Ce} & \text { cerium } \\ \mathrm{CO} & \text { carbon monoxide } \\ \mathrm{Co} & \text { cobalt } \\ \mathrm{CO}_{2} & \text { carbon dioxide } \\ \mathrm{DOE} & \text { U.S. Department of Energy } \\ \mathrm{FT} & \text { Fischer-Tropsch } \\ \mathrm{Ga} & \text { gallium } \\ \mathrm{GC} & \text { gas chromatograph } \\ \mathrm{GHSV} & \text { gas hourly space velocity } \\ \mathrm{H}_{2} & \text { hydrogen } \\ \mathrm{HPLC} & \text { high-pressure liquid chromatograph } \\ \mathrm{In} & \text { indium } \\ \mathrm{Ir} & \text { iridium } \\ \mathrm{La} & \text { lanthanum } \\ \mathrm{Li} & \text { lithium } \\ \mathrm{Mg} & \text { magnesium } \\ \mathrm{Mn} & \text { manganese } \\ \mathrm{Mo} & \text { molybdenum } \\ \mathrm{N}_{2} & \text { nitrogen } \\ \mathrm{Na} & \text { sodium } \\ \mathrm{Ni} & \text { nickel } \\ \mathrm{NREL} & \text { National Renewable Energy Laboratory } \\ \mathrm{Pt} & \text { platinum } \\ \mathrm{PNNL} & \text { Pacific Northwest National Laboratory } \\ \mathrm{Rh} & \text { rhodium } \\ \mathrm{Ru} & \text { ruthenium } \\ \mathrm{SiO} & \text { silica } \\ \mathrm{STY} & \text { space-time yield } \\ \text { syngas } & \text { synthesis gas } \\ \mathrm{V} & \text { vanadium } \\ \mathrm{W} & \text { tungsten } \\ \mathrm{Zn} & \text { zinc } \\ & \end{array}$





\section{Contents}

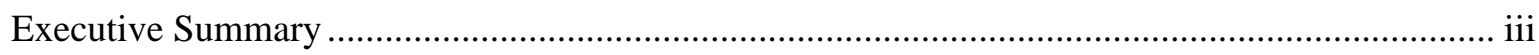

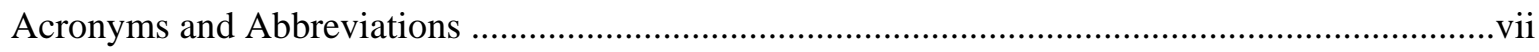

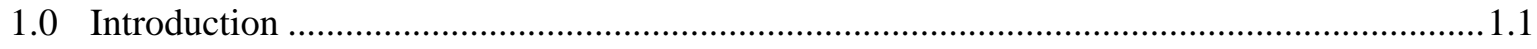

1.1 Catalyst Performance Requirements ....................................................................... 1.2

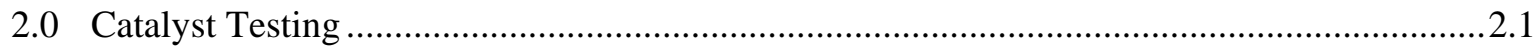

2.1 Synthesis Reactor System Description ......................................................................... 2.1

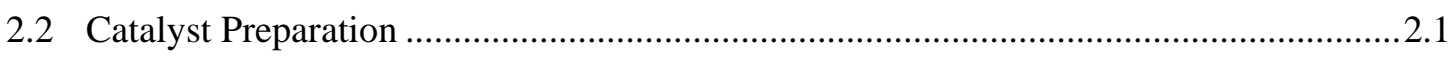

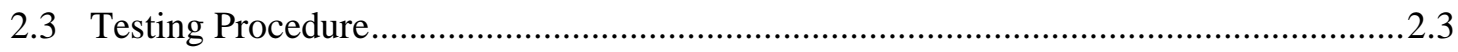

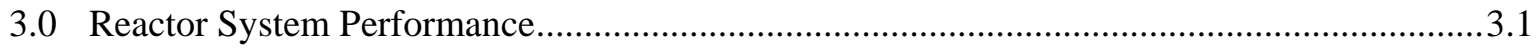

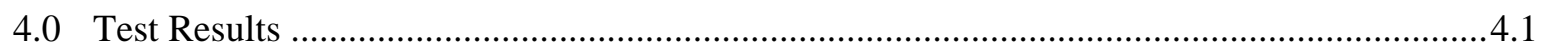

4.1 Silica Supported Catalyst Optimization Tests................................................................ 4.1

4.1.1 Effect of Overall Metal Concentration on Catalyst Performance..........................4.2

4.1.2 Effect of Mn Concentration on Catalyst Performance for $\mathrm{RhMn} / \mathrm{SiO}_{2}$

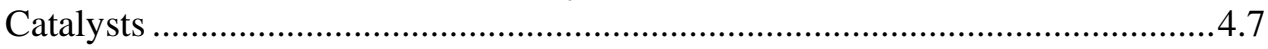

4.1.3 Effect of Iridium Concentration on Catalyst Performance for Rh- $\mathrm{Mn} / \mathrm{SiO}_{2}$

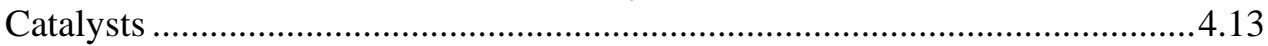

4.1.4 Effect of Lithium and Lithium Plus Iridium Concentration on Catalyst Performance for Rh-Mn/ $\mathrm{SiO}_{2}$ Catalysts ........................................................4.18

4.2 Catalyst Screening Tests ...................................................................................24

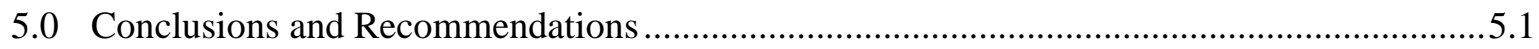

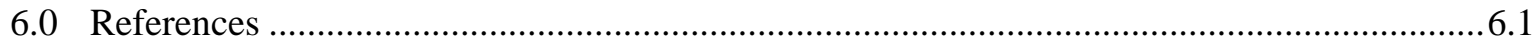

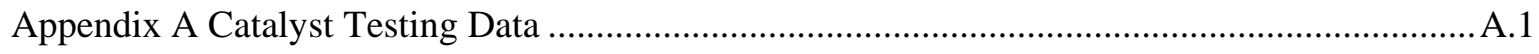

Appendix B Summary of Individual Test Results .............................................................. B. 1 


\section{Figures}

2.1 Simplified Diagram of the Reactor System Used to Test Catalysts......

4.1 Effect of Total Metal Concentration on Carbon Selectivity to $\mathrm{C}_{2}+$ Oxygenates for the Davisil $645 \mathrm{SiO}_{2}$-Supported RhMn Catalysts

4.2 Effect of Total Metal Concentration on Carbon Selectivity to $\mathrm{C}_{2}+$ Oxygenates for the Davisil $645 \mathrm{SiO}_{2}$-Supported RhMn Catalysts

4.3 Effect of Total Metal Concentration on $\mathrm{C}_{2}+$ Oxygenates STYs for the Davisil $645 \mathrm{SiO}_{2}$ Supported RhMn Catalysts

4.4 Effect of Total Metal Concentration on Carbon Selectivity of $\mathrm{C}_{2}+$ Oxygenates to Alcohols for the Davisil $645 \mathrm{SiO}_{2}$-Supported RhMn Catalysts.

4.5 Effect of Mn Concentration on Carbon Conversion for the Davisil $645 \mathrm{SiO}_{2}$-Supported RhMn Catalysts at $300^{\circ} \mathrm{C}$ and $315^{\circ} \mathrm{C}$.

4.6 Effect of Mn Concentration on Carbon Selectivity to $\mathrm{C}_{2}+$ Oxygenates for the Davisil 645 $\mathrm{SiO}_{2}$-Supported RhMn Catalysts at $300^{\circ} \mathrm{C}$ and $315^{\circ} \mathrm{C}$.

4.7 Effect of Mn Concentration on $\mathrm{C}_{2}+$ Oxygenates STY for the Davisil $645 \mathrm{SiO}_{2}$-Supported RhMn Catalysts at $300^{\circ} \mathrm{C}$ and $315^{\circ} \mathrm{C}$

4.8 Effect of Mn Concentration on Carbon Selectivity of $\mathrm{C}_{2}+$ Oxygenates to Alcohols for the Davisil $645 \mathrm{SiO}_{2}$-Supported RhMn Catalysts at $300^{\circ} \mathrm{C}$ and $315^{\circ} \mathrm{C}$

4.9 Effect of Ir Concentration on Carbon Conversion for the Davisil $645 \mathrm{SiO}_{2}$-Supported $\mathrm{RhMn}$ Catalysts at $275^{\circ} \mathrm{C}$ and $300^{\circ} \mathrm{C}$

4.10 Effect of Ir Concentration on Carbon Selectivity to $\mathrm{C}_{2}+$ Oxygenates for the Davisil 645 $\mathrm{SiO}_{2}$-Supported RhMn Catalysts at $275^{\circ} \mathrm{C}$ and $300^{\circ} \mathrm{C}$.

4.11 Effect of Ir Concentration on $\mathrm{C}_{2}+$ Oxygenates STY for the Davisil $645 \mathrm{SiO}_{2}$-Supported RhMn Catalysts at $275^{\circ} \mathrm{C}$ and $300^{\circ} \mathrm{C}$.

4.12 Effect of Ir Concentration on Carbon Selectivity of $\mathrm{C}_{2}+$ Oxygenates to Alcohols for the Davisil $645 \mathrm{SiO}_{2}$-Supported RhMn Catalysts at $275^{\circ} \mathrm{C}$ and $300^{\circ} \mathrm{C}$

4.13 Effect of Li Concentration on Carbon Conversion for the Davisil $645 \mathrm{SiO}_{2}$-Supported RhMn and RhMnIr Catalysts at $300^{\circ} \mathrm{C}$ and $315^{\circ} \mathrm{C}$

4.14 Effect of Li Concentration on Carbon Selectivity to $\mathrm{C}_{2}+$ Oxygenates for the Davisil 645 $\mathrm{SiO}_{2}$-Supported RhMn and RhMnIr Catalysts at $300^{\circ} \mathrm{C}$ and $315^{\circ} \mathrm{C}$

4.15 Effect of Li Concentration on $\mathrm{C}_{2}+$ Oxygenates STY for the Davisil $645 \mathrm{SiO}_{2}$-Supported RhMn and RhMnIr Catalysts at $300^{\circ} \mathrm{C}$ and $315^{\circ} \mathrm{C}$

4.16 Effect of Li Concentration on Carbon Selectivity of $\mathrm{C}_{2}+$ Oxygenates to Alcohols for the Davisil $645 \mathrm{SiO}_{2}$-Supported RhMn and RhMnIr Catalysts at $300^{\circ} \mathrm{C}$ and $315^{\circ} \mathrm{C}$

4.17 STYs of Promoted Catalysts at Conditions for Maximum STYs

4.18 Carbon Selectivity of Promoted Catalysts at Conditions for Maximum STYs

4.19 STYs of Promoted Catalysts at $300^{\circ} \mathrm{C}$ and $11,000 \mathrm{~L} / \mathrm{Lcat} / \mathrm{hr}$ 4.31

4.20 Carbon Selectivity of Promoted Catalysts at $300^{\circ} \mathrm{C}$ and $11,000 \mathrm{~L} / \mathrm{L}_{\text {cat }} / \mathrm{hr}$ 


\section{Tables}

4.1 Comparison of Carbon Conversions and STYs of Promoted $\mathrm{RhMn} / \mathrm{SiO}_{2}$ Catalysts at Conditions Maximizing $\mathrm{C}_{2}+$ Oxygenates STYs.

4.2 Comparison of Carbon Selectivity to Products of Promoted $\mathrm{RhMn} / \mathrm{SiO}_{2}$ Catalysts at Conditions Maximizing $\mathrm{C}_{2}+$ Oxygenates STYs...

4.3 Comparison of Carbon Conversions and STYs of Promoted $\mathrm{RhMn} / \mathrm{SiO}_{2}$ Catalysts at $300^{\circ} \mathrm{C}$, $11,000 \mathrm{~L} / \mathrm{L}_{\mathrm{cat}} / \mathrm{hr}$

4.4 Comparison of Carbon Selectivity to Products of Promoted $\mathrm{RhMn} / \mathrm{SiO}_{2}$ Catalysts at $300^{\circ} \mathrm{C}$ and $11000 \mathrm{~L} / \mathrm{L}_{\mathrm{cat}} / \mathrm{hr}$. 



\subsection{Introduction}

As part of its thermochemical platform to efficiently produce biobased fuels and co-products via thermochemical conversion, the U.S. Department of Energy (DOE) is conducting a program to produce mixed alcohols from lignocellulosic biomass using synthesis gas (syngas) produced from a biomass gasifier. The platform aligns its research and development with the program's goals, which include using stand-alone thermochemical conversion and integrating efficient, complementary thermochemicalconversion technology into a model biorefinery.

During 2007, DOE’s National Renewable Energy Laboratory (NREL) conducted a technical and economic assessment of the feasibility of producing mixed $\mathrm{C}_{2}+$ alcohols as a primary product from biomass-derived syngas to complement alcohol fuel biosynthesis in an integrated biorefinery (Phillips et al. 2007). The model for the mixed alcohol synthesis section was based on the expected performance of a cobalt (Co)/molybdenum (Mo) sulfide catalyst using methanol recycle in the synthesis reactor. Operating conditions and catalyst performance assumptions were based in part on 1) the catalysts developed and tested by Quarderer (1986) and Quarderer and Cochran (1986) and patented by Dow Chemical Company and 2) on typical values reported in the literature for similar catalysts in this class. The mixed alcohol synthesis catalyst chosen as the reference for this evaluation was based on a class of catalysts consisting of alkali-doped Mo sulfide with other metals such as Co added to promote the selective production of mixed alcohols. DOE then began a research program involving NREL and Pacific Northwest National Laboratory (PNNL) to select a catalyst and experimentally validate the performance assumptions used in the model.

After a review of the literature and discussions with selected catalyst manufacturers, PNNL determined that no Mo-based catalysts were available commercially at that time. In fact, the only mixed alcohol synthesis catalyst offered by a catalyst manufacturer at the time of our initial investigation was a modified methanol catalyst (MeOH-X). The only other company found to have previously offered a commercial catalyst was the Institut Francais du Petrole in France, which developed catalysts based on copper $(\mathrm{Cu}) / \mathrm{Co}$ and $\mathrm{Cu} /$ nickel $(\mathrm{Ni})$ systems. Their work has been discontinued, and there is no longer any catalyst available for testing.

In the absence of commercial catalysts that can promote the higher alcohol production rates needed to achieve economic viability, this project was undertaken to identify the most promising catalysts from the information published in the literature and to test the most promising ones in a bench-scale system. Potential catalysts were divided into six general classes:

- Modified methanol catalysts (based on $\mathrm{Cu} / \mathrm{zinc}[\mathrm{Zn}]$ and $\mathrm{Cu} /$ manganese [Mn] combinations)

- Modified Mo sulfide catalysts

- Modified Mo oxide catalysts

- Rhodium (Rh)-based catalysts

- Modified Fischer-Tropsch (FT) catalysts.

Our initial approach was to obtain or prepare catalysts that were either representative of each class of catalysts or that had the potential to achieve high space-time yields (STYs) for $\mathrm{C}_{2}+$ oxygenates, and to test the prepared catalysts under conditions that would optimize $\mathrm{C}_{2}+$ STYs at a common operating pressure (80 atm). Ten catalysts representative of the different catalyst classes were prepared and tested in 2006 
and early 2007 along with a modified methanol catalyst product provided by a catalyst manufacturer (Gerber et al. 2007). Of these catalysts, only the modified FT and rhodium (Rh)-based catalysts showed promise for achieving the necessary STYs. The two FT catalysts, which were modified to improve oxygenate yields, achieved $\mathrm{C}_{2}+$-oxygenates STYs that were within a recommended range for screening purposes (nominally 800 to $1300 \mathrm{~g} / \mathrm{L}_{\text {cat }} / \mathrm{hr}$ ). However, because of their much higher selectivity to FT liquids, the STYs for total organic liquids exceeded the recommended range under optimum operating conditions. Under test conditions that produced a total organic liquid within the recommended range (i.e., $1200 \mathrm{~g} / \mathrm{L}_{\text {cat }} / \mathrm{hr}$ total organic liquids STY), one of these catalysts achieved a much lower $\mathrm{C}_{2}+$ oxygenates STY $\left(230 \mathrm{~g} / \mathrm{L}_{\text {cat }} / \mathrm{hr}\right)$ that, while higher than that achieved by the modified methanol and modified molybdenum catalysts, was still well below the recommended STY range. Carbon selectivity to $\mathrm{C}_{2}+$ oxygenates was only about $10 \%$ under these conditions.

The two Rh-based catalysts, $\mathrm{Rh} / \mathrm{Mn} /$ silica $\left(\mathrm{SiO}_{2}\right)$ and $\mathrm{Rh} / \mathrm{Mn} / \mathrm{iron}(\mathrm{Fe}) / \mathrm{SiO}_{2}$, were very selective to $\mathrm{C}_{2}+$ oxygenates. The $\mathrm{Rh} / \mathrm{Mn} / \mathrm{Fe} / \mathrm{SiO}_{2}$ achieved higher $\mathrm{C}_{2}+$ oxygenates STYs under optimum conditions than any of the modified methanol and Mo-based catalysts tested at their optimum conditions and the FT catalysts at conditions that limited the total organic STYs to within the recommended range. The maximum achieved $\mathrm{C}_{2}+$ oxygenates STY (approximately $400 \mathrm{~g} / \mathrm{L}_{\text {cat }} / \mathrm{hr}$ ), however, was still below the recommended minimum. The carbon selectivity to $\mathrm{C}_{2}+$ oxygenates under this condition was approximately $24 \%$, which was significantly better than the FT catalysts. This Rh catalyst also was unique because it produced very few $\mathrm{C}_{1}+$ oxygenates or FT liquids.

During 2007, a second set of catalyst testing was performed at PNNL to evaluate 22 promoters for the $\mathrm{RhMn} / \mathrm{SiO}_{2}$ catalysts including the Fe-promoted catalyst that was tested in previous catalyst screening. All of these catalysts used the same Rh:Mn:M atomic ratio (M representing the promoter) except one that used lithium (Li) as the promoter. The results of these tests identified several promoters that showed promise for improving the $\mathrm{C}_{2}+$ oxygenates STY and/or improving the selectivity of the $\mathrm{C}_{2}+$ oxygenates to alcohols (Gerber et al. 2008).

During 2009, the testing program shifted to optimization of the $\mathrm{SiO}_{2}$ supported $\mathrm{RhMn}$ based catalysts. Optimization involved examination of different total concentrations and atomic ratios of $\mathrm{Rh}$ and $\mathrm{Mn}$ as well as that of some of the more promising promoters identified in the earlier screening studies (iridium [Ir] and Li). In addition, limited catalyst screening continued to examine some additional promoters not previously tested. This report summarizes the progress made to date on catalyst optimization and screening.

\subsection{Catalyst Performance Requirements}

The performance of the catalyst affects the capital costs of the mixed alcohols synthesis process in terms of reactor vessel size for a given throughput and gas recycle requirements, as well as vessel wall materials and thickness to meet design requirements for the expected operating pressure and temperature. Catalyst performance also affects the operating costs of the process, in terms of energy required to pressurize and heat the incoming gas feed and the yield and distribution of key products (higher alcohols) and potential byproducts with significant economic value. For a catalyst to be considered suitable for mixed $\mathrm{C}_{2}+$ alcohol synthesis, it must be able to achieve a sufficiently high production rate of mixed higher alcohols in the synthesis reactor so that the capital costs of the reactor are not prohibitively high. At the same time, the catalyst needs to minimize the production of undesirable byproducts (carbon 
dioxide $\left[\mathrm{CO}_{2}\right]$ and hydrocarbons) that either reduce the yield of the desired product or require converting them back into syngas for recycle to the reactor to maintain an acceptable product yield. Both of the latter approaches result in additional process costs for a given productivity and overall product yield. This project uses three criteria for evaluating the performance of the catalysts:

1. Acceptable catalyst activity for $\mathrm{C}_{2}+$ oxygenates

2. Acceptable catalyst selectivity to $\mathrm{C}_{2}+$ oxygenates

3. Acceptable catalyst selectivity of the $\mathrm{C}_{2}+$ oxygenates to $\mathrm{C}_{2}+$ alcohols.

The three performance criteria are interrelated, because as improvements are made in any one criterion, more latitude in the improvements required for the other two criteria is gained.

The primary screening and selection criterion for catalyst performance is the STY of $\mathrm{C}_{2}{ }^{+- \text {oxygenated }}$ hydrocarbons, with consideration given to the co-production of methanol and liquid hydrocarbons. STY is a measure of catalyst activity with respect to the desired products. The criterion is based on the production of all $\mathrm{C}_{2}+$ oxygenates under the premise that the nonalcoholic oxygenates can be further converted into alcohols (albeit at a greater expense), thereby providing an upper limit for the expected $\mathrm{C}_{2}+$ alcohol STY resulting from the catalyst. While the NREL techno-economic study (Phillips et al. 2007) cited an STY of 250 to $350 \mathrm{~g}$ mixed alcohol/ $\mathrm{L}_{\text {cat }} / \mathrm{hr}$ as a productivity rate typical of the Mo catalysts, this value is considered marginal based on the assessment made by Stiles et al. (1991), who found that the STYs of catalysts used in commercial methanol synthesis plants ranged from approximately 670 to $1,340 \mathrm{~g}_{\mathrm{MeOH}} / \mathrm{L}_{\mathrm{cat}} / \mathrm{hr}$. According to Stiles and his co-workers, higher methanol production rates create heat dissipation requirements that are difficult to manage. Production rates involving higher alcohol production create higher exothermic heat loads than a comparable production rate of methanol. Furthermore, when significant methane or methane and higher hydrocarbons are produced along with the alcohols, heat dissipation can become unmanageable at the higher production rates. Consequently, it may not be practical to obtain higher alcohol production rates at the upper end of the range for methanol production in conventional fixed-bed reactor systems. On the other hand, rates significantly lower than the lower production range for methanol will likely result in unacceptable process economics. For catalyst evaluation, a minimum $\mathrm{C}_{2}+$ oxygenates STY of at least $800 \mathrm{~g} / \mathrm{L}_{\text {cat }} / \mathrm{hr}$ is needed for a mixed alcohol synthesis catalyst with higher STYs required as catalyst selectivity decreases.

The second most important performance criterion is the selectivity of the catalyst to $\mathrm{C}_{2}+$ oxygenates. In the case of the RhMn-based catalysts, the main byproducts other than the nonalcoholic $\mathrm{C}_{2}+$ oxygenates are hydrocarbons; previous tests have shown that $\mathrm{CO}_{2}$ is not a significant product of alcohol synthesis using RhMn-based catalysts. Hydrocarbons are undesirable because they act as diluents if they are recycled to the alcohol synthesis reactor along with unconverted hydrogen $\left[\mathrm{H}_{2}\right]$ and carbon monoxide (CO), thereby requiring a higher total pressure to preserve adequate partial pressures for the $\mathrm{H}_{2}$ and $\mathrm{CO}$ in the syngas. The only ways to eliminate hydrocarbons from the recycle gas stream is to either purge a portion of the recycle gas stream as a relatively low value fuel gas, thereby reducing overall product yield, or divert the recycle gas stream to a reformer to reconvert the hydrocarbons to syngas. The latter option adds considerable cost to hydrocarbon reforming in an integrated system. Most of the catalysts tested to date have had converted carbon selectivity to hydrocarbons greater than $50 \%$ when the catalyst achieves high $\mathrm{C}_{2}+$ oxygenates activity. Under these conditions, the concentration of the hydrocarbons in the product gas following liquid product removal is about $3 \%$. This concentration level is considered to be low enough to allow some product gas recycle to the alcohol synthesis reactor before unacceptable 
dilution effects occur, but would be unacceptably high in terms of overall product yield. For purposes of catalyst evaluation, carbon selectivity to hydrocarbons of less than $30 \%$ has been selected as a target.

The third performance criterion is the selectivity of the $\mathrm{C}_{2}+$ oxygenates to alcohols. Consequences of producing nonalcoholic $\mathrm{C}_{2}+$ oxygenates are the needs to either 1 ) further convert them into alcohols in a separate process prior to recovery from the product gas stream or 2) undergo a more complex separation process to purify the alcohols recovered in the liquid product stream. The latter option produces byproduct oxygenates that would need to be recovered and sold as byproducts or further converted into alcohols in a separated step. Both options increase the overall production cost for the product alcohols. At this time, there is only a qualitative goal of maximizing the selectivity to alcohols while meeting the other two criteria. However, achieving carbon selectivity to $\mathrm{C}_{2}+$ alcohols exceeding $80 \%$ are considered to be noteworthy if the $\mathrm{C}_{2}+$ oxygenates STY is high. 


\subsection{Catalyst Testing}

\subsection{Synthesis Reactor System Description}

The bench-scale tubular reactor system used to test catalysts is designed to operate at pressures up to 1200 psig and temperatures up to $450^{\circ} \mathrm{C}$. This system is shown in Figure 2.1. The catalyst chamber is $1.67 \mathrm{~cm}$ long and $0.635 \mathrm{~cm}$ in diameter. A $0.159-\mathrm{cm}$ outer diameter thermocouple sheath is extended through the center of the reactor, creating an annulus-shaped catalyst chamber. Two thermocouples inside the sheath are spaced so one thermocouple is at the center of the catalyst bed and the other just upstream. The reactor is heated with hot oil to obtain better temperature control because this approach more efficiently removes the heat of reaction, thus preventing a thermal excursion when the carbon conversion is too high.

The syngas fed to the reactor is metered through a mass flow controller. The system also meters reducing gas $\left(10 \% \mathrm{H}_{2}\right.$ in nitrogen $\left.\left[\mathrm{N}_{2}\right]\right)$ and $\mathrm{N}_{2}$ to the reactor during catalyst reduction. The raw product gas leaving the reactor is passed through one of two cold traps to condense liquids at $0^{\circ} \mathrm{C}$ and through a back-pressure regulator that controls the system pressure. Gas flow is redirected from one trap to the other to isolate the former trap for liquid sample recovery.

The nominal feed rate to the reactor is determined by calibrating the mass flow controllers at system pressure before the tests. A Bios DryCal flow meter located downstream of the back-pressure flow regulator is used for this calibration. Flow-meter readings are corrected for standard pressure and temperature. The flow meter also is used to monitor product gas flow rate downstream of the liquid sample cold traps during each test.

Dry product gas grab samples for analysis in a gas chromatograph (GC) are obtained downstream of the back-pressure regulator in a line separate from that containing the bubble flow meter, as shown in Figure 2.1. The reactor inlet, catalyst bed, cold sample trap, ambient temperature, and the upstream gas and ambient pressures are monitored during tests.

Gas cylinders containing a specified syngas mixture are used in the tests. The gas mixture consists of $\mathrm{H}_{2}, \mathrm{CO}, \mathrm{CO}_{2}$, and $\mathrm{N}_{2}$. Most of the tests conducted with the Rh-based catalysts used a gas that had a nominal $\mathrm{H}_{2}$ : $\mathrm{CO}$ ratio of 1.8, with the ratio ranging from 1.7 to 1.9. The nominal concentrations of $\mathrm{CO}_{2}$ and $\mathrm{N}_{2}$ were each $4 \%$ in the gas mixture. Variations in the $\mathrm{H}_{2}: \mathrm{CO}$ ratios in the feed gas are attributed to variations in the composition of the individual gas cylinder mixtures supplied for the tests.

\subsection{Catalyst Preparation}

Catalysts tested during this portion of the testing program were based on a baseline catalyst composition of $5.56 \% \mathrm{Rh}$ and $1.69 \% \mathrm{Mn}$ on $\mathrm{SiO}_{2}$, and a promoter other than $\mathrm{Li}$ and $\mathrm{Na}$ added at a concentration so that the Rh:Mn:M ( $\mathrm{M}=$ promoter) atomic ratios were 1.00:0.57:0.10, respectively. When Li or Na were used as the promoter, the baseline Rh:Mn:M atomic ratio was 1.00:0.57:0.30. Catalyst optimization tests involved variations in the overall metals concentrations while maintaining the baseline atomic ratios, and/or varying one of the three components of a three-component catalyst from the baseline atomic ratio. 


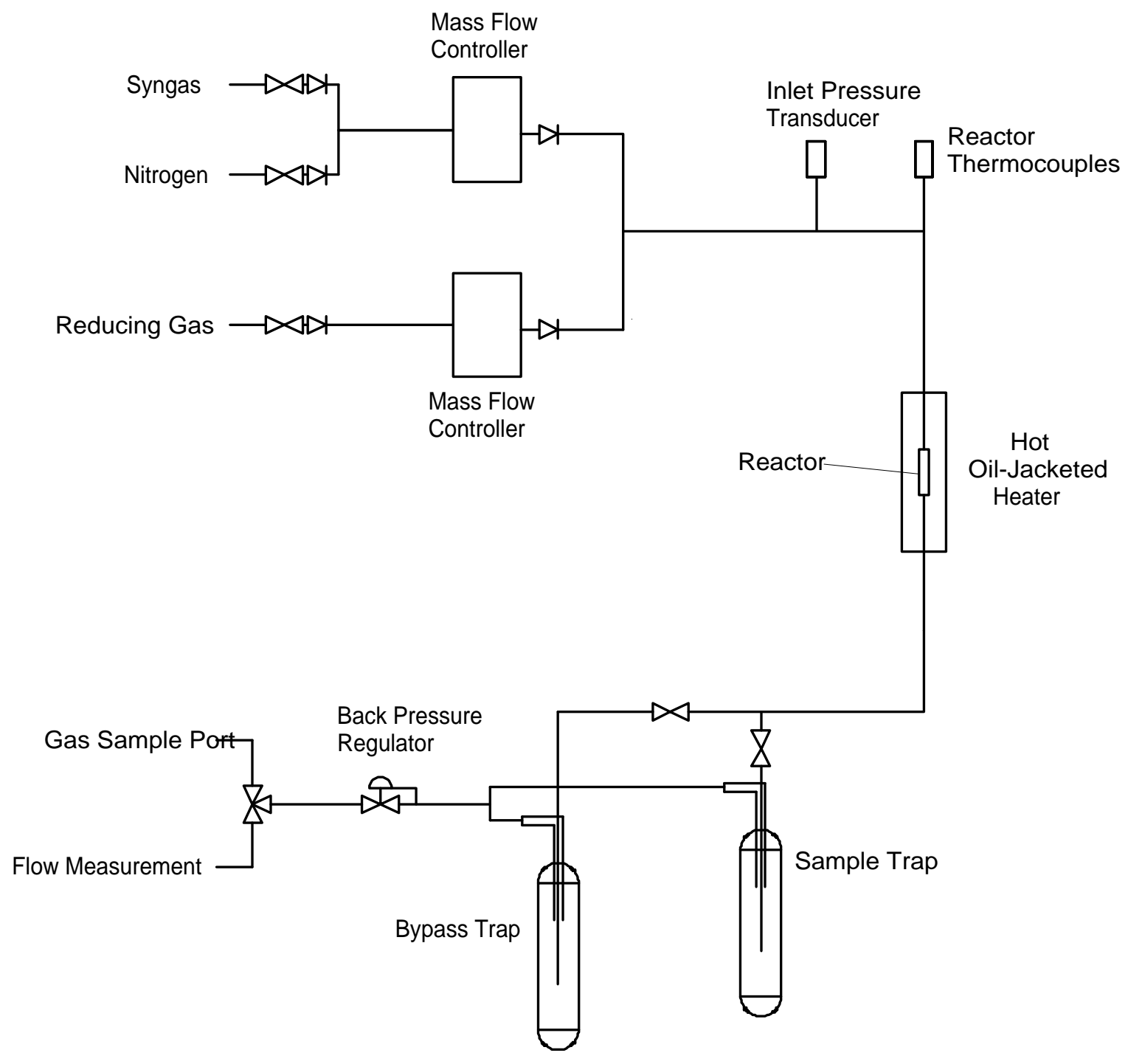

Figure 2.1. Simplified Diagram of the Reactor System Used to Test Catalysts

The catalysts that were tested were supported on Davisil 645 high-surface-area $\mathrm{SiO}_{2}$. In addition, three tests that used $\mathrm{Rh}$ and $\mathrm{Mn}$ at different concentrations were performed using Davisil LC $150 \mathrm{SiO}_{2}$. Catalyst preparation consisted of a single-step impregnation procedure using the incipient wetness technique. This procedure is different than that reported in previous reports (Gerber et. al. 2007, Gerber et. al. 2008). The $\mathrm{SiO}_{2}$ was pretreated by calcining at $500^{\circ} \mathrm{C}$ for 2 hours (ramping up at a $5^{\circ} \mathrm{C} / \mathrm{min}$ rate during heating and ramping down at $10^{\circ} \mathrm{C} / \mathrm{min}$ during cooling). The appropriate quantities of a rhodium nitrate solution (10 wt\% Rh concentration in solution) and manganese nitrate tetrahydrate and a soluble compound (usually a nitrate salt) of the selected promoter were combined with enough deionized water to bring the total volume of the impregnation solution to the water adsorption pore volume of the support. The solution was impregnated onto the $\mathrm{SiO}_{2}$ in drop-wise fashion, dried under an infrared lamp while being shaken until a steady weight was achieved, and then dried overnight at $110^{\circ} \mathrm{C}$ in a drying oven. The dried catalyst was calcined at $400^{\circ} \mathrm{C}$ in air using a muffle furnace. Catalysts with other supports were prepared in a similar manner but using methods that were compatible with the type of catalyst support used. 
Before conducting the tests, the calcined catalysts were loaded into the reactor and reduced using a $10 \% \mathrm{H}_{2}$-in- $\mathrm{N}_{2}$ gas mixture. All catalysts were heated in the reducing atmosphere to $220^{\circ} \mathrm{C}$ at $2.5^{\circ} \mathrm{C} / \mathrm{min}$ ramp-up rate and held that temperature for 1 hour, then heated from $220^{\circ} \mathrm{C}$ to $260^{\circ} \mathrm{C}$ at a rate of $1{ }^{\circ} \mathrm{C} / \mathrm{min}$ and held at that temperature for 8 hours, and finally heated to approximately $350^{\circ} \mathrm{C}$ at a rate of $1.5^{\circ} \mathrm{C} / \mathrm{min}$ and held at that temperature for 2 hours.

\subsection{Testing Procedure}

During a typical test series, a measured volume of catalyst was loaded into the reactor, and its net weight was determined. The reactor was placed in the reactor system, and reduced in situ at atmospheric pressure. The reactor was cooled after catalyst reduction, and the desired syngas feed rate and pressure were established. The reactor was heated slowly to a temperature at which the reaction rate was significant and maintained at that temperature for at least 24 hours to allow the catalyst to age. The product stream was directed through one of the cold traps during this time. After aging the catalyst, the product stream was redirected through the other cold trap for a period sufficient for at least 10 bed volumes of gas feed (based on the operating pressure and gas feed rate) to pass through the cold trap. This period of time provides a representative gas sample and a sufficiently large liquid sample for subsequent analysis. The operating conditions were recorded before sampling with two or more grab samples of product gas obtained and analyzed in a GC along with a feed gas sample and a calibration gas sample. The liquid recovered from the cold trap was weighed and, if two phases were present, separated into an aqueous phase and an organic phase. The weighed organic phase was not analyzed and was assumed to have a composition comparable to hexane for purposes of a carbon balance. The weighed aqueous phase was analyzed using a high-pressure liquid chromatograph (HPLC) to quantify the $\mathrm{C}_{1}-\mathrm{C}_{5}$ oxygenates, which principally were alcohols, acids, aldehydes, esters, and any other products associated with significant peaks identified by the HPLC. After sampling, a new set of conditions (i.e., temperature and feed rate) was established, and another cold trap sample was collected at the new conditions. This procedure was repeated until a representative set of conditions was obtained to evaluate catalyst performance in terms of STY, carbon selectivity, and single-pass carbon conversion. In most cases, tests progressively advanced to higher temperatures with one or more space velocities examined during each test. In most tests, an earlier test condition was re-examined to determine whether further catalyst ageing during testing affected the performance of the catalyst.

To calculate a representative average outlet flow rate during a sample collection period, an $\mathrm{N}_{2}$ balance was used with the calibrated feed flow rates. The product gas flow rate downstream of the cold trap was monitored and recorded for estimating the product gas flow rate and to provide a rough check on the accuracy of the calculated flow using a $\mathrm{N}_{2}$ balance. Carbon balances measured using this method were usually within approximately $\pm 6 \%$. 



\subsection{Reactor System Performance}

As was reported in previous progress reports (Gerber et. al. 2007, Gerber et. al. 2008), heat management was still a problem with the more active catalysts during this phase of testing even when using circulating hot oil to maintain reactor temperature instead of a furnace. When the more reactive catalysts were operated at reaction rates approaching the limits of the ability of the hot oil to remove excess heat, small changes in reactor temperature could cause large fluctuations in the catalyst bed temperature. These excursions lasted anywhere from a few hours to a half a day and, in some cases, produced a periodic temperature cycle that ranged as much as $20^{\circ} \mathrm{C}$ over time. When this happened, a new set of conditions was sought that produced a stable temperature and data, and a liquid sample was collected. As a result, not all test conditions were evaluated by all of the catalysts. When stable conditions existed, the temperature of the reactor generally stayed within a $\pm 3{ }^{\circ} \mathrm{C}$ during the liquid sample collection period. 



\subsection{Test Results}

The majority of testing to optimize the RhMn-based catalysts has centered on evaluating the effects that alter the concentrations of the various catalyst materials on a $\mathrm{SiO}_{2}$ support, including $\mathrm{Rh}, \mathrm{Mn}, \mathrm{Ir}$, and $\mathrm{Li}$ as the active components. In addition, a few tests were conducted to examine promoters that were not evaluated in the previous screening tests. For the purpose of comparison, the compositions tested were based on baseline compositions in which the baseline Rh concentration was $5.56 \mathrm{~g} / \mathrm{g}$ catalyst, and the $\mathrm{Rh}: \mathrm{Mn}$ atomic ratio was 1.0:0.57. The baseline $\mathrm{Rh}: \mathrm{M}_{1}$ ratios for the screened promoters metals were 1.0:0.1 except for $\mathrm{Na}$ in which the $\mathrm{Rh}: \mathrm{M}_{1}$ ratio was 1.0:0.3. Where four catalytic components were tested, the baseline Rh concentration and the Rh:Mn:M1: $\mathrm{M}_{2}$ atomic ratios followed the same rules as the three-component catalysts. The test results are presented for the optimization tests and catalyst screening tests of the $\mathrm{SiO}_{2}$-supported catalysts. Table A.1 in Appendix A summarizes the optimization test results while Table A.2 summarizes the screening test results. The screening test results according to the type of promoter added to the $\mathrm{RhMn} / \mathrm{SiO}_{2}$ catalyst are discussed in more detail in Appendix B.

\subsection{Silica Supported Catalyst Optimization Tests}

Several test series were conducted to examine the effects of varying the total concentration of active components and/or the atomic ratios of components for catalysts containing $\mathrm{Rh}$ and $\mathrm{Mn}$ with and without Ir and $\mathrm{Li}$ as additional promoters. Iridium was selected for evaluation because it achieved the highest $\mathrm{C}_{2}{ }^{+}$ oxygenates STY during the promoter screening tests (Gerber et al. 2008) in which a baseline composition (e.g., 5.56\% Rh with a Rh:Mn:Ir atomic ratio of 1:0.57:0.10) was used. Lithium was selected because it also achieved one of the better STYs in the promoter screening tests at its baseline condition (5.56\% Rh with a Rh:Mn:Ir atomic ratio of 1:0.57:0.30) while also showing some improvement in the carbon selectivity to $\mathrm{C}_{2}+$ oxygenates compared to the other active catalysts.

The specific test series investigated the following:

- Effect of overall metal concentration with RhMn catalyst on different $\mathrm{SiO}_{2}$ supports

- Effect of Mn concentration on a $\mathrm{RhMn} / \mathrm{SiO}_{2}$ catalyst

- Effect of Ir concentration on a $\mathrm{RhMnIr} / \mathrm{SiO}_{2}$ catalyst (fixed $\mathrm{Rh}$ and fixed $\mathrm{Rh}+\mathrm{Mn}$ )

- Effect of Li concentration on a $\mathrm{RhMnLi} / \mathrm{SiO}_{2}$ catalyst (fixed $\mathrm{Rh}$ and fixed $\mathrm{Rh}+\mathrm{Mn}$ )

- Effect of $\mathrm{Li}$ on a $\mathrm{RhMnIrLi} / \mathrm{SiO}_{2}$ catalyst (fixed $\mathrm{Rh}$ and fixed $\mathrm{Rh}+\mathrm{Mn}+\mathrm{Ir}$ ).

All of these tests used Davisil $645 \mathrm{SiO}_{2}$ from the same lot obtained from Fischer Scientific. It should be noted that this lot of Davisil $\mathrm{SiO}_{2}$ may produce slightly different results than the Davisil $\mathrm{SiO}_{2}$ obtained from Altech that was used for most of the catalyst promoter screening tests (Gerber et al. 2008). Specifically, the new lot of $\mathrm{SiO}_{2}$ may achieve slightly lower catalyst activities for similar compositions under similar operating conditions, as well as slightly higher selectivity to methanol (MeOH). These differences are believed to be attributable to slightly different impurity levels in the $\mathrm{SiO}_{2}$, which will be evaluated in future tests. It also should be noted that the three- and four-component catalysts used in these tests were prepared using a single impregnation, while the three-component catalysts used during the previous catalyst promoter screening tests (Gerber et al. 2008) were prepared from a single impregnation of Rh and Mn followed by drying and a second impregnation of the third component. 
It also should be noted that the parametric studies were not exhaustive in scope. In most cases, a limited number of tests conditions were examined to optimize selected parameters. In several cases, further examination to confirm trends were not conducted because the levels of activity and/or selectivity were so far away from desired targets as to render any further conclusions moot. However, in some cases additional tests may be warranted but have not been conducted to date.

\subsubsection{Effect of Overall Metal Concentration on Catalyst Performance}

Four tests were conducted using different fractions of the baseline composition for $\mathrm{RhMn} / \mathrm{SiO}_{2}$ catalysts using the Davisil $645 \mathrm{SiO}_{2}$ support to examine the effect of the overall metal concentration on the catalyst performance. The compositions tested included:

- Baseline composition (5.56 wt\% Rh, 1.69 wt\% Mn)

- 2/3X baseline composition

- 1/2X baseline composition

- 1/3X baseline composition.

A fourth test was also performed using 4/3X the baseline composition. This composition was very reactive, producing much higher concentrations of hydrocarbons at temperatures as low as $246^{\circ} \mathrm{C}$. However, because of heat management problems, it could not be tested above $271^{\circ} \mathrm{C}$.

In addition, three tests were conducted using Davisil LC $150 \mathrm{SiO}_{2}$ as the support. The concentrations of the metals evaluated were at 1/2X, 2/3X, and 3/3X of the baseline Rh and Mn concentrations.

Figures 4.1 through 4.4 provide comparative data for two test conditions: 1) $275^{\circ} \mathrm{C}$ and $7,500 / \mathrm{hr}$ gas hourly space velocity (GHSV) and 2) $300^{\circ} \mathrm{C}$ and 11,000/hr GHSV. These conditions were chosen because the maximum $\mathrm{C}_{2}+$ oxygenates STYs were achieved at $300^{\circ} \mathrm{C}$ and the data at $275^{\circ} \mathrm{C}$ provides additional information on the trends at lower temperatures. Although data were obtained at higher temperatures, it is apparent that some deactivation was occurring at these temperatures at the higher concentrations, thus making side-by-side comparisons of different tests difficult. Carbon conversions obtained at lower temperatures were less than $5 \%$; therefore, hydrocarbon gases with compositions close to their detection limits produced results that may not be comparable.

Figure 4.1 compares the carbon conversions for the different metal concentrations and supports at $275^{\circ} \mathrm{C}$ and $300^{\circ} \mathrm{C}$. It is clear that there is a significant effect in carbon conversion as the metals concentrations change. For example, increasing the metal concentrations by a factor of $1.5 \mathrm{X}$ from $2 / 3$ to $3 / 3$ of the baseline composition, results in a $7 \mathrm{X}$ increase in the carbon conversion at $275^{\circ} \mathrm{C}$ and a $2.5 \mathrm{X}$ increase at $300^{\circ} \mathrm{C}$ for the Davisil 645 support, and a $5 \mathrm{X}$ increase at $275^{\circ} \mathrm{C}$ and a $3.9 \mathrm{X}$ increase at $300^{\circ} \mathrm{C}$

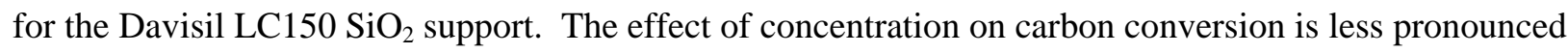
for lower metal concentrations. We hypothesize that the heat generation rate, for carbon conversions greater than about $5 \%$, becomes sufficiently significant, so that the actual catalyst temperatures within the catalyst particles, and with respect to their spatial position in the catalyst bed, become higher than that represented by the temperature measured by the thermocouple located in the middle of the catalyst bed. 
$275^{\circ} \mathrm{C}, 1,200$ psig, $7,500 / \mathrm{hr}$ GHSV

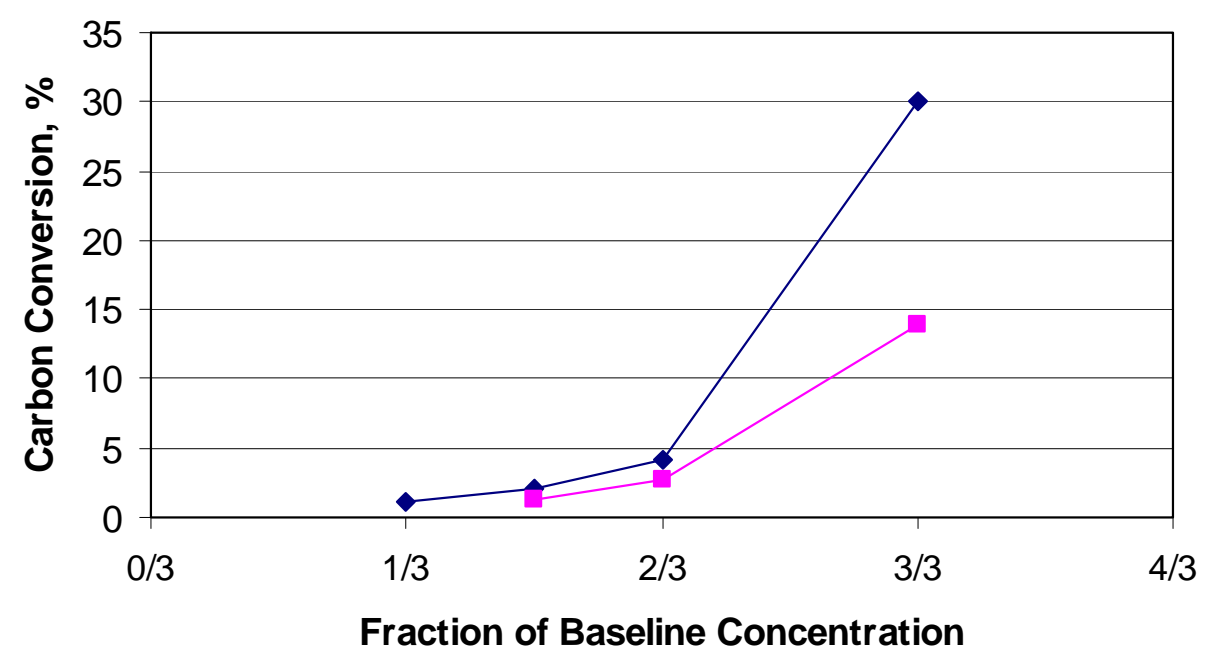

_Davisil 645 Davisil LC 150

$300^{\circ} \mathrm{C}, 1,200 \mathrm{psig}, 11,000 / \mathrm{hr}$ GHSV

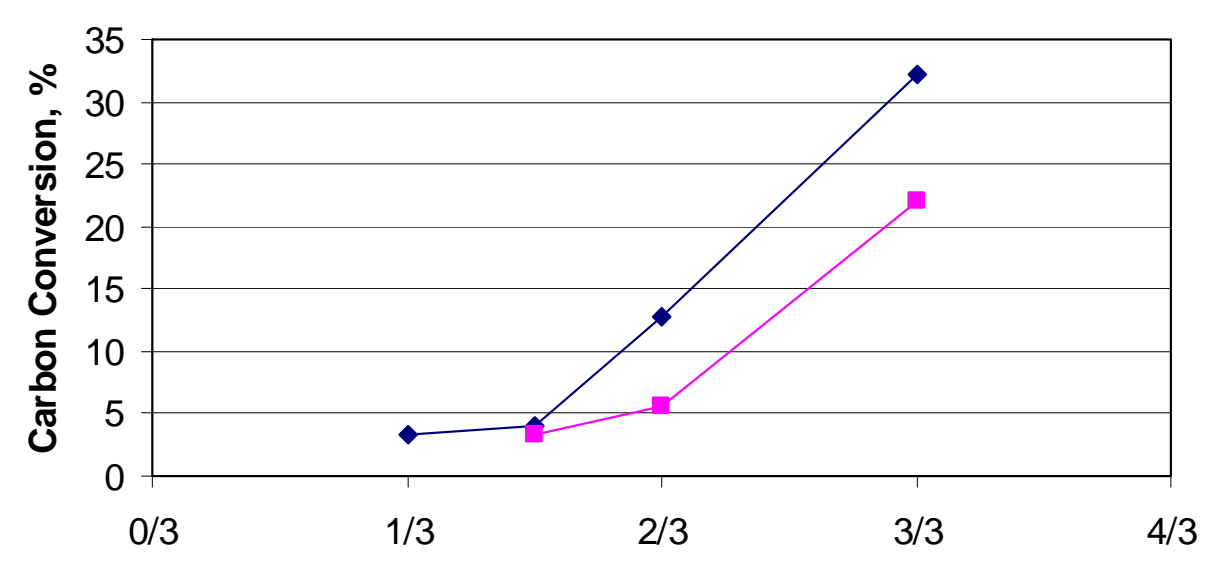

Fraction of Baseline Concentration

$\multimap$ Davisil $645 \multimap$ Davisil LC 150

Figure 4.1. Effect of Total Metal Concentration on Carbon Selectivity to $\mathrm{C}_{2}+$ Oxygenates for the Davisil $645 \mathrm{SiO}_{2}$-Supported RhMn Catalysts 
$275^{\circ} \mathrm{C}, 1,200 \mathrm{psig}, 7,500 / \mathrm{hr}$ GHSV

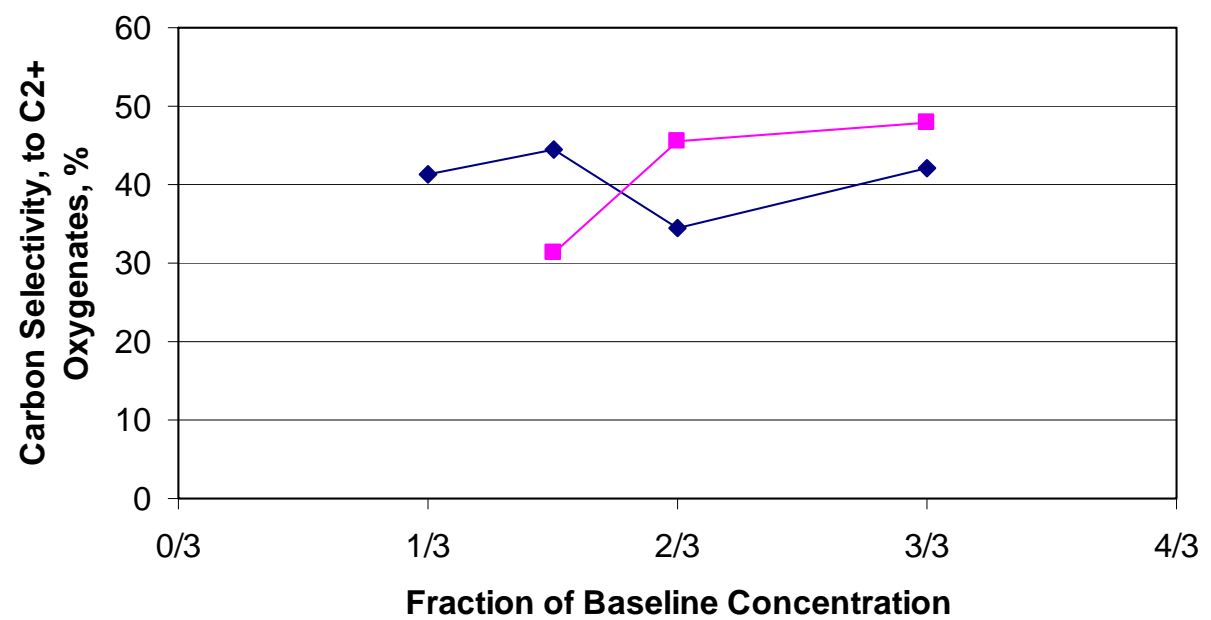

$\multimap$ Davisil $645 \multimap$ Davisil LC 150

$300^{\circ} \mathrm{C}, 1,200 \mathrm{psig}, 11,000 / \mathrm{hr}$ GHSV

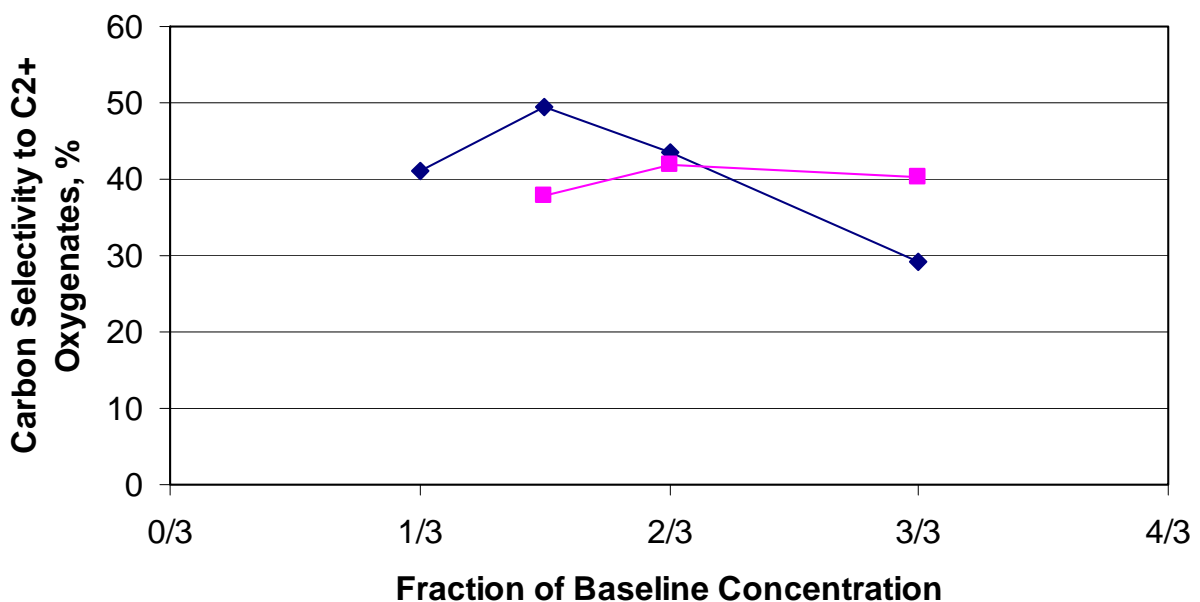

Davisil 645 — Davisil LC 150

Figure 4.2. Effect of Total Metal Concentration on Carbon Selectivity to $\mathrm{C}_{2}+$ Oxygenates for the Davisil $645 \mathrm{SiO}_{2}$-Supported RhMn Catalysts 
$275^{\circ} \mathrm{C}, 1,200 \mathrm{psig}, 7,500 / \mathrm{hr}$ GHSV

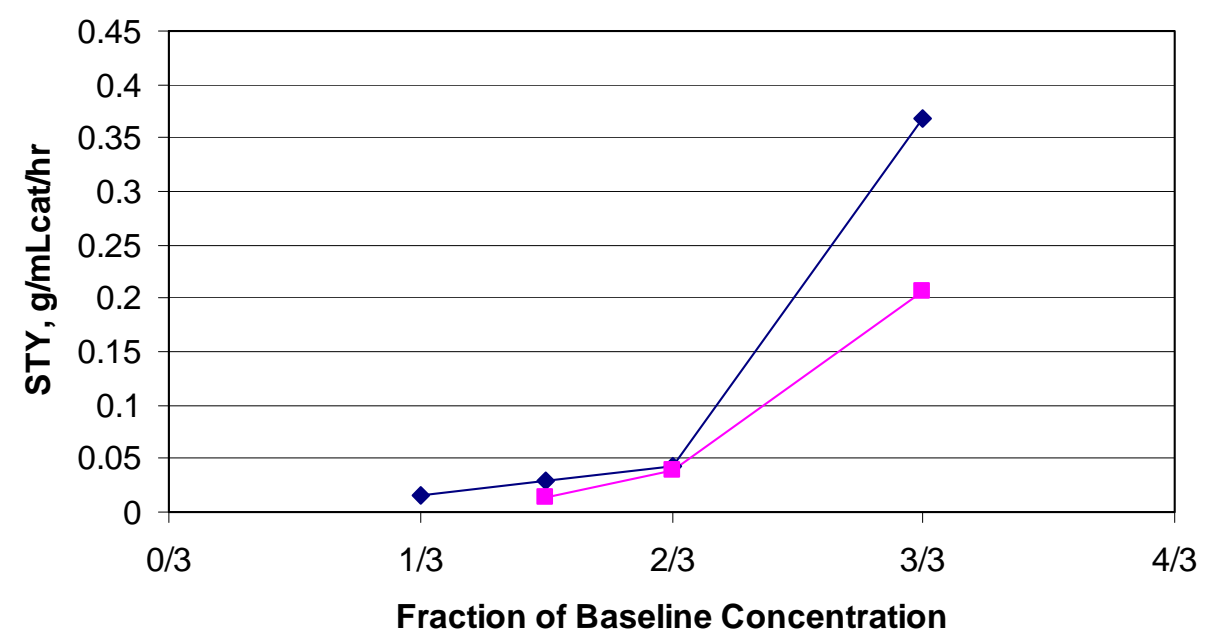

$\multimap$ Davisil $645 \multimap$ Davisil LC 150

$275^{\circ} \mathrm{C}, 1,200 \mathrm{psig}, 7,500 / \mathrm{hr}$ GHSV

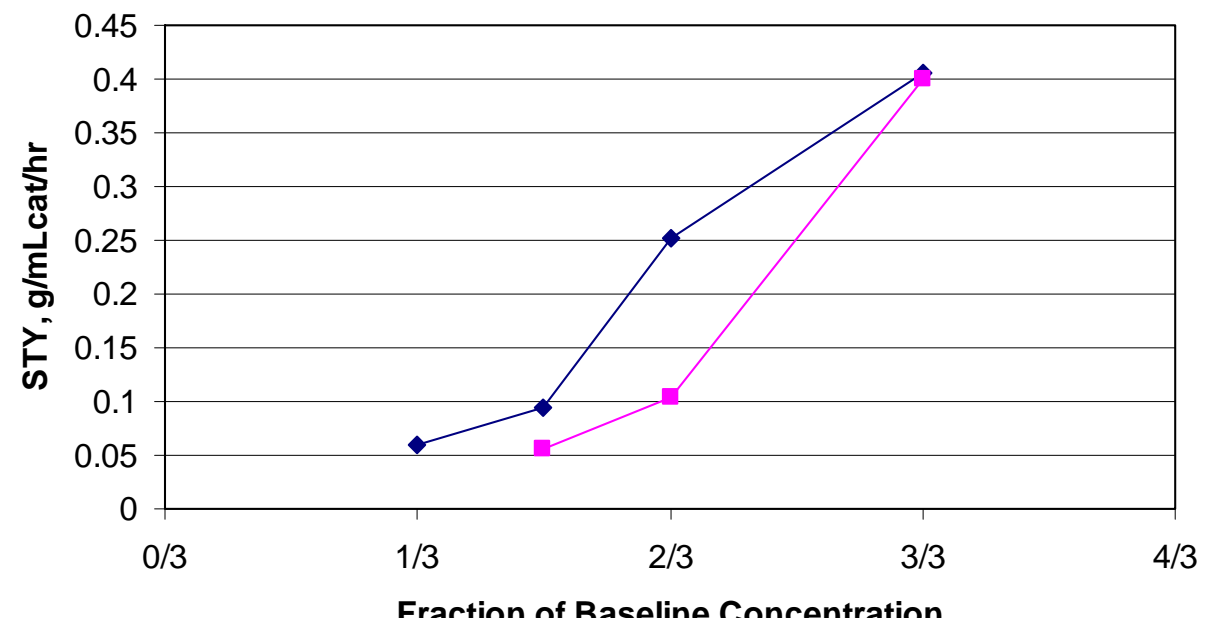

Fraction of Baseline Concentration

$\multimap$ Davisil $645 \multimap$ Davisil LC 150

Figure 4.3. Effect of Total Metal Concentration on $\mathrm{C}_{2}+$ Oxygenates STYs for the Davisil $645 \mathrm{SiO}_{2}$-Supported RhMn Catalysts 
$275^{\circ} \mathrm{C}, 1,200 \mathrm{psig}, 7,500 / \mathrm{hr}$ GHSV

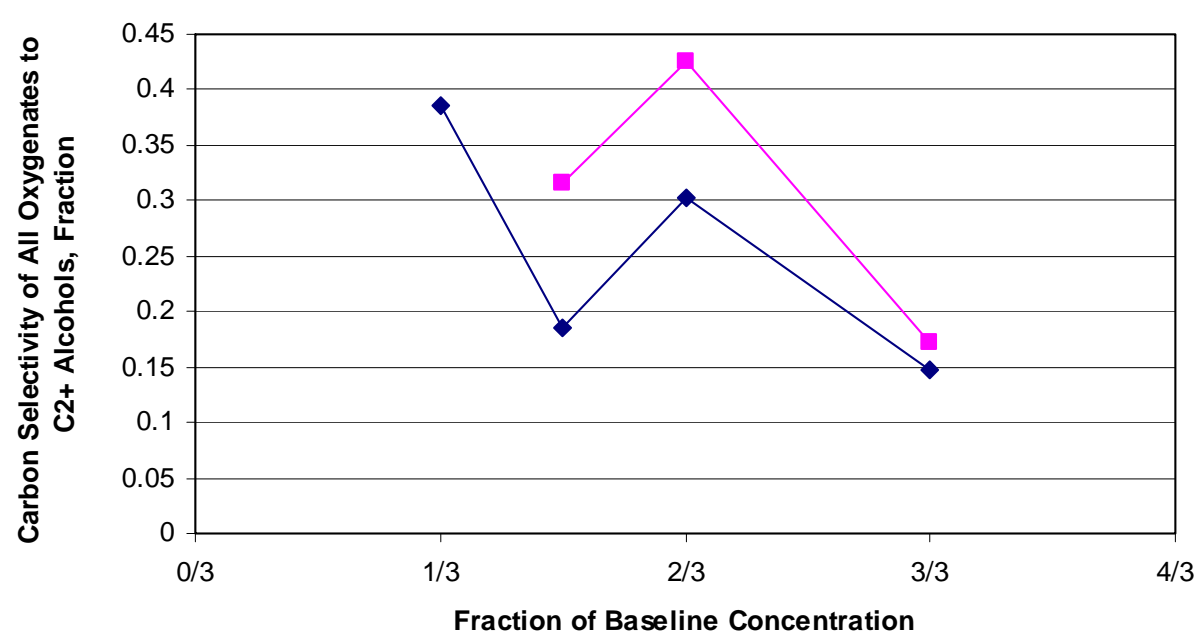

$\multimap$ Davisil $645 \multimap$ Davisil LC 150

$300^{\circ} \mathrm{C}, 1,200 \mathrm{psig}, 11,000 / \mathrm{hr}$ GHSV

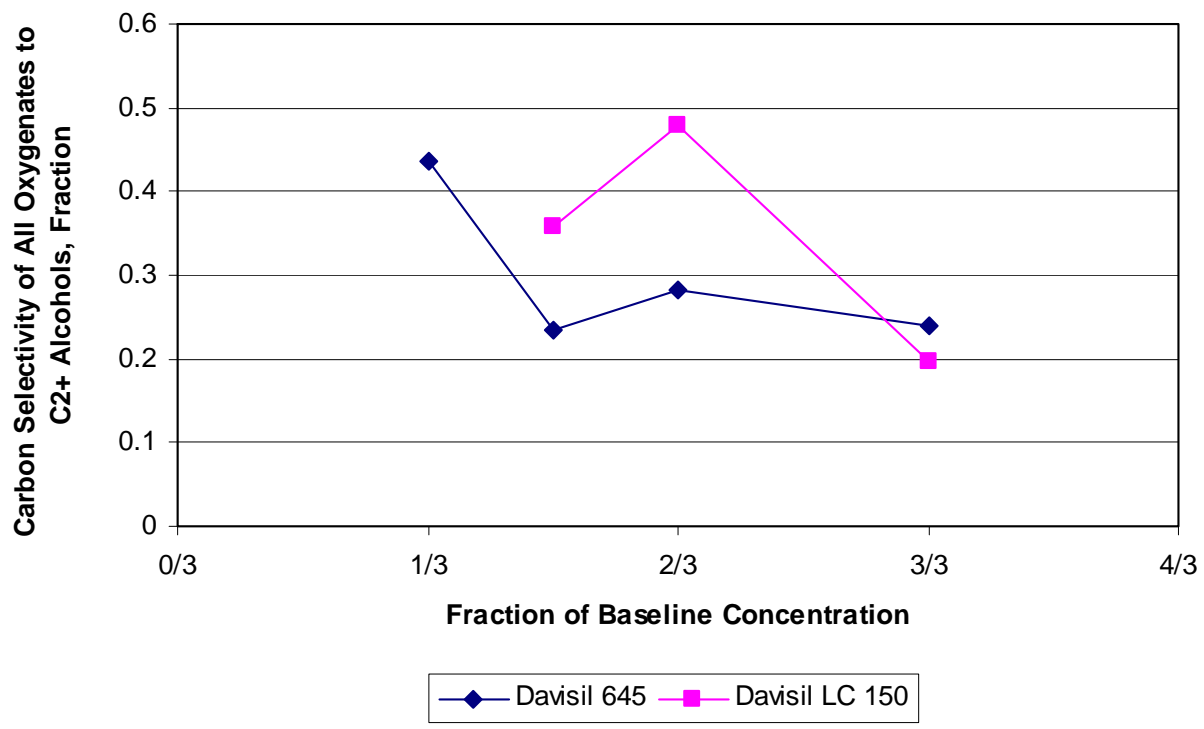

Figure 4.4. Effect of Total Metal Concentration on Carbon Selectivity of $\mathrm{C}_{2}+$ Oxygenates to Alcohols for the Davisil $645 \mathrm{SiO}_{2}$-Supported RhMn Catalysts 
Figure 4.2 compares the converted carbon selectivity to $\mathrm{C}_{2}+$ oxygenates for the different metal concentrations at $275^{\circ} \mathrm{C}$ and $300^{\circ} \mathrm{C}$. There is no clear trend in the effect of the metal concentrations on carbon selectivity to $\mathrm{C}_{2}+$ oxygenates for the Davisil $645 \mathrm{SiO}_{2}$-supported catalysts with the data falling within a $10 \%$ range centered on approximately $40 \%$ conversion. At $300^{\circ} \mathrm{C}$, a similar trend, within a $10 \%$ range centered on approximately $45 \%$ carbon selectivity, occurred for metal concentrations below the baseline concentration. However, at the baseline concentration, the carbon selectivity decreases to 29\%,

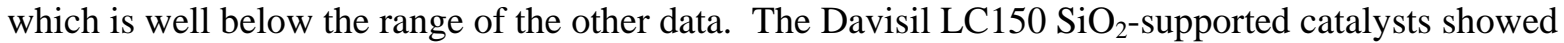
similar behavior, but with more scatter in the data obtained at $275^{\circ} \mathrm{C}$. There is no obvious explanation for the scatter in the data at this time. It could be speculated that that some combination of a high exotherm, partial deactivation, and a higher GHSV could account for the scatter. Overall, there does not appear to be any optimal concentration with regard to carbon selectivity to $\mathrm{C}_{2}+$ oxygenates for either support.

Figure 4.3 compares the $\mathrm{C}_{2}+$ oxygenates STY for the different metal concentrations at $275^{\circ} \mathrm{C}$ and $300^{\circ} \mathrm{C}$. In general, the STY at both temperatures follows the same trend as the carbon conversion for both $\mathrm{SiO}_{2}$ supports, with the highest STYs occurring at the highest metal concentrations.

Figure 4.4 compares the carbon selectivity of the oxygenates to $\mathrm{C}_{2}+$ alcohols for the different metal concentrations at $275^{\circ} \mathrm{C}$ and $300^{\circ} \mathrm{C}$ for both $\mathrm{SiO}_{2}$ supports. While there is some scatter in the data, selectivity appears to trend away from $\mathrm{C}_{2}+$ alcohols as the metal concentration increases, particularly at the highest concentration. However, there may be an anomaly at 2/3X the baseline composition on both $\mathrm{SiO}_{2}$ supports, suggesting that there is a localized maximum in the selectivity towards $\mathrm{C}_{2}+$ alcohols. However, considering the scatter in the selectivity data to $\mathrm{C}_{2}+$ oxygenates in Figure 4.2, any conclusions would be speculative at this time.

Overall, it appears that the optimum RhMn concentration is near 5.56\% (1X the baseline concentration), where the maximum $\mathrm{C}_{2}+$ oxygenates STY occurs. At this concentration, the convertedcarbon selectivity to $\mathrm{C}_{2}+$ oxygenates is fairly insensitive to the Rh concentration, while the carbon conversion is very significantly affected. The selectivity of the oxygenates to $\mathrm{C}_{2}+$ alcohols is low at this concentration, but the range of selectivity over the range of temperatures and $\mathrm{Rh}$ concentrations also were relatively low, ranging from about $15 \%$ to $50 \%$. It may be possible to get further improvements at high Rh concentrations, but the heat management problem at high conversion rates makes evaluation of this possibility very difficult at this time.

\subsubsection{Effect of $\mathrm{Mn}$ Concentration on Catalyst Performance for $\mathrm{RhMn} / \mathrm{SiO}_{2}$ Catalysts}

Six tests were conducted using different concentrations of Mn co-impregnated with the baseline concentration of $\mathrm{Rh}(5.56 \% \mathrm{Rh})$ using the Davisil $645 \mathrm{SiO}_{2}$ support to examine the effect of the Mn concentration on the catalyst performance The Mn concentrations investigated included:

- $\mathrm{wt} \%$ (no Mn)

- $0.28 \mathrm{wt} \%$ (1/6X baseline concentration)

- $0.56 \mathrm{wt} \%$ (1/3X baseline concentration)

- $1.13 \mathrm{wt} \%$ (2/3X baseline concentration)

- $1.69 \mathrm{wt} \%$ (3/3X baseline concentration)

- $2.25 \mathrm{wt} \%$ (4/3X baseline concentration). 
Figures 4.5 through 4.8 provide comparative data for the following two test conditions: 1) $300^{\circ} \mathrm{C}$ and $11,000 / \mathrm{hr}$ GHSV and 2) $315^{\circ} \mathrm{C}$ and $11,000 / \mathrm{hr}$ GHSV. These conditions were chosen because the maximum $\mathrm{C}_{2}+$ oxygenates STYs were achieved in this temperature range. Although data were obtained at higher temperatures, it is apparent that some deactivation was occurring at these temperatures at the higher concentrations. The general behavior of the catalysts at lower temperatures and space velocities $\left(255^{\circ} \mathrm{C}\right.$ and $275^{\circ} \mathrm{C}$ at $7500 / \mathrm{hr}$ GHSV) with respect to the effects of the Mn concentrations, were similar to the behavior observed at $300^{\circ} \mathrm{C}$ and $315^{\circ} \mathrm{C}$.

Figure 4.5 compares the carbon conversions for different Mn concentrations at $300^{\circ} \mathrm{C}$ and $315^{\circ} \mathrm{C}$. It appears that the carbon conversion increases significantly as the Mn concentration increases to about 2/3X of the baseline concentration (1.13 wt\% Mn), and then levels off at higher concentrations. The leveling of carbon conversion at the higher Mn concentrations is concurrent with relatively high conversion rates (38\% to $43 \%$ ). Under these conditions, some deactivation at $300^{\circ} \mathrm{C}$ and $315^{\circ} \mathrm{C}$ may occur at these high conversion rates because of locally elevated temperatures within individual catalyst particles and with respect to spatial positions within the bed.

Figure 4.6 compares the converted carbon selectivity to $\mathrm{C}_{2}+$ oxygenates for the different $\mathrm{Mn}$ concentrations at $275^{\circ} \mathrm{C}$ and $300^{\circ} \mathrm{C}$. The addition of $0.28 \% \mathrm{Mn}(1 / 6 \mathrm{X}$ baseline $\mathrm{Mn})$ to the $\mathrm{Rh}$ catalyst appears to significantly improve the carbon selectivity to $\mathrm{C}_{2}+$ oxygenates for the Davisil $645 \mathrm{SiO}_{2}$ support. However, further increases in the Mn concentration appear to result in a gradual decline in the selectivity.

Figure 4.7 compares the $\mathrm{C}_{2}+$ oxygenates STY for the different Mn concentrations at $300^{\circ} \mathrm{C}$ and $315^{\circ} \mathrm{C}$. In general, the STY at both temperatures follows the same general trend as the carbon conversion with a significant improvement in the STY with the addition of up to 2/3X of the baseline Mn concentration $(1.13 \% \mathrm{Mn})$. At higher Mn concentrations, the STYs decrease modestly because of a leveling off of carbon conversion and a continual decrease in selectivity to the C2+ oxygenates.

Figure 4.8 compares the carbon selectivity of oxygenates to $\mathrm{C}_{2}+$ alcohols for the different $\mathrm{Mn}$ concentrations at $300^{\circ} \mathrm{C}$ and $315^{\circ} \mathrm{C}$. There appears to be a gradual decrease in the selectivity to $\mathrm{C}_{2}+$ alcohols with increasing $\mathrm{Mn}$ concentration up to $1 / 3 \mathrm{X}$ the baseline concentration $(0.56 \% \mathrm{Mn})$ followed by little if any increase in the selectivity at higher concentrations.

Overall, it appears that the optimum manganese concentration is near to 2/3X of the baseline composition of $1.69 \%$. This concentration $(1.13 \% \mathrm{Mn})$ provides the highest $\mathrm{C}_{2}+$ oxygenates STY without significantly sacrificing, converted carbon selectivity to $\mathrm{C}_{2}+$ oxygenates, which are slightly higher at $\mathrm{Mn}$ concentrations as low as $0.56 \%$. At even lower Mn concentrations, the loss of catalyst activity because of carbon conversion overrides any further improvement in selectivity, while concentrations above $1.13 \%$ Mn produce modest decreases in both $\mathrm{C}_{2}+$ oxygenates STYs and selectivity. The selectivity of the $\mathrm{C}_{2}+$ oxygenates to alcohols does not appear to be affected significantly by Mn concentrations above $0.55 \%$. 



Figure 4.5. Effect of Mn Concentration on Carbon Conversion for the Davisil $645 \mathrm{SiO}_{2}$-Supported RhMn Catalysts at $300^{\circ} \mathrm{C}$ and $315^{\circ} \mathrm{C}$ 

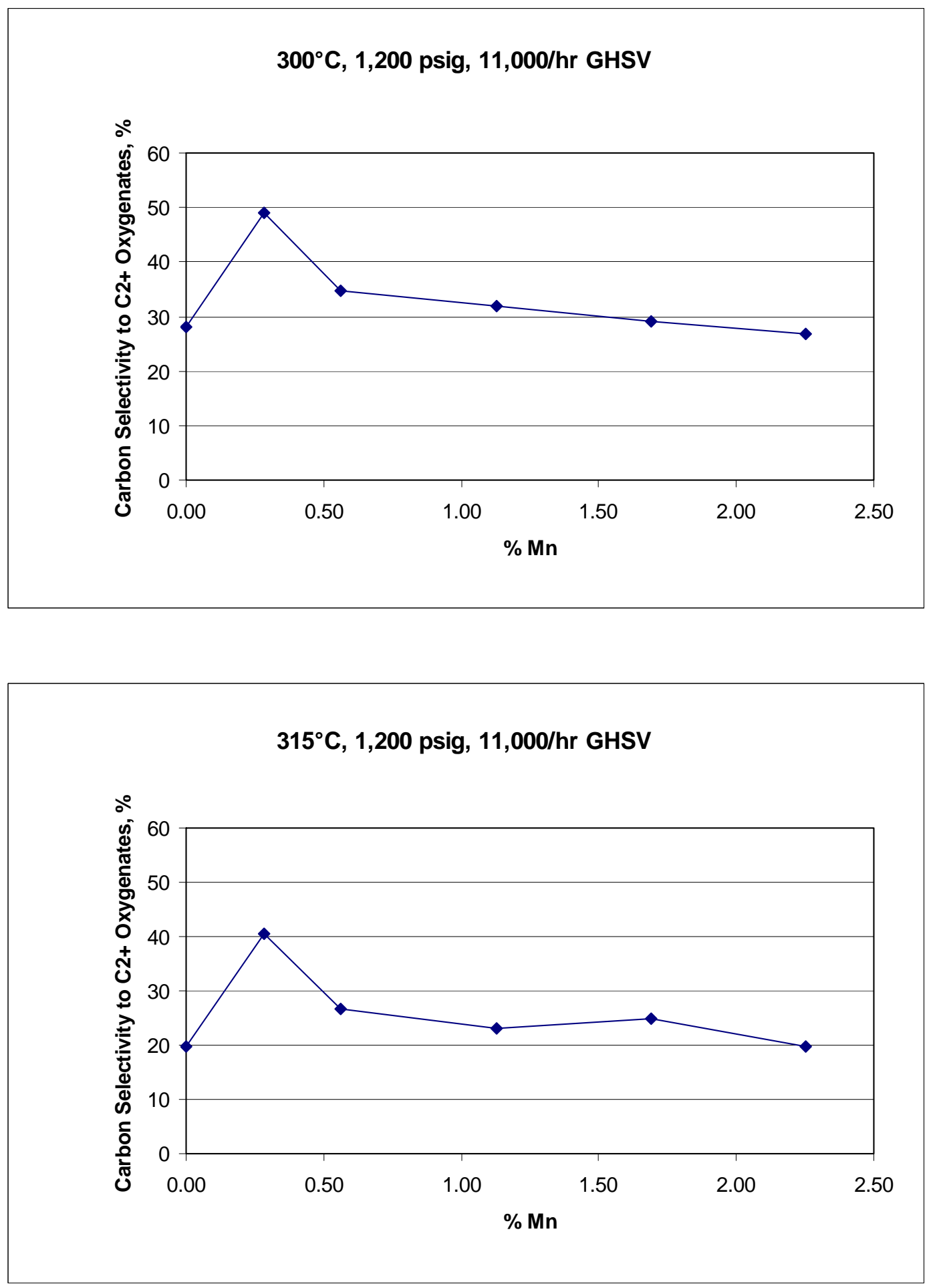

Figure 4.6. Effect of Mn Concentration on Carbon Selectivity to $\mathrm{C}_{2}+$ Oxygenates for the Davisil 645 $\mathrm{SiO}_{2}$-Supported RhMn Catalysts at $300^{\circ} \mathrm{C}$ and $315^{\circ} \mathrm{C}$ 

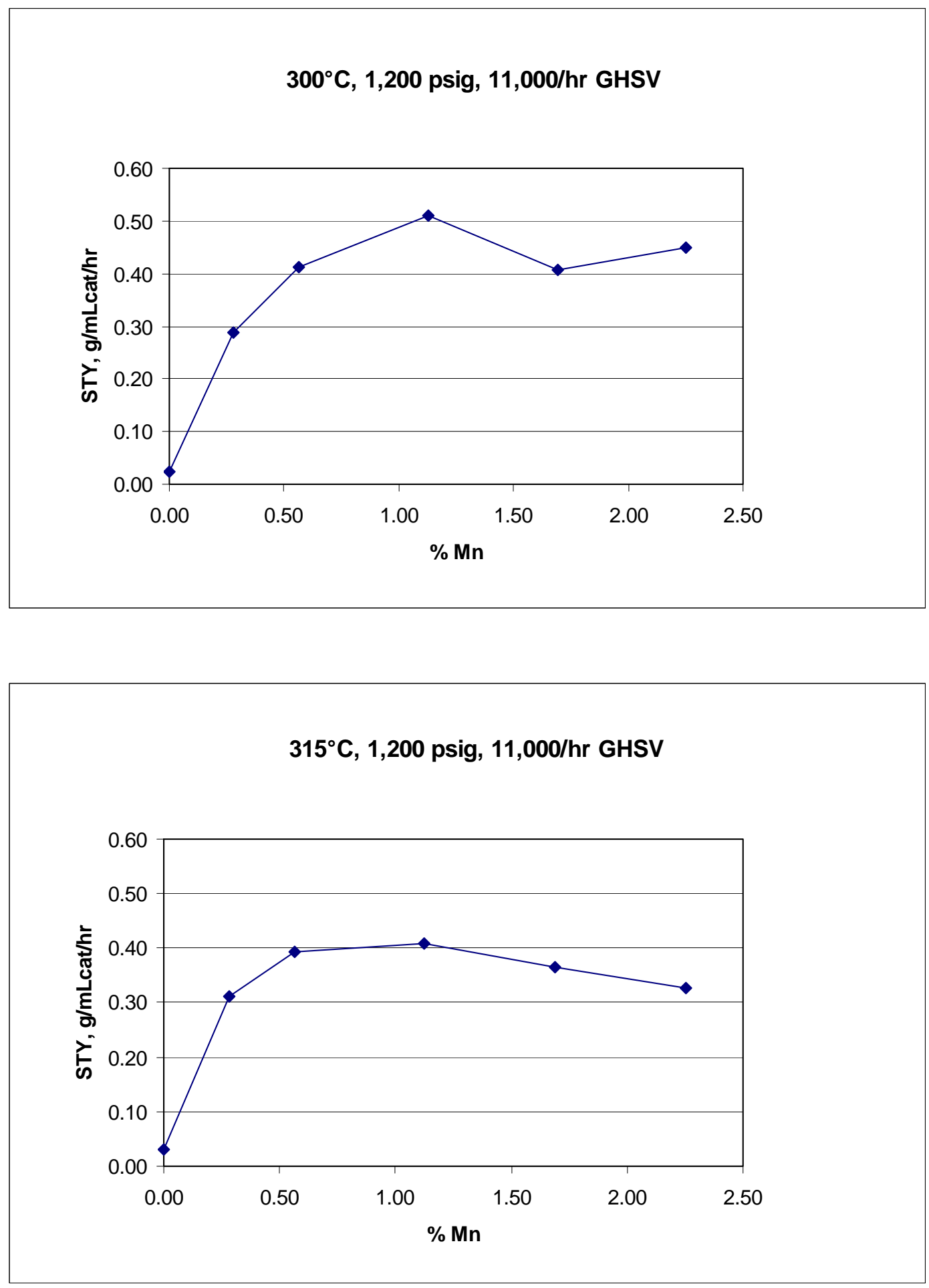

Figure 4.7. Effect of Mn Concentration on $\mathrm{C}_{2}+$ Oxygenates STY for the Davisil $645 \mathrm{SiO}_{2}-\mathrm{Supported}$ RhMn Catalysts at $300^{\circ} \mathrm{C}$ and $315^{\circ} \mathrm{C}$ 
$300^{\circ} \mathrm{C}, 1,200 \mathrm{psig}, 11,000 / \mathrm{hr}$ GHSV

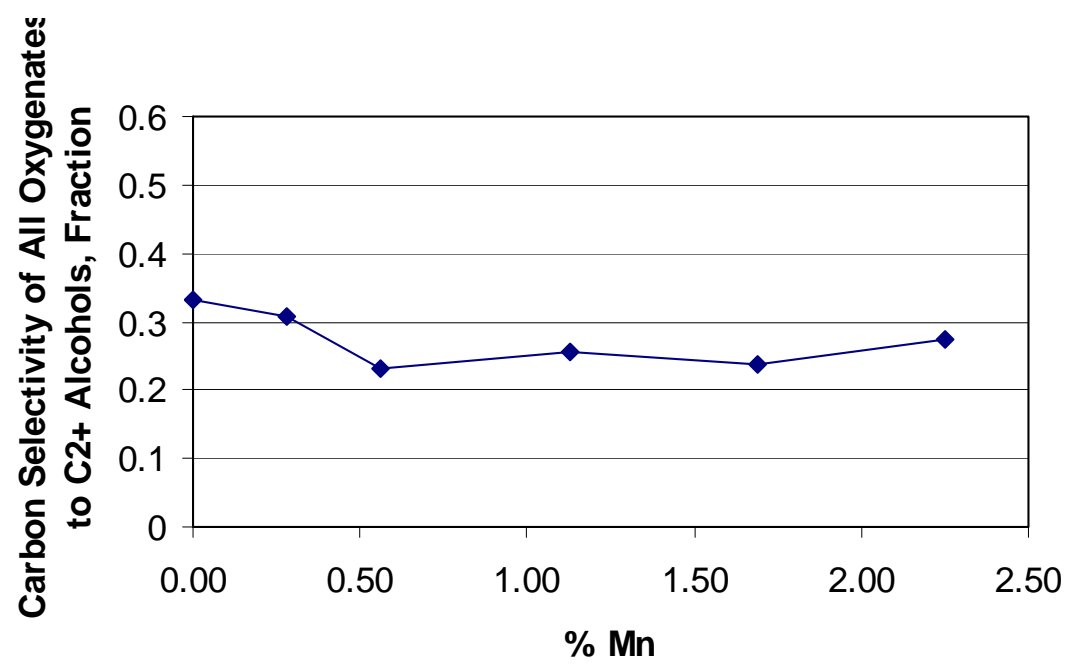

$315^{\circ} \mathrm{C}, 1,200 \mathrm{psig}, 11,000 / \mathrm{hr}$ GHSV

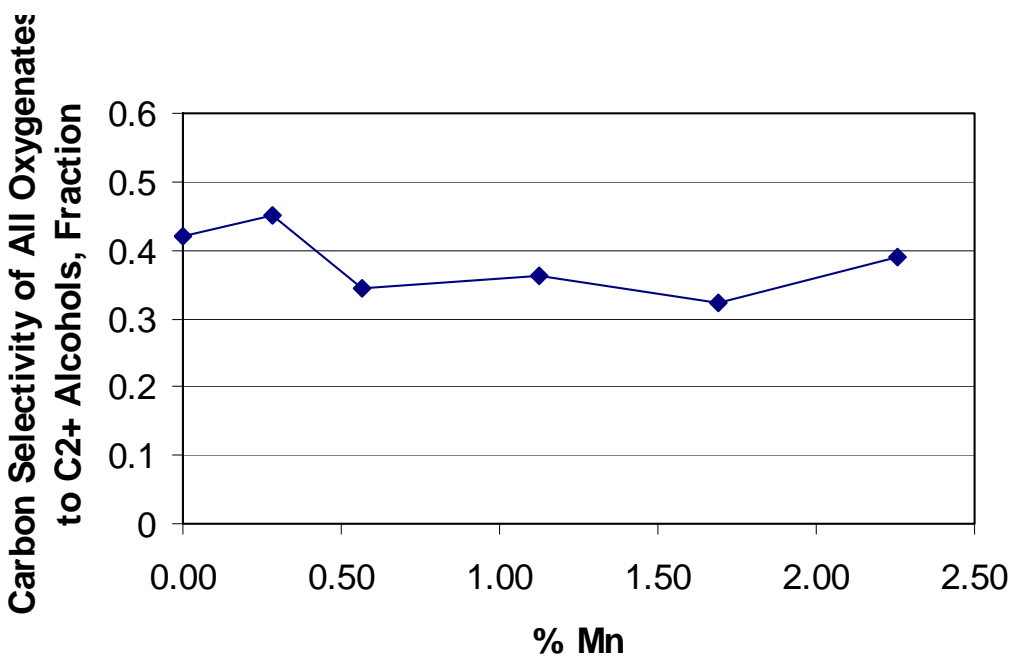

Figure 4.8. Effect of Mn Concentration on Carbon Selectivity of $\mathrm{C}_{2}+$ Oxygenates to Alcohols for the Davisil $645 \mathrm{SiO}_{2}$-Supported RhMn Catalysts at $300^{\circ} \mathrm{C}$ and $315^{\circ} \mathrm{C}$ 


\subsubsection{Effect of Iridium Concentration on Catalyst Performance for $\mathrm{Rh}-\mathrm{Mn} / \mathrm{SiO}_{2}$ Catalysts}

Six tests were conducted using different concentrations of Ir co-impregnated with the baseline concentrations of Rh (5.56\% Rh) and $\mathrm{Mn}(1.69 \% \mathrm{Mn})$ using the Davisil $645 \mathrm{SiO}_{2}$ support to examine the effect of the Ir concentration on the catalyst performance. The Ir concentrations investigated included:

- wt\% (no Ir)

- $0.017 \mathrm{wt} \%$ (1/60X baseline concentration)

- $0.34 \mathrm{wt} \%$ (1/3X baseline concentration)

- $1.03 \mathrm{wt} \%$ (3/3X baseline concentration)

- $1.37 \mathrm{wt} \%$ (4/3X baseline concentration)

- $2.72 \mathrm{wt} \%$ (5/3X baseline concentration).

Figures 4.9 through 4.12 provide comparative data for the following two test conditions: 1$) 275^{\circ} \mathrm{C}$ and $7500 / \mathrm{hr}$ GHSV and 2) $300^{\circ} \mathrm{C}$ and $11,000 / \mathrm{hr}$ GHSV. These conditions were chosen because the maximum $\mathrm{C}_{2}+$ oxygenates STYs were achieved at $300^{\circ} \mathrm{C}$, and the data at $275^{\circ} \mathrm{C}$ provides additional information on the trends at lower temperatures. Although data were obtained from higher temperatures, it is apparent that some deactivation was occurring at these temperatures at the higher concentrations, thus making side-by-side comparisons of different tests difficult.

Figure 4.9 compares the carbon conversions for different Ir concentrations. The addition of very little Ir $(0.017 \%$ or $1 / 60$ of the baseline concentration) resulted in an immediate decrease in the carbon conversion. Further increases in Ir concentration, however, resulted in an increase in carbon conversion. It should be noted, however, that there was very little increase in carbon conversion at either temperature as the Ir increased from $1 / 3 \mathrm{X}$ to $1 \mathrm{X}$ of the baseline concentration $(0.34 \%$ to $1.03 \% \mathrm{Ir})$. This behavior occurred at all tested temperatures and, in particular, at $256^{\circ} \mathrm{C}$ where the carbon conversion increased from about $10 \%$ to $17 \%$, which is well below the carbon conversions where the effect of the exothermic reactions might significantly influence actual catalyst temperatures as discussed previously. It is possible that very different behaviors occur in this concentration range than occur at higher concentrations. Alternatively, there may have been a problem with the experiment using $1 \mathrm{X}$ of the baseline concentration of Ir. Further evaluation in this concentration range would be needed to further refine the effect of Ir.

Figure 4.10 compares the converted carbon selectivity to $\mathrm{C}_{2}+$ oxygenates for the different $\mathrm{Ir}$ concentrations. Again, adding very little Ir had a pronounced effect on the selectivity. However, the behavior was different at $256^{\circ} \mathrm{C}$ (not shown) where the Ir addition resulted in a decrease in the selectivity compared to $300^{\circ} \mathrm{C}$ and higher temperatures where the Ir addition resulted in a pronounced increase in the selectivity (there was very little effect at $275^{\circ} \mathrm{C}$ ). Differences in behavior depending on the reaction temperature also occurred with further increasing the Ir concentration up to $1 \mathrm{X}$ baseline concentration $(1.03 \% \mathrm{Ir})$. At $256^{\circ} \mathrm{C}$ and $275^{\circ} \mathrm{C}$, the highest selectivity to $\mathrm{C}_{2}+$ oxygenates occurred at 1/3X of the baseline concentration followed by a gradual decrease in selectivity at $1 \mathrm{X}$ of the baseline concentration. At $300^{\circ} \mathrm{C}$ and $315^{\circ} \mathrm{C}$, the maximum converted carbon selectivity to $\mathrm{C}_{2}+$ oxygenates occurred at $1 \mathrm{X}$ the baseline Ir concentration. Increasing the Ir concentration above $1 \mathrm{X}$ the baseline concentration resulted in a significant decrease in the carbon selectivity at all catalyst temperatures although there was significant scatter in the data. The decrease in converted carbon selectivity to $\mathrm{C}_{2}+$ oxygenates coincides with a significant increase in carbon conversion over the same concentration range suggesting that the exotherms are producing higher than measured temperatures in 
the catalyst bed, as previously discussed, and some deactivation that may be changing the selectivity of the catalysts.
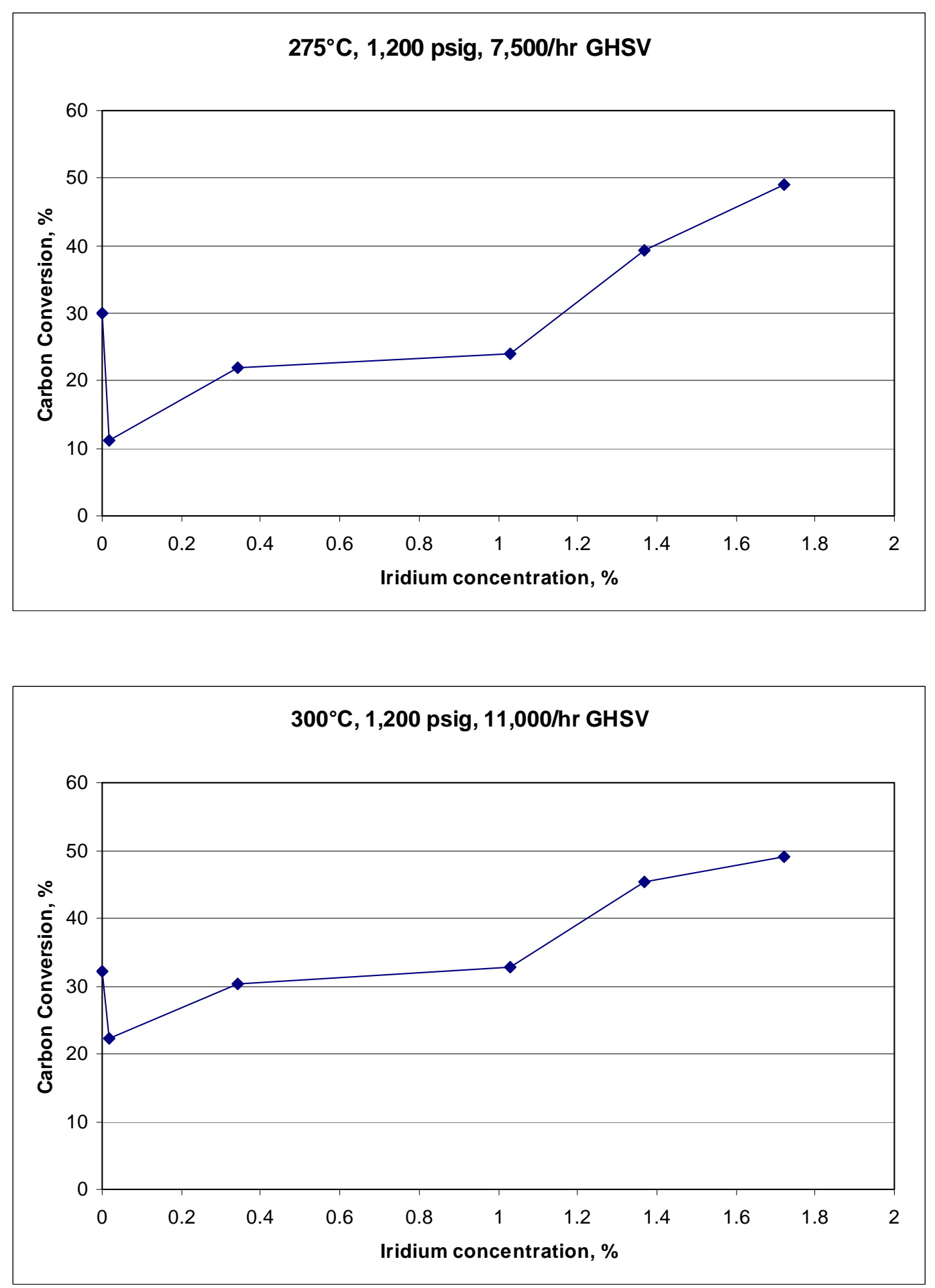

Figure 4.9. Effect of Ir Concentration on Carbon Conversion for the Davisil $645 \mathrm{SiO}_{2}$-Supported RhMn Catalysts at $275^{\circ} \mathrm{C}$ and $300^{\circ} \mathrm{C}$ 

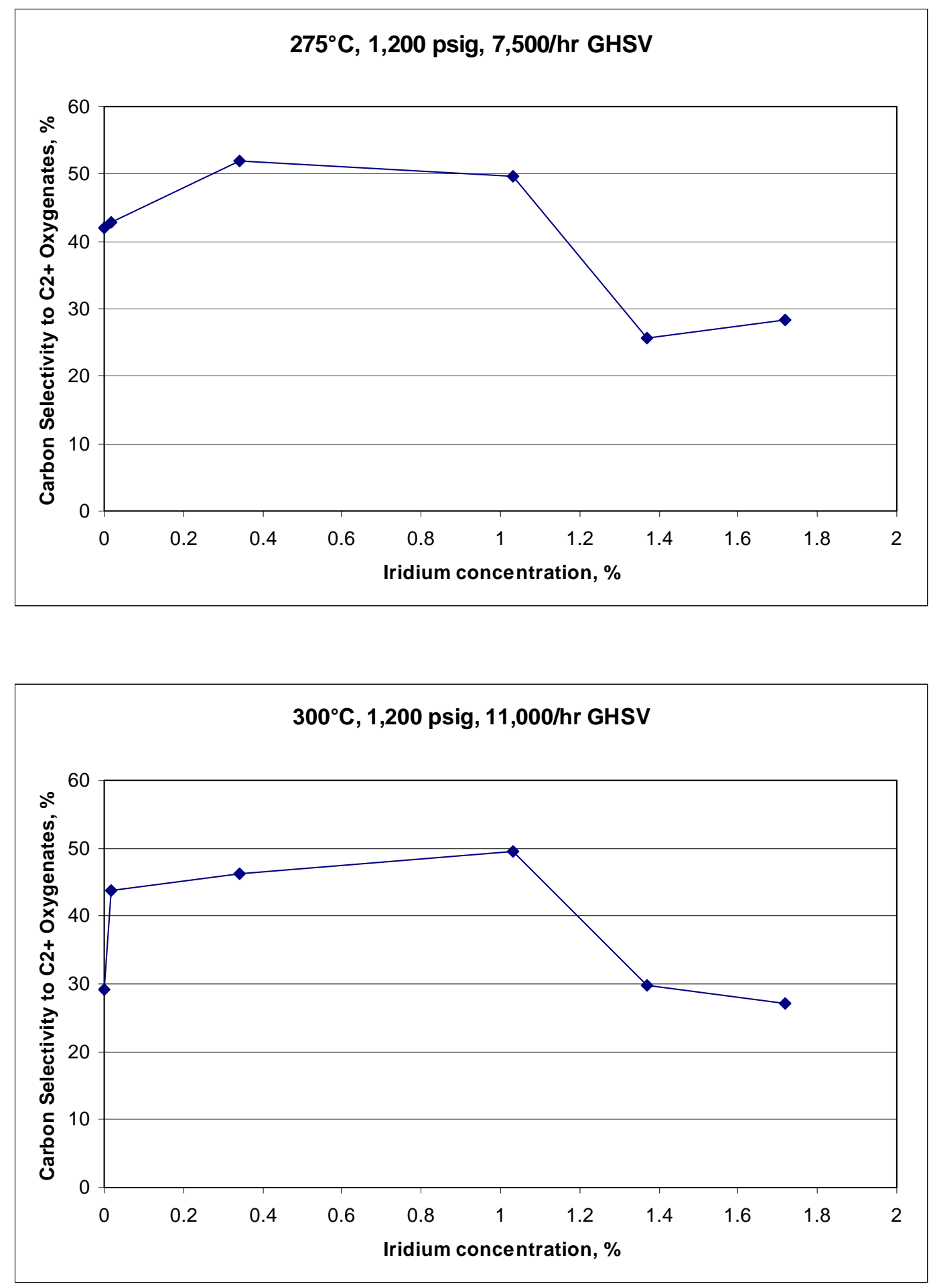

Figure 4.10. Effect of Ir Concentration on Carbon Selectivity to $\mathrm{C}_{2}+$ Oxygenates for the Davisil 645 $\mathrm{SiO}_{2}$-Supported $\mathrm{RhMn}$ Catalysts at $275^{\circ} \mathrm{C}$ and $300^{\circ} \mathrm{C}$ 

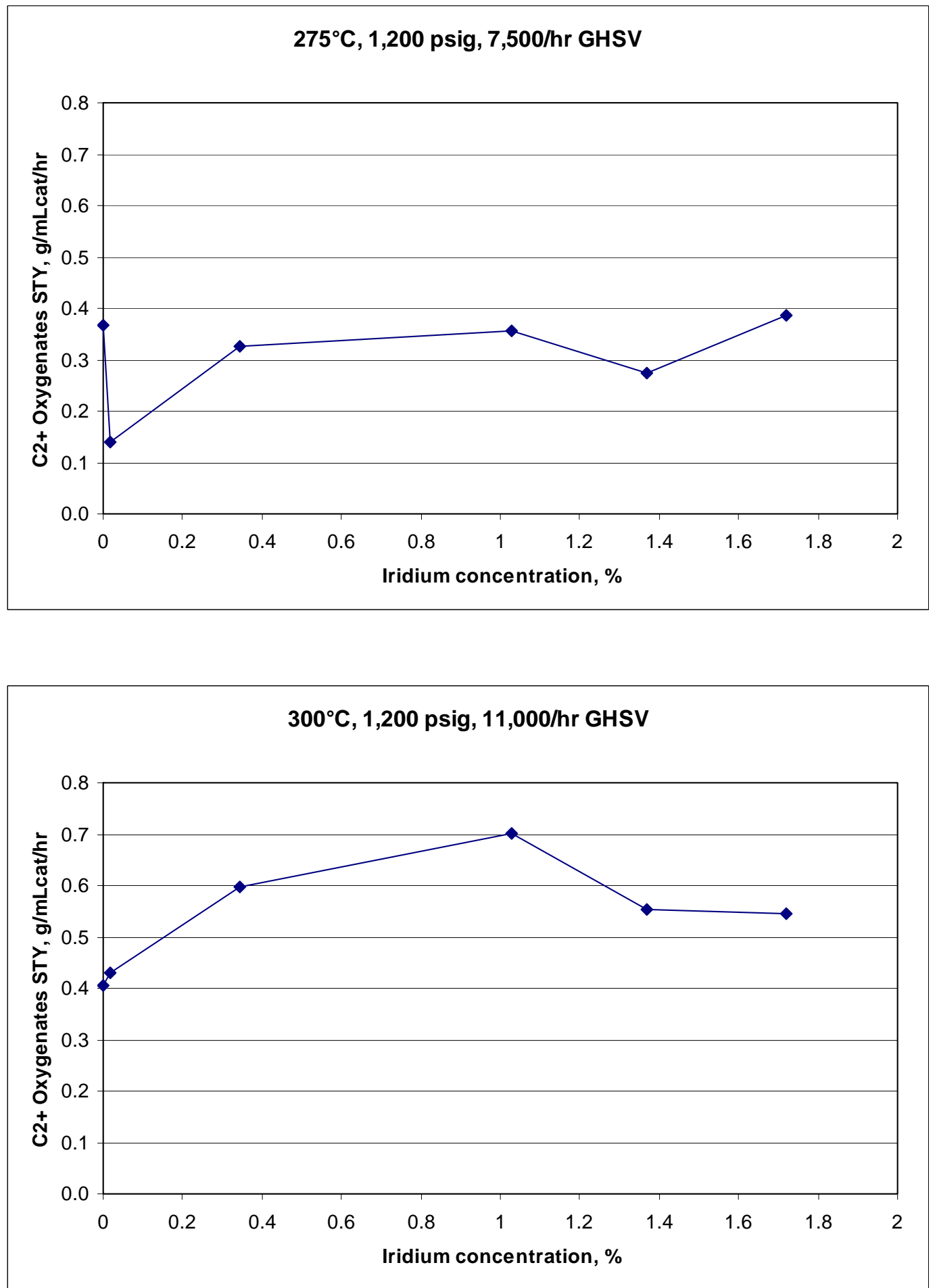

Figure 4.11. Effect of Ir Concentration on $\mathrm{C}_{2}+$ Oxygenates $\mathrm{STY}$ for the Davisil $645 \mathrm{SiO}_{2}$-Supported RhMn Catalysts at $275^{\circ} \mathrm{C}$ and $300^{\circ} \mathrm{C}$ 

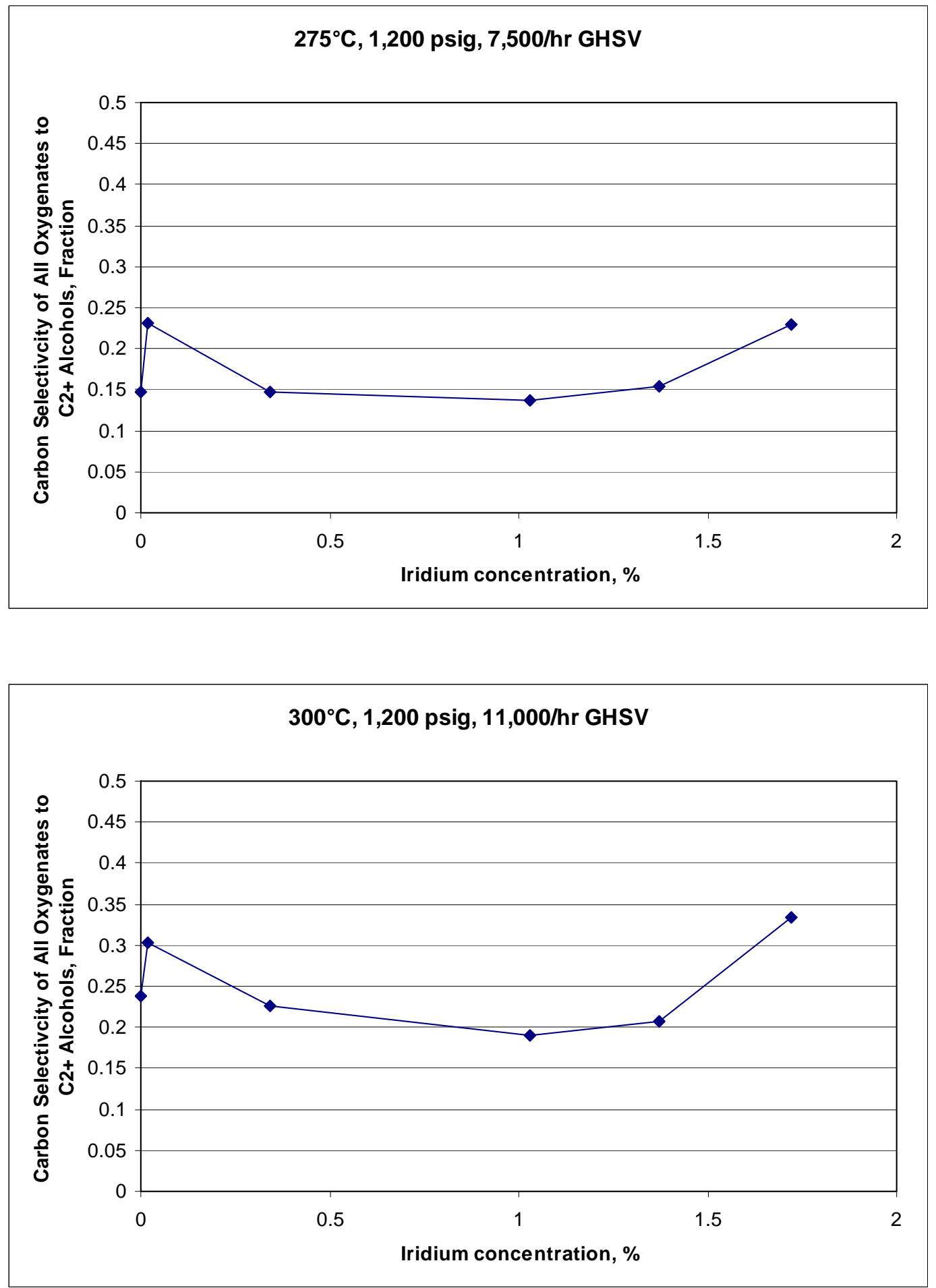

Figure 4.12. Effect of Ir Concentration on Carbon Selectivity of $\mathrm{C}_{2}+$ Oxygenates to Alcohols for the Davisil $645 \mathrm{SiO}_{2}$-Supported RhMn Catalysts at $275^{\circ} \mathrm{C}$ and $300^{\circ} \mathrm{C}$ 
Figure 4.11 compares the $\mathrm{C}_{2}+$ oxygenates STY for different Ir concentrations. In general, the STY at $256^{\circ} \mathrm{C}$ (not shown) and $275^{\circ} \mathrm{C}$ showed significant decreases in STY with the addition of $1 / 60 \mathrm{X}$ the baseline Ir concentration, followed by a significant increase in the STY at a Ir concentration of 1/3X the baseline concentration. Higher Ir concentrations produced a gradual further increase in the STY with considerable scatter in the data. At $300^{\circ} \mathrm{C}$ and $315^{\circ} \mathrm{C}$ (not shown), the opposite behavior in the STY occurred with the addition of $1 / 60 \mathrm{X}$ of the baseline concentration. The peak STY at $300^{\circ} \mathrm{C}$ occurred at $1 \mathrm{X}$ the baseline Ir concentration, while at $315^{\circ} \mathrm{C}$, the peak STY occurred at $1 / 3 \mathrm{X}$ the baseline concentration, (although very little decrease occurred at concentrations up to the baseline concentration at this temperature). Further increases in the Ir concentration above the baseline at the higher temperatures resulted in a decrease in the $\mathrm{C}_{2}+$ oxygenates STYs. This latter behavior is attributed to some level of catalyst deactivation at the higher temperatures.

Figure 4.12 compares the carbon selectivity of oxygenates to $\mathrm{C}_{2}+$ alcohols for different $\mathrm{Ir}$ concentrations. Again, the addition of very $1 / 60$ of the baseline Ir concentration had a pronounced effect on the selectivity of oxygenates to $\mathrm{C}_{2}+$ alcohols, with a significant increase in the selectivity at all temperatures. Further increases in Ir concentrations to about 1/3X of the baseline concentration resulted in a significant decrease in the selectivity at all reaction temperatures. With further increases in the Ir concentration to $1 \mathrm{X}$ the baseline composition, the selectivity increases very slightly at $256^{\circ} \mathrm{C}$ and decreases at the higher reaction temperatures. At higher Ir concentrations, the selectivity of the $\mathrm{C}_{2}+$ oxygenates to alcohols increased at all reaction temperatures.

Overall, it appears that the optimum Ir concentration is no higher than 1.03\% (1X baseline concentration), and probably is between $1.03 \%$ and $0.34 \%$. This concentration range provides a high $\mathrm{C}_{2}+$ oxygenates STY accompanied by favorable carbon selectivity to $\mathrm{C}_{2}+$ oxygenates. Selectivity of the oxygenates to $\mathrm{C}_{2}+$ alcohols is relatively low over this concentration range but none of the conditions achieved a very good selectivity, with the selectivity ranging from about $20 \%$ to $50 \%$ over the range of temperatures and Ir concentrations evaluated.

\subsubsection{Effect of Lithium and Lithium Plus Iridium Concentration on Catalyst Performance for Rh-Mn/SiO ${ }_{2}$ Catalysts}

Four tests were conducted using different concentrations of Li co-impregnated with the baseline concentrations of Rh (5.56 wt\% Rh) and Mn (1.69 wt\% Mn) using the Davisil $645 \mathrm{SiO}_{2}$ support to examine the effect of the Li concentration on the catalyst performance The Li concentrations investigated included:

- 0.00 wt\% (no Li)

- $0.0113 \mathrm{wt} \%$ (1X baseline concentration)

- $0.170 \mathrm{wt} \%$ (3/2X baseline concentration)

- $0.226 \mathrm{wt} \%$ (2X baseline concentration).

A second set of tests was conducted using three different concentrations of Li co-impregnated with the baseline concentrations of Rh, Mn, and Ir (1.03\% Ir) to investigate the effect of Li addition to the Ir-promoted baseline RhMn catalyst. The Li concentrations investigated included:

- $0.00 \%$ (no Li)

- $0.170 \%$ (3/2X baseline concentration)

- $0.226 \%$ (2X baseline concentration). 
Figures 4.13 through 4.16 provide comparative data for both sets of catalysts at the following test conditions: 1) $300^{\circ} \mathrm{C}$ and $11,000 \mathrm{GHSV}$ and 2) $315^{\circ} \mathrm{C}$ and $11,000 / \mathrm{hr}$ GHSV. These conditions were chosen because the maximum $\mathrm{C}_{2}+$ oxygenates STYs were achieved at $300^{\circ} \mathrm{C}$, and carbon conversion at lower testing temperatures was very low to nonexistent, which made comparisons impractical. However, while the tests can be compared at $315^{\circ} \mathrm{C}$, the data suggests some evidence of deactivation. Data also was obtained from higher temperatures that showed significant deactivation making comparisons impractical.
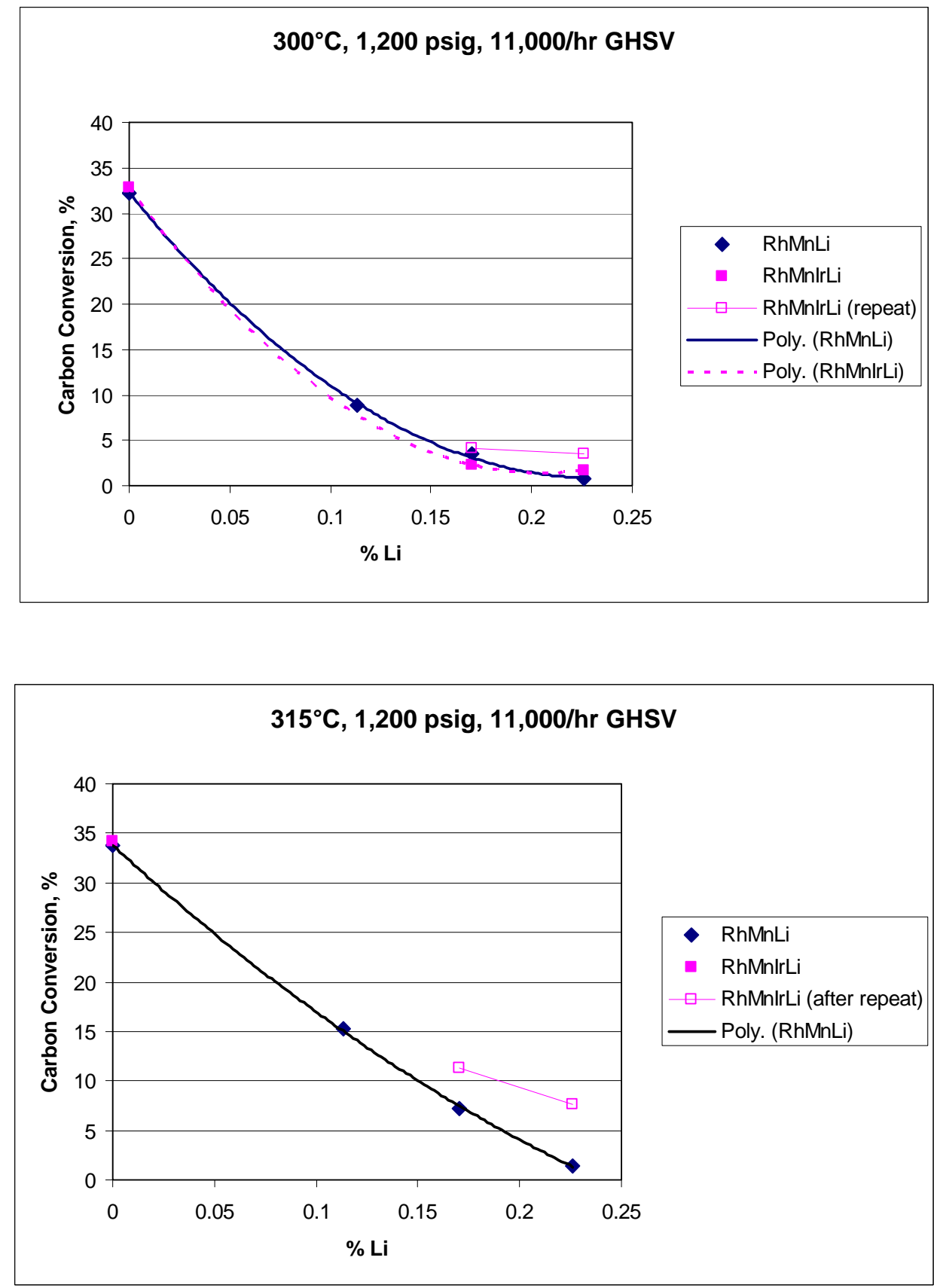

Figure 4.13. Effect of Li Concentration on Carbon Conversion for the Davisil $645 \mathrm{SiO}_{2}$-Supported RhMn and RhMnIr Catalysts at $300^{\circ} \mathrm{C}$ and $315^{\circ} \mathrm{C}$ 

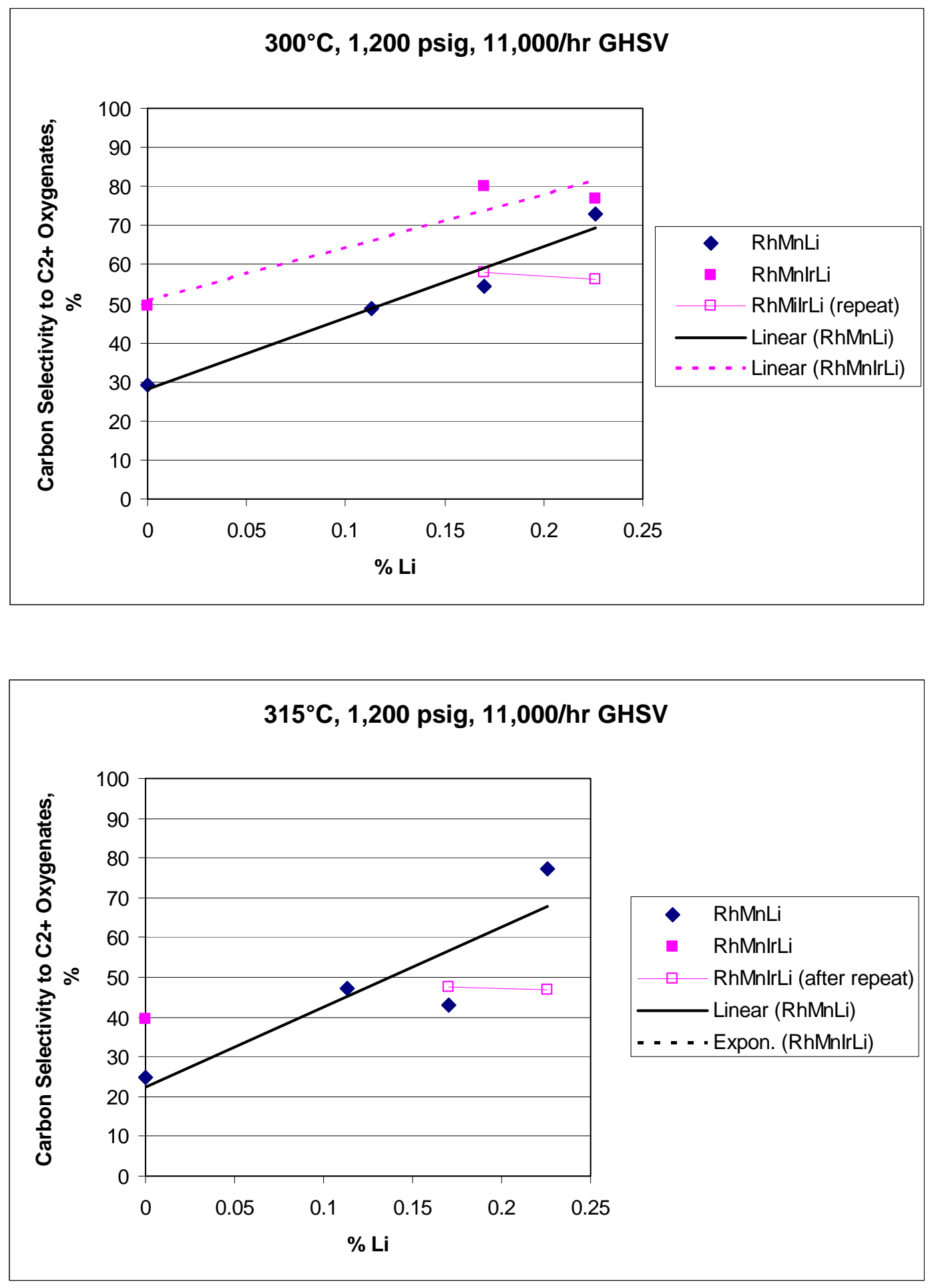

Figure 4.14. Effect of Li Concentration on Carbon Selectivity to $\mathrm{C}_{2}+$ Oxygenates for the Davisil 645 $\mathrm{SiO}_{2}$-Supported $\mathrm{RhMn}$ and RhMnIr Catalysts at $300^{\circ} \mathrm{C}$ and $315^{\circ} \mathrm{C}$ 

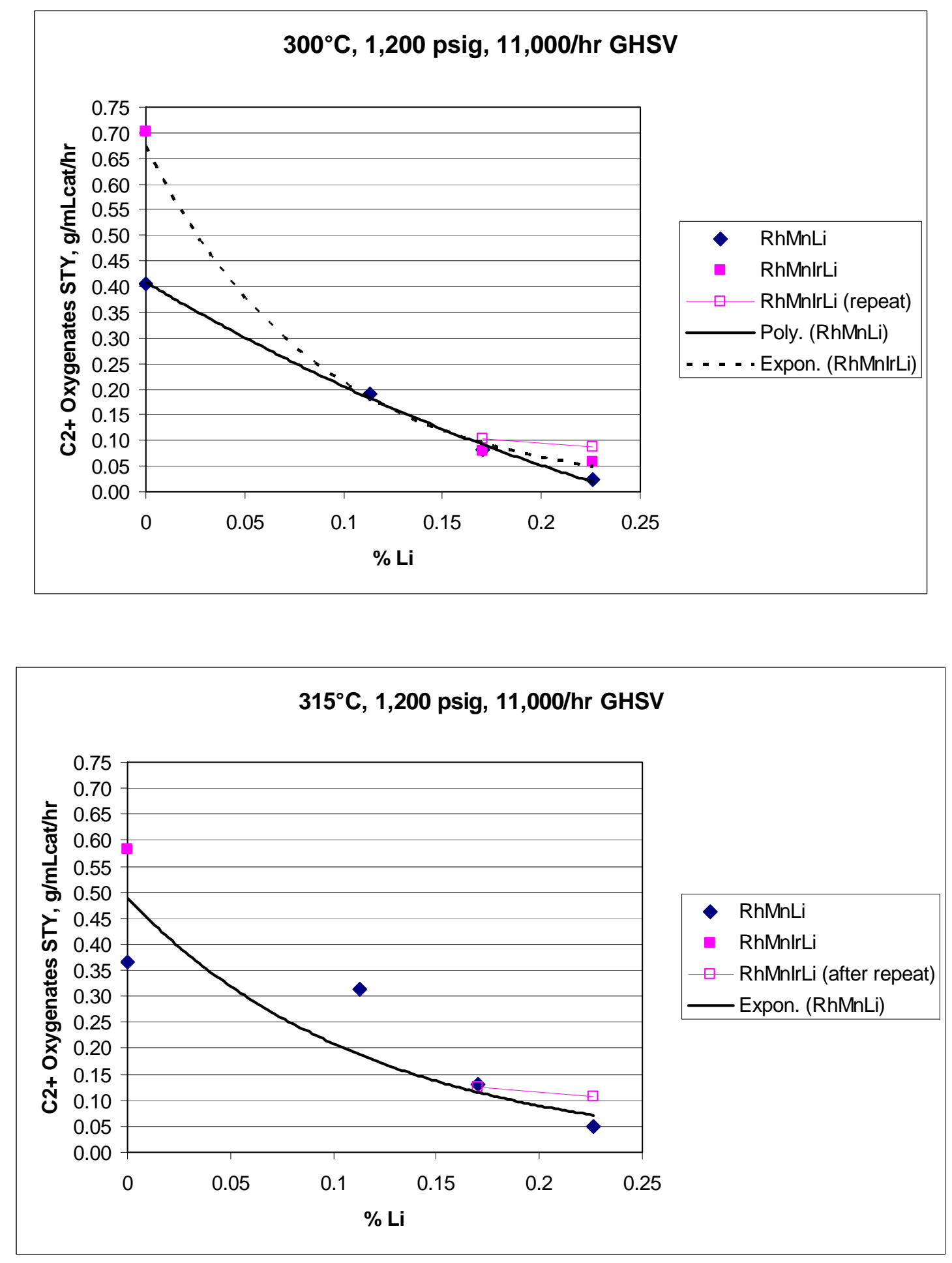

Figure 4.15. Effect of Li Concentration on $\mathrm{C}_{2}+$ Oxygenates STY for the Davisil $645 \mathrm{SiO}_{2}$-Supported RhMn and RhMnIr Catalysts at $300^{\circ} \mathrm{C}$ and $315^{\circ} \mathrm{C}$ 

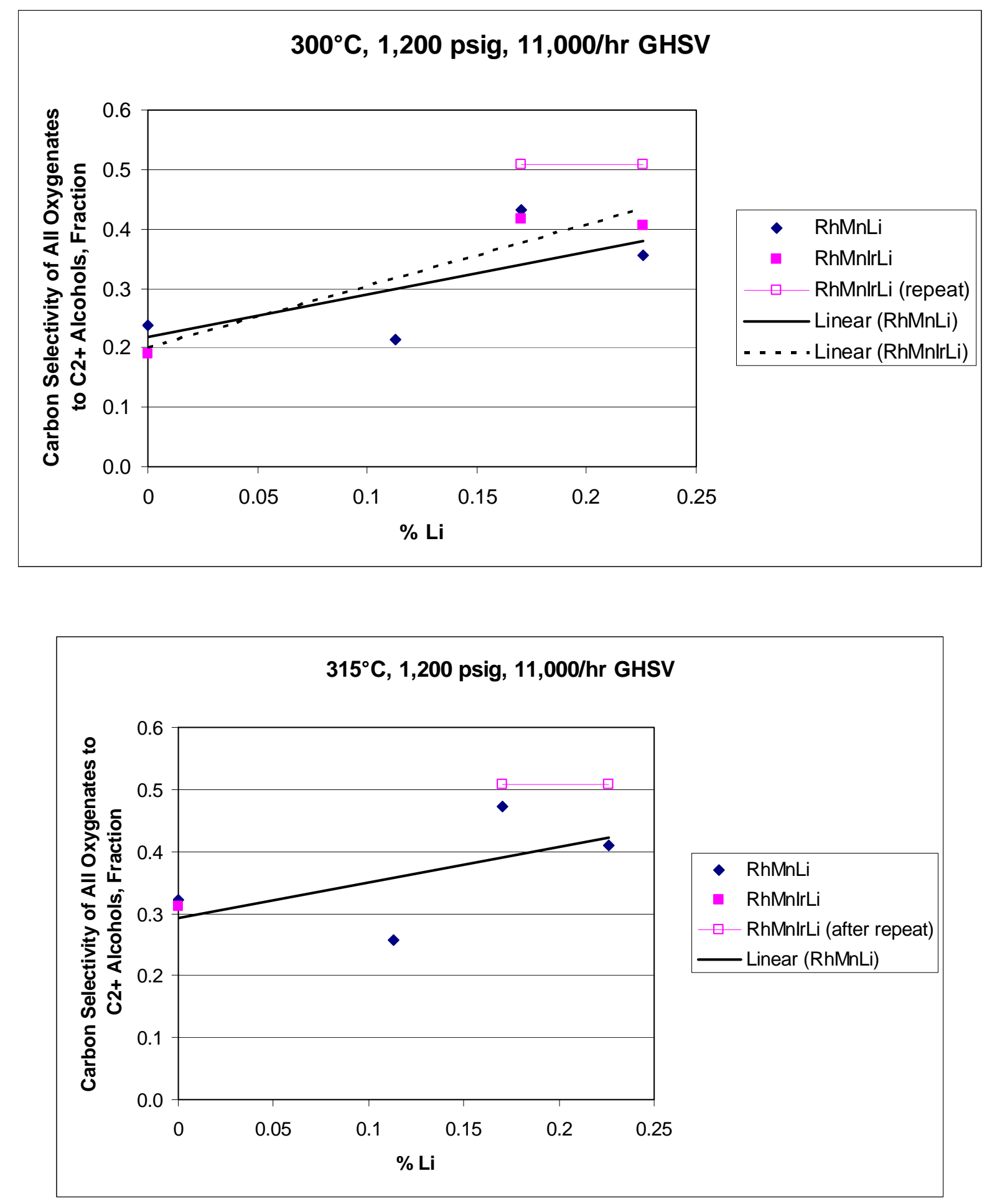

Figure 4.16. Effect of Li Concentration on Carbon Selectivity of $\mathrm{C}_{2}+$ Oxygenates to Alcohols for the Davisil $645 \mathrm{SiO}_{2}$-Supported RhMn and RhMnIr Catalysts at $300^{\circ} \mathrm{C}$ and $315^{\circ} \mathrm{C}$ 
Figure 4.13 compares the carbon conversions for different Li concentrations. Before examining the results, it should be noted that the conversion data for the $1.5 \mathrm{X}$ and $2 \mathrm{X} \mathrm{Li}$ with $1 \mathrm{X}$ Ir were obtained after the catalyst had been heated to testing temperatures as high as $345^{\circ} \mathrm{C}$. A repeat of the test conditions at $300^{\circ} \mathrm{C}$ before testing at $315^{\circ} \mathrm{C}$ indicated that the catalyst had not deactivated and, in fact, had become slightly more active, at least with respect to carbon conversion. It also should be noted that no methane was detected by the GC for both of these catalysts when they were first evaluated at $300^{\circ} \mathrm{C}$ (a trace quantity of higher hydrocarbon gases were detected for the catalyst containing 1.5X Li and Ir), but methane was detected and reported when the conditions were repeated(see Appendix A). The catalyst with $2 \mathrm{X} \mathrm{Li}$ also did not have any hydrocarbons detected by the GC when it was tested at $300^{\circ} \mathrm{C}$. Neither the catalyst with $2 \mathrm{X} \mathrm{Li}$ nor $1.5 \mathrm{X} \mathrm{Li}$ were tested at $345^{\circ} \mathrm{C}$, and the conditions were not repeated after being tested at $325^{\circ} \mathrm{C}$.

Taking into account the caveats described above, it appears that the addition of increasing concentrations of Li resulted in a corresponding substantial decrease in carbon conversion. Furthermore, the incorporation of Ir provided no significant improvement in carbon conversion over the range of Li concentrations investigated. However, there did appear to be an improvement in carbon conversion when the two catalysts containing Ir were first tested at temperatures up to $345^{\circ} \mathrm{C}$ and then cooled to retest $300^{\circ} \mathrm{C}$ and $315^{\circ} \mathrm{C}$. None of the other catalysts were tested at repeated conditions for comparison.

Figure 4.14 compares the converted carbon selectivity to $\mathrm{C}_{2}+$ oxygenates for different $\mathrm{Li}$ concentrations. The addition of increasing concentrations of $\mathrm{Li}$ appears to result in a corresponding substantial increase in the carbon selectivity. It also appears that the presence of Ir significantly improves the selectivity at $300^{\circ} \mathrm{C}$ provided the catalyst has not seen higher temperatures. However, as previously discussed, the two catalysts containing $2 \mathrm{X} \mathrm{Li}$ (with and without Ir) and the catalyst containing $1.5 \mathrm{X} \mathrm{Li}$ with Ir did not produce measurable quantities of hydrocarbons, and the selectivity values result only from methanol production (see data in Appendix A). After the two catalysts containing Ir had been tested at $345^{\circ} \mathrm{C}$, methane and other hydrocarbon gases were detected resulting in a significant decrease in carbon selectivity to the $\mathrm{C}_{2}+$ oxygenates. The results from the tests run at $315^{\circ} \mathrm{C}$ are similar to those run at $300^{\circ} \mathrm{C}$, but there are no comparable test conditions for the catalysts containing Li with and without Ir to make further comparisons of a possible beneficial effect of Ir on selectivity.

Figure 4.15 compares the $\mathrm{C}_{2}+$ oxygenates STYs for different Li concentrations. The STYs for both the RhMn and RhMnIr catalysts generally followed the trend of carbon conversion with little, if any, benefit from the presence of Ir in the catalyst.

Figure 4.16 compares the carbon selectivity of oxygenates to $\mathrm{C}_{2}+$ alcohols. Even though there is considerable scatter in the data, it appears that the addition of Li to the catalyst improves the selectivity to ethanol, and the presence of Ir provides additional, although modest, improvement.

Overall, the addition of Li to the RhMn catalyst improves the converted carbon selectivity to both the $\mathrm{C}_{2}+$ oxygenates and ethanol, but at the expense of a significant decrease in the STYs of both.

Consequently, it is not possible to specify an optimum Li concentration. Instead, it becomes an issue as to which parameter is more important, STY or selectivity, within the constraint that too high a catalyst temperature will cause the catalyst to significantly deactivate.

The presence of Ir in the catalyst does not improve the $\mathrm{C}_{2}+$ oxygenates STYs when $\mathrm{Li}$ is present in the catalyst. However, it does appear to modestly improve the converted carbon selectivity to both $\mathrm{C}_{2}{ }^{+}$ oxygenates and oxygenates to $\mathrm{C}_{2}+$ alcohols. 


\subsection{Catalyst Screening Tests}

A total of seven tests were conducted to screen additional promoters using the baseline $\mathrm{RhMn} / \mathrm{SiO}{ }_{2}$ catalyst composition of 5.56\% Rh and 1.69\% $\mathrm{Mn}$ (Rh:Mn atomic ratio of 1:0.57) on Davisil $645 \mathrm{SiO}_{2}$. The promoters were added at concentrations corresponding to a Rh:M atomic ratio of 1.0:0.1, where $\mathrm{M}$ represents Mg, vanadium (V), lanthanum (La), Ce, B, or tungsten (W), which was the atomic ratio used to screen other promoters, except for $\mathrm{Li}$, in earlier tests. A Rh:M atomic ratio of 1.0:0.30 was used for $\mathrm{Na}$, so it could be compared to the ratio used to evaluate $\mathrm{Li}$. $\mathrm{RhMn} / \mathrm{SiO}_{2}$ and $\mathrm{Rh} / \mathrm{SiO}_{2}$ catalysts also were prepared for comparison to catalysts with promoters added. All catalysts were prepared using a single impregnation to add the $\mathrm{Rh}, \mathrm{Mn}$, and additional promoter $\mathrm{M}$ to the catalyst support. This differs from the procedure previously reported for catalyst promoter screening (Gerber et al. 2008).

Two bases were used to compare the performance of the catalysts: 1) at the conditions under which the maximum STYs were achieved and 2) at a common set of operating conditions $\left(300^{\circ} \mathrm{C}\right.$ and $11,000 \mathrm{~L} / \mathrm{L}_{\mathrm{cat}} / \mathrm{hr}$ ). The results for conditions under which the maximum STYs were achieved acknowledges the possibility that the different test conditions may be needed to maximize STYs because of differences in the interplay among temperature, space velocity, carbon conversion, and selectivity to $\mathrm{C}_{2}+$ oxygenates. Comparison of catalyst performance under a common set of conditions provides a common basis for those comparing carbon conversion and selectivity to products. The chosen set of conditions was selected because better catalysts also performed very well under these conditions, and in most cases, the catalysts had not undergone significant deactivation because of operating at higher temperatures. It also is the same set of conditions for comparison used in the previous report (Gerber et al. 2008).

Table 4.1 lists the test conditions at which the maximum $\mathrm{C}_{2}+$ oxygenates STYs were achieved for the various promoters along with the corresponding carbon and CO conversions and liquid-product STYs. The STYs under these conditions are compared in Figure 4.17. In all cases, the maximum STY was obtained at a space velocity of $11,000 \mathrm{~L} / \mathrm{L}_{\text {cat }} / \mathrm{hr}$. The carbon selectivity to various products are listed and compared in Tables 4.2 and Figure 4.18, respectively. Tables 4.3 and 4.4 and Figures 4.19 and 4.20 list and compare similar performance parameters for catalysts tested at the same operating conditions $\left(300^{\circ} \mathrm{C}\right.$ and $\left.11,000 \mathrm{~L} / \mathrm{L}_{\text {cat }} / \mathrm{hr}\right)$.

It can be seen from Figure 4.17 that the $\mathrm{Mg}$ and $\mathrm{B}$ promoted catalysts performed nearly as well as the similarly prepared $\mathrm{RhMn} / \mathrm{SiO}_{2}$ catalyst in terms of the $\mathrm{C}_{2}+$ oxygenates STYs. The $\mathrm{W}$ - and La-promoted catalysts achieved STYs that were more than $50 \%$ of that achieved by the $\mathrm{RhMn} / \mathrm{SiO}_{2}$ catalyst, while the V-promoted catalyst had a STY that was just below $50 \%$ of that achieved by the RhMn/SiO2 catalyst. The Ce- and Na-promoted catalysts were not very active. As expected, the $\mathrm{Rh} / \mathrm{SiO}_{2}$ catalyst also was not very active even at $345^{\circ} \mathrm{C}$. When compared at a common temperature of $300^{\circ} \mathrm{C}$ (Figure 4.18), the ranking of the catalysts are nearly the same, with the exceptions that only the B-promoted catalyst had $\mathrm{C}_{2}+$ oxygenates STY that was comparable to the unpromoted catalysts with a STY of about $90 \%$ of that achieved by the unpromoted $\mathrm{MgMn} / \mathrm{SiO} 2$ catalyst. The Mg- and W-promoted catalysts had similar STYs that were about $75 \%$ of that achieved by the unpromoted catalyst. The La-promoted catalysts was only marginally active with a STY that was less than $40 \%$ of that achieved by the unpromoted catalysts and the V-promoted catalyst was nearly inactive with an STY that was less than $20 \%$ of that achieved by the unpromoted catalyst. While the $\mathrm{Rh} / \mathrm{SiO}_{2}$ catalyst is slightly more active than the Na-Promoted $\mathrm{RhMn} / \mathrm{SiO}_{2}$ catalyst, both were considered to be essentially inactive. Repeating the test conditions at 
$300^{\circ} \mathrm{C}$ for the B-, Mg-, La-, and W-promoted catalysts (not shown in the figure) showed that the catalysts did deactivate during tests at temperatures above $300^{\circ} \mathrm{C}$ as did the RhMn catalyst tested earlier.

Table 4.2 summarizes the carbon selectivity to the various oxygenated organics and hydrocarbon products for the catalysts under the conditions for achieving maximum $\mathrm{C}_{2}+$ oxygenates STYs, and Table 4.4 summarizes the carbon selectivity at the common operating conditions $\left(300^{\circ} \mathrm{C}\right.$ and $11,000 \mathrm{~L} / \mathrm{L}_{\text {cat }} / \mathrm{hr}$ GHSV), respectively. Figures 4.19 and 4.20 compare the selectivity of the catalysts for these respective test conditions. It can be seen that of the more active promoted catalysts (i.e., the $\mathrm{Mg}, \mathrm{B}, \mathrm{W}$, and $\mathrm{La}$ promoters) only the La-promoted catalysts had significantly greater converted carbon selectivity to $\mathrm{C}_{2}+$ oxygenates, while operating at their conditions for maximum $\mathrm{C}_{2}+$ oxygenates STYs. When operating at the common testing temperature of $300^{\circ} \mathrm{C}$, the $\mathrm{Mg}$ - and B-promoted catalysts also had higher selectivity. Both the Mg- and the La-promoted catalysts had significantly greater selectivity to $\mathrm{C}_{2}+$ alcohols at both the common temperature of $300^{\circ} \mathrm{C}$ and at their conditions for achieving maximum $\mathrm{C}_{2}+$ oxygenates STYs.

Overall, none of the promoted catalysts was more active than the unpromoted $\mathrm{RhMn} / \mathrm{SiO}_{2}$ catalyst. However, the B-, Mg-, and La-promoted catalysts did achieve comparable or better converted carbon selectivity to $\mathrm{C}_{2}+$ oxygenates at both the conditions where they achieved their maximum $\mathrm{C}_{2}+$ oxygenates STYs and at the common testing temperature of $300^{\circ} \mathrm{C}$, with the Mg- and La-promoted catalysts achieving significantly greater selectivity to alcohols. Considering these results, the remaking of catalysts with these three promoters added in a second impregnation would be warranted to see if this method of adding the promoters could improve performance of the catalysts. 
Table 4.1. Comparison of Carbon Conversions and STYs of Promoted $\mathrm{RhMn} / \mathrm{SiO}_{2}$ Catalysts at Conditions Maximizing $\mathrm{C}_{2}+$ Oxygenates STYs

\begin{tabular}{|c|c|c|c|c|c|c|c|c|c|c|c|}
\hline \multirow[b]{2}{*}{ Catalyst } & \multirow[b]{2}{*}{$\begin{array}{c}\text { Space } \\
\text { Velocity, } \\
\mathrm{L} / \mathrm{L}_{\text {cat }} / \mathrm{hr}\end{array}$} & \multirow[b]{2}{*}{$\begin{array}{c}\text { Temp., } \\
{ }^{\circ} \mathrm{C}\end{array}$} & \multirow[b]{2}{*}{$\begin{array}{c}\text { Carbon } \\
\text { Conv., } \\
\%\end{array}$} & \multirow[b]{2}{*}{$\begin{array}{c}\text { CO } \\
\text { Conv., } \\
\%\end{array}$} & \multirow[b]{2}{*}{$\begin{array}{l}\text { CO Conv. } \\
\text { to } \mathrm{CO}_{2}, \%\end{array}$} & \multicolumn{6}{|c|}{ STY (g/mL $\left.L_{\text {cat }} / \mathrm{hr}\right)$} \\
\hline & & & & & & $\mathrm{MEOH}$ & $\begin{array}{c}\mathrm{C}_{2}+ \\
\text { Alcohols } \\
\end{array}$ & $\begin{array}{c}\text { Other } \mathrm{C}_{2}+ \\
\text { Oxygenates }\end{array}$ & $\begin{array}{c}\text { HC } \\
\text { Liquids }\end{array}$ & $\begin{array}{c}\text { Total } \\
\text { Liquids }\end{array}$ & $\begin{array}{c}\text { Carbon } \\
\text { Balance } \\
\left(\mathrm{C}_{\text {out }} / \mathrm{C}_{\text {in }}\right), \%\end{array}$ \\
\hline RhMn & 11000 & 301 & 32.24 & 36.36 & -0.17 & 0.01 & 0.10 & 0.31 & 0.03 & 0.44 & 98 \\
\hline RhMnMg & 11000 & 323 & 24.64 & 27.35 & -0.60 & 0.03 & 0.17 & 0.23 & 0.00 & 0.43 & 98 \\
\hline RhMnB & 11000 & 325 & 31.44 & 34.96 & -0.35 & 0.02 & 0.13 & 0.27 & 0.01 & 0.43 & 99 \\
\hline RhMnW & 11000 & 314 & 30.06 & 37.05 & 3.30 & 0.02 & 0.10 & 0.22 & 0.02 & 0.36 & 98 \\
\hline RhMnLa & 11000 & 325 & 14.21 & 15.16 & -0.87 & 0.04 & 0.16 & 0.09 & 0.00 & 0.28 & 98 \\
\hline RhMnV & 11000 & 343 & 11.22 & 12.03 & -0.70 & 0.02 & 0.13 & 0.07 & 0.00 & 0.22 & 99 \\
\hline RhMnCe & 11000 & 327 & 5.31 & 4.99 & -1.00 & 0.03 & 0.06 & 0.02 & 0.00 & 0.12 & 98 \\
\hline $\mathrm{RhMnNa}$ & 11000 & 345 & 4.32 & 5.61 & 0.78 & 0.04 & 0.04 & 0.04 & 0.00 & 0.11 & 98 \\
\hline $\mathrm{Rh}$ & 11000 & 345 & 8.25 & 9.14 & -0.12 & 0.02 & 0.04 & 0.02 & 0.00 & 0.08 & 99 \\
\hline
\end{tabular}




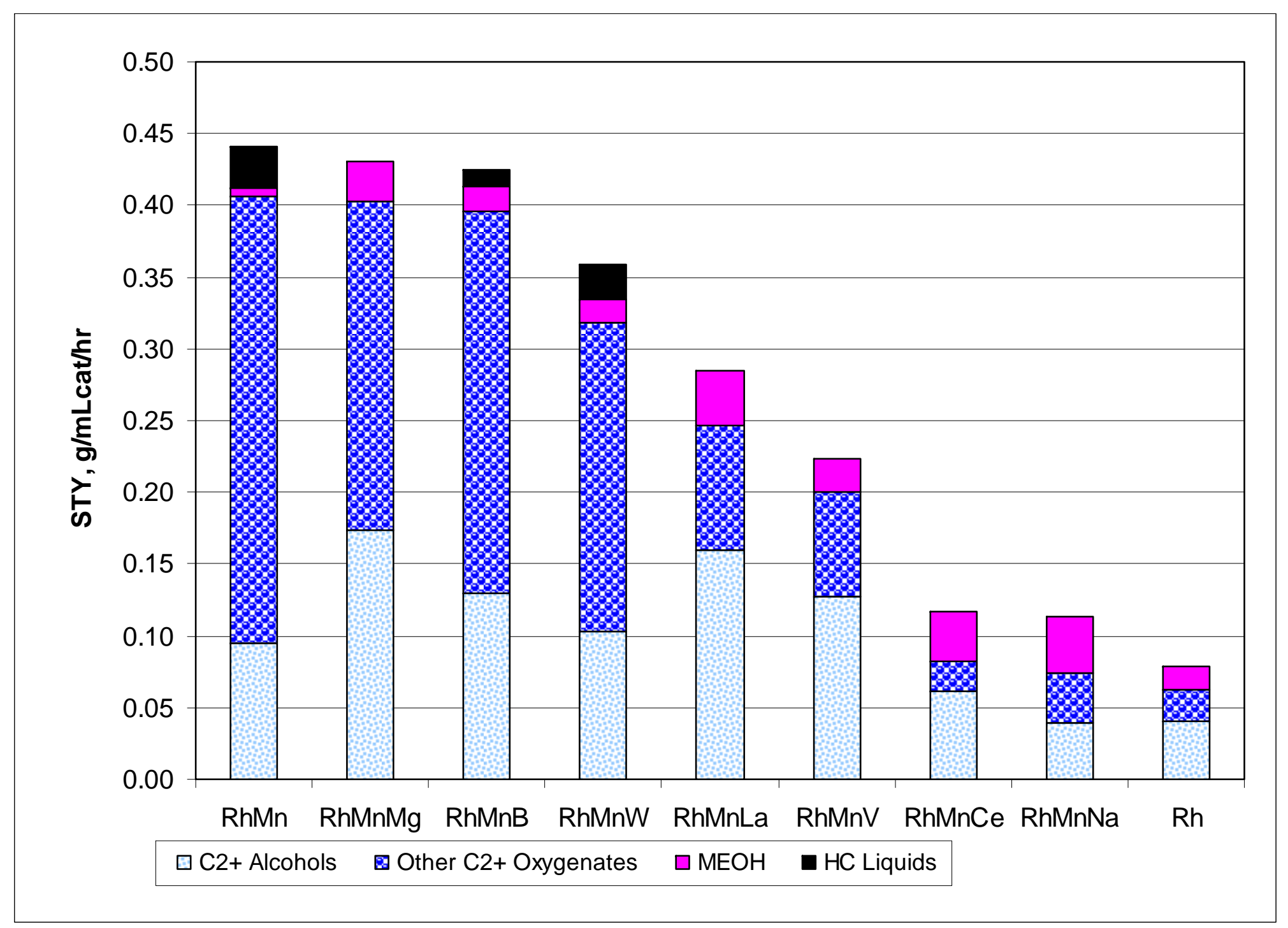

Figure 4.17. STYs of Promoted Catalysts at Conditions for Maximum STYs 
Table 4.2. Comparison of Carbon Selectivity to Products of Promoted $\mathrm{RhMn} / \mathrm{SiO}_{2}$ Catalysts at Conditions Maximizing $\mathrm{C}_{2}+$ Oxygenates STYs

\begin{tabular}{|c|c|c|c|c|c|c|c|c|c|c|}
\hline \multirow[b]{2}{*}{ Catalyst } & \multirow[b]{2}{*}{$\begin{array}{c}\text { Space } \\
\text { Velocity, } \\
\text { L/L/hr }\end{array}$} & \multirow[b]{2}{*}{$\begin{array}{c}\text { Temp., } \\
{ }^{\circ} \mathrm{C}\end{array}$} & \multirow[b]{2}{*}{$\begin{array}{c}\text { Carbon } \\
\text { Conv., } \\
\%\end{array}$} & \multicolumn{7}{|c|}{ Carbon Selectivity (C-Mol\%) } \\
\hline & & & & MEOH & $\begin{array}{c}\text { Other } \mathrm{C}_{1} \\
\text { Oxygenates }\end{array}$ & $\begin{array}{c}\mathrm{C}_{2}+ \\
\text { Alcohols }\end{array}$ & $\begin{array}{c}\text { Other } \mathrm{C}_{2}+ \\
\text { Oxygenates }\end{array}$ & Methane & $\begin{array}{c}\text { Higher HC } \\
\text { Gases }\end{array}$ & $\begin{array}{l}\text { Higher HC } \\
\text { Liquids } \\
\text { (est) }\end{array}$ \\
\hline RhMn & 11,000 & 301 & 32.24 & 0.29 & 0.00 & 7.04 & 22.20 & 50.41 & 16.71 & 3.36 \\
\hline RhMnMg & 11,000 & 323 & 24.64 & 1.98 & 0.00 & 17.17 & 13.38 & 55.20 & 12.26 & 0.00 \\
\hline RhMnB & 11,000 & 325 & 31.44 & 0.93 & 0.00 & 10.01 & 18.96 & 53.54 & 15.07 & 1.49 \\
\hline RhMnW & 11,000 & 314 & 30.06 & 0.88 & 0.00 & 8.44 & 16.59 & 45.67 & 25.30 & 3.12 \\
\hline RhMnLa & 11,000 & 325 & 14.21 & 4.55 & 0.00 & 26.56 & 9.12 & 48.96 & 10.81 & 0.00 \\
\hline RhMnV & 11,000 & 343 & 11.22 & 3.49 & 0.00 & 27.36 & 9.91 & 49.32 & 9.92 & 0.00 \\
\hline RhMnCe & 11,000 & 327 & 5.31 & 11.02 & 0.00 & 27.28 & 8.69 & 49.97 & 3.03 & 0.00 \\
\hline $\mathrm{RhMnNa}$ & 11,000 & 345 & 4.32 & 15.25 & 0.00 & 21.84 & 17.70 & 41.06 & 4.15 & 0.00 \\
\hline $\mathrm{Rh}$ & 11,000 & 345 & 8.25 & 3.17 & 0.00 & 11.53 & 5.97 & 65.14 & 14.19 & 0.00 \\
\hline
\end{tabular}




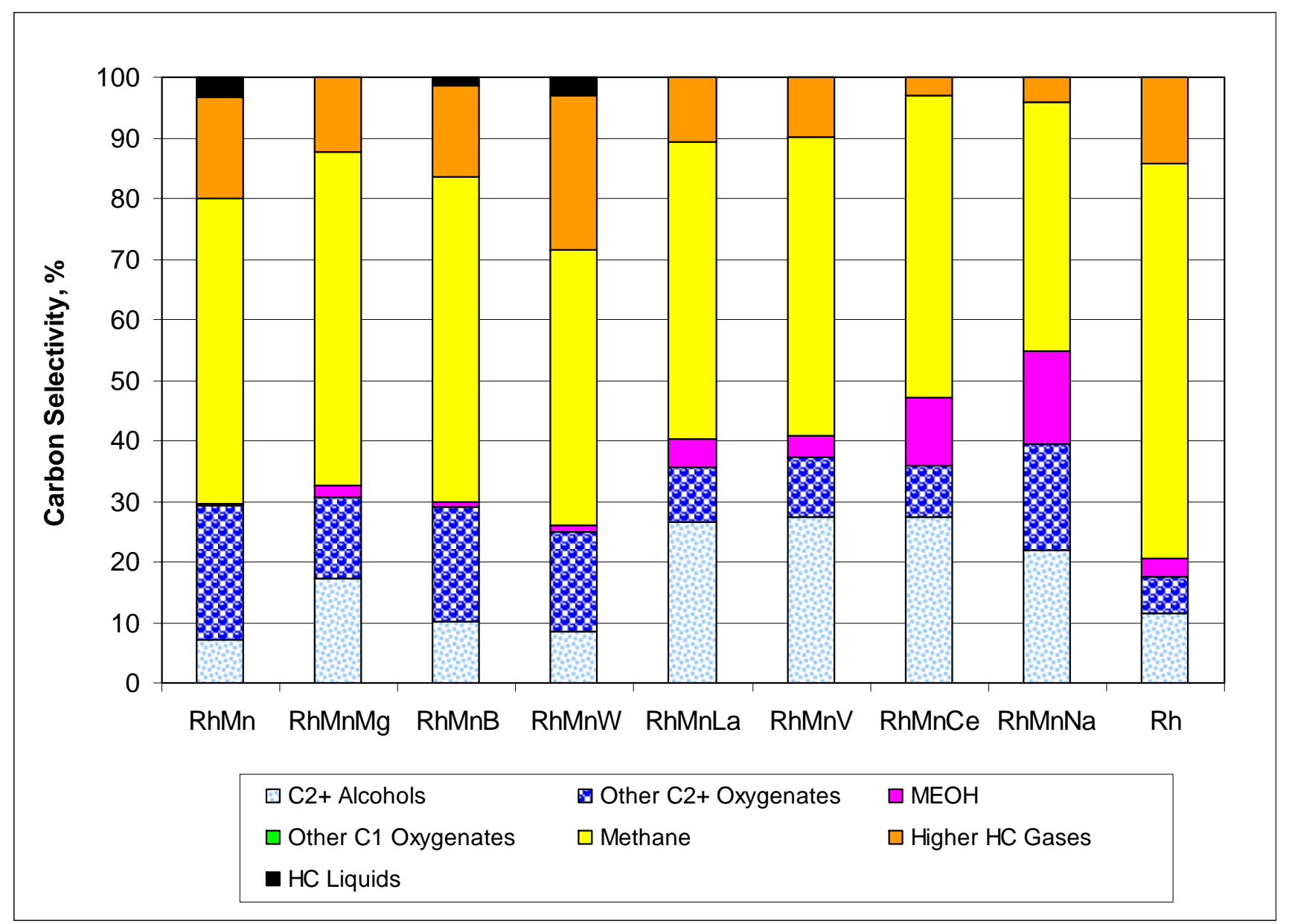

Figure 4.18. Carbon Selectivity of Promoted Catalysts at Conditions for Maximum STYs 
Table 4.3. Comparison of Carbon Conversions and STYs of Promoted $\mathrm{RhMn} / \mathrm{SiO}_{2}$ Catalysts at $300^{\circ} \mathrm{C}, 11,000 \mathrm{~L} / \mathrm{L}_{\mathrm{cat}} / \mathrm{hr}$

\begin{tabular}{|c|c|c|c|c|c|c|c|c|c|c|c|}
\hline \multirow[b]{2}{*}{ Catalyst } & \multirow[b]{2}{*}{$\begin{array}{c}\text { Space } \\
\text { Velocity, } \\
\text { L/L/hr } \\
\end{array}$} & \multirow[b]{2}{*}{$\begin{array}{c}\text { Temp., } \\
{ }^{\circ} \mathrm{C} \\
\end{array}$} & \multirow[b]{2}{*}{$\begin{array}{c}\text { Carbon } \\
\text { Conv., } \\
\% \\
\end{array}$} & \multirow[b]{2}{*}{$\begin{array}{c}\text { CO } \\
\text { Conv., } \\
\% \\
\end{array}$} & \multirow[b]{2}{*}{$\begin{array}{c}\mathrm{CO} \\
\text { Conv. to } \\
\mathrm{CO}_{2}, \% \\
\end{array}$} & \multicolumn{5}{|c|}{ STY (g/mLcat/hr) } & \multirow[b]{2}{*}{$\begin{array}{c}\text { Carbon } \\
\text { Balance } \\
\left(\mathrm{C}_{\text {out }} / \mathrm{C}_{\text {in }}\right), \\
\% \\
\end{array}$} \\
\hline & & & & & & $\mathrm{MEOH}$ & $\begin{array}{c}\mathrm{C}_{2}+ \\
\text { Alcohols } \\
\end{array}$ & $\begin{array}{c}\text { Other } \mathrm{C}_{2}+ \\
\text { Oxygenates }\end{array}$ & $\begin{array}{c}\text { HC } \\
\text { Liquids } \\
\end{array}$ & $\begin{array}{c}\text { Total } \\
\text { Liquids }\end{array}$ & \\
\hline RhMn & 11,000 & 301 & 32.24 & 36.36 & -0.17 & 0.01 & 0.10 & 0.31 & 0.03 & 0.44 & 99 \\
\hline RhMnB & 11,000 & 301 & 21.45 & 23.73 & -0.27 & 0.01 & 0.08 & 0.29 & 0.01 & 0.39 & 98 \\
\hline RhMnMg & 11,000 & 300 & 13.91 & 14.81 & -0.86 & 0.02 & 0.10 & 0.20 & 0.00 & 0.31 & 97 \\
\hline RhMnW & 11,000 & 299 & 25.26 & 31.32 & 2.98 & 0.01 & 0.09 & 0.20 & 0.02 & 0.33 & 98 \\
\hline RhMnLa & 11,000 & 301 & 7.96 & 8.38 & -0.55 & 0.02 & 0.07 & 0.09 & 0.00 & 0.18 & 98 \\
\hline RhMnV & 11,000 & 300 & 2.89 & 2.47 & -0.78 & 0.01 & 0.03 & 0.04 & 0.00 & 0.08 & 98 \\
\hline RhMnCe & 11,000 & 301 & 2.17 & 1.92 & -0.52 & 0.02 & 0.02 & 0.02 & 0.00 & 0.05 & 99 \\
\hline $\mathrm{Rh}$ & 11,000 & 301 & 1.76 & 1.34 & -0.63 & 0.00 & 0.01 & 0.01 & 0.00 & 0.03 & 98 \\
\hline RhMnNa & 11,000 & 301 & 0.33 & 0.07 & -0.30 & 0.01 & 0.00 & 0.01 & 0.00 & 0.02 & 98 \\
\hline
\end{tabular}




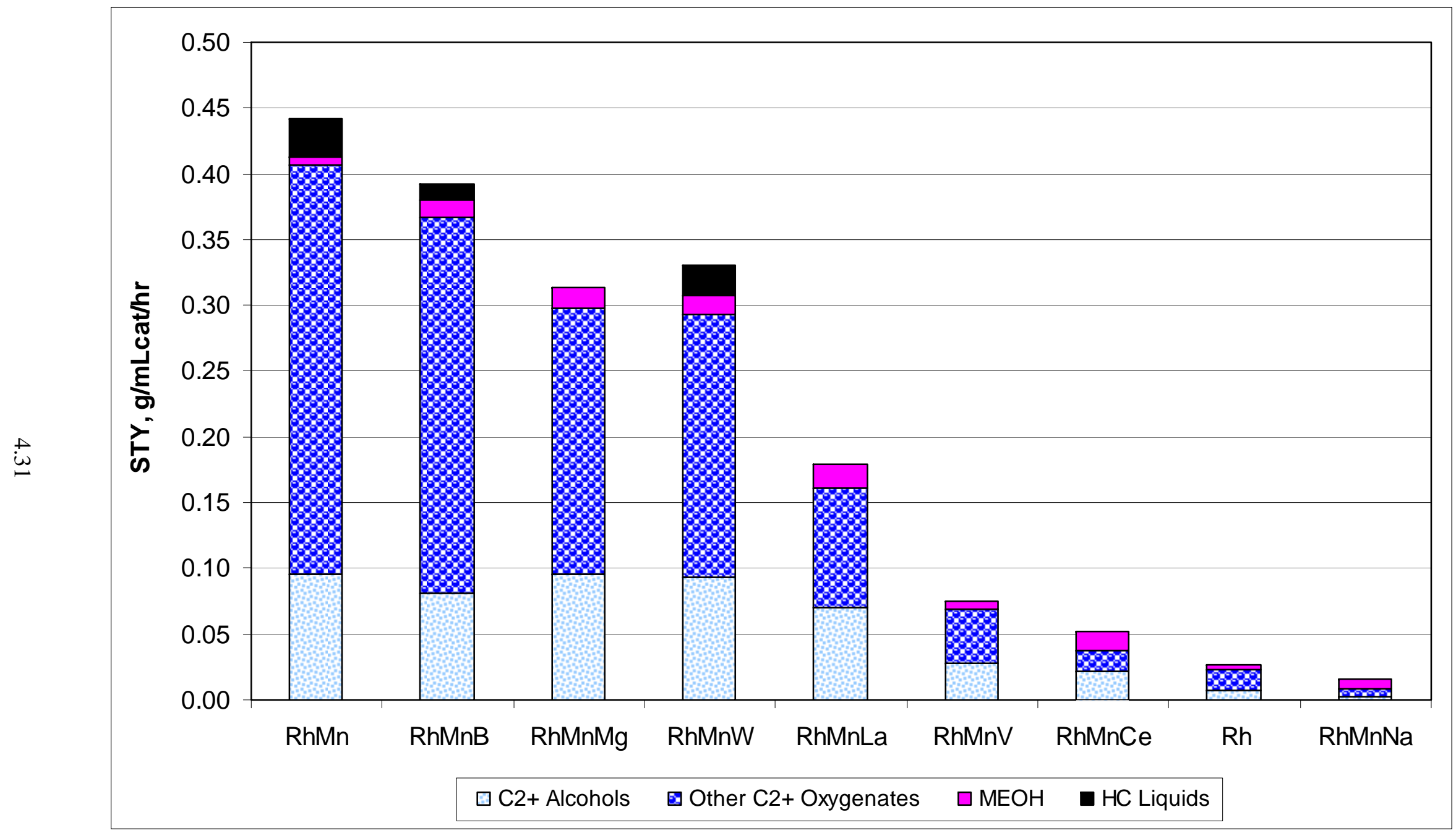

Figure 4.19. STYs of Promoted Catalysts at $300^{\circ} \mathrm{C}$ and $11,000 \mathrm{~L} / \mathrm{Lcat} / \mathrm{hr}$ 
Table 4.4. Comparison of Carbon Selectivity to Products of Promoted $\mathrm{RhMn} / \mathrm{SiO}_{2}$ Catalysts at $300^{\circ} \mathrm{C}$ and $11000 \mathrm{~L} / \mathrm{L}_{\mathrm{cat}} / \mathrm{hr}$

\begin{tabular}{|c|c|c|c|c|c|c|c|c|c|c|}
\hline \multirow[b]{2}{*}{ Catalyst } & \multirow[b]{2}{*}{$\begin{array}{c}\text { Space } \\
\text { Velocity, } \\
\text { L/L } \mathrm{L}_{\text {cat }} / \mathrm{hr}\end{array}$} & \multirow[b]{2}{*}{$\begin{array}{l}\text { Temp., } \\
{ }^{\circ} \mathrm{C}\end{array}$} & \multirow[b]{2}{*}{$\begin{array}{c}\text { Carbon } \\
\text { Conv., } \\
\%\end{array}$} & \multicolumn{7}{|c|}{ Carbon Selectivity (C-Mol\%) } \\
\hline & & & & $\mathrm{MEOH}$ & $\begin{array}{c}\text { Other } \mathrm{C}_{1} \\
\text { Oxygenates }\end{array}$ & $\begin{array}{c}\mathrm{C}_{2}{ }^{+} \\
\text {Alcohols }\end{array}$ & $\begin{array}{l}\text { Other } \mathrm{C}_{2}+ \\
\text { Oxygenates }\end{array}$ & Methane & $\begin{array}{c}\text { Higher HC } \\
\text { Gases }\end{array}$ & $\begin{array}{l}\text { Higher HC } \\
\text { Liquids (est) }\end{array}$ \\
\hline RhMn & 11,000 & 301 & 32.24 & 0.29 & 0.00 & 7.04 & 22.20 & 50.41 & 16.71 & 3.36 \\
\hline RhMnB & 11,000 & 301 & 21.45 & 1.03 & 0.00 & 9.14 & 29.21 & 41.52 & 16.93 & 2.17 \\
\hline RhMnMg & 11,000 & 300 & 13.91 & 1.98 & 0.00 & 16.68 & 21.50 & 46.22 & 13.61 & 0.00 \\
\hline RhMnW & 11,000 & 299 & 25.26 & 0.95 & 0.00 & 8.94 & 17.61 & 41.46 & 27.73 & 3.32 \\
\hline RhMnLa & 11,000 & 301 & 7.96 & 3.93 & 0.00 & 21.53 & 17.46 & 42.16 & 14.93 & 0.00 \\
\hline RhMnV & 11,000 & 300 & 2.89 & 3.96 & 0.00 & 23.02 & 22.29 & 46.98 & 3.75 & 0.00 \\
\hline RhMnCe & 11,000 & 301 & 2.17 & 11.95 & 0.00 & 24.34 & 14.82 & 45.21 & 3.68 & 0.00 \\
\hline $\mathrm{Rh}$ & 11,000 & 301 & 1.76 & 3.68 & 0.00 & 10.53 & 17.61 & 64.23 & 3.95 & 0.00 \\
\hline RhMnNa & 11,000 & 301 & 0.33 & 34.71 & 0.00 & 21.13 & 35.40 & 0.00 & 8.76 & 0.00 \\
\hline
\end{tabular}




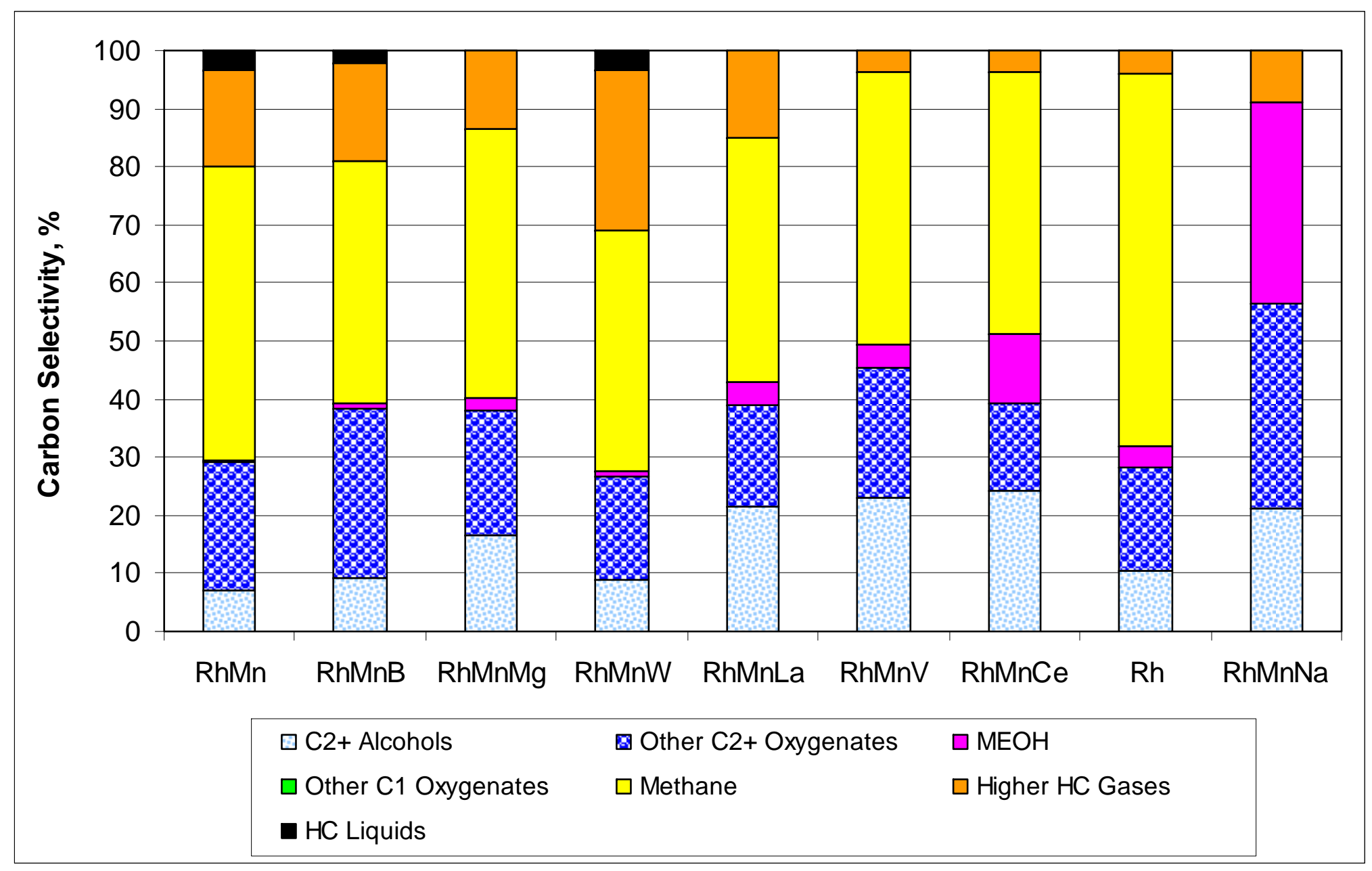

Figure 4.20. Carbon Selectivity of Promoted Catalysts at $300^{\circ} \mathrm{C}$ and $11,000 \mathrm{~L} / \mathrm{L}_{\text {cat }} / \mathrm{hr}$ 



\subsection{Conclusions and Recommendations}

Parametric tests were conducted to optimize the amounts of $\mathrm{Rh}, \mathrm{Mn}, \mathrm{Li}$, and $\mathrm{Ir}$ on a $\mathrm{SiO}_{2}$ support with respect to the $\mathrm{C}_{2}+$ oxygenates carbon conversion, STY, converted carbon selectivity to $\mathrm{C}_{2}+$ oxygenates, and selectivity of the $\mathrm{C}_{2}+$ oxygenates to alcohols. Based on the results of the parametric tests, several conclusions were reached.

It appears that the optimum Rh concentration is about $5.56 \mathrm{wt} \%$ (1X the baseline concentration) when used in combination with $\mathrm{Mn}$ in which the $\mathrm{Mn}$ :Rh atomic ratio was 0.57 (1.69\% $\mathrm{Mn})$. It may be possible to get further improvements at slightly higher Rh concentrations, but in a test at $1.5 \mathrm{X}$ the baseline concentration, the high hydrocarbon concentrations in the product gas accompanied by heat management problems at temperatures as low as $271^{\circ} \mathrm{C}$ made evaluation very difficult.

It also appears that the optimum manganese concentration is about $1.13 \mathrm{wt} \%$ (2/3X the baseline concentration) when $\mathrm{Rh}$ is at the baseline concentration of $5.56 \mathrm{wt} \%$. This concentration provides the highest $\mathrm{C}_{2}+$ oxygenates STY, while not significantly compromising the converted carbon selectivity to $\mathrm{C}_{2}+$ oxygenates. The selectivity of the $\mathrm{C}_{2}+$ oxygenates to alcohols does not appear to be affected significantly by Mn concentrations above $0.55 \%$.

The optimum Ir concentration is between $0.34 \%$ and $1.03 \%$ (1/3X and $1 \mathrm{X}$ the baseline concentration), when the RhMn concentrations are at their baseline concentrations (5.56 wt\% Rh and $1.69 \mathrm{wt} \% \mathrm{Mn}$ ). This concentration range provides high $\mathrm{C}_{2}+$ oxygenates STYs accompanied by favorable converted carbon selectivity on the order of $45 \%$ to $52 \%$ to $\mathrm{C}_{2}+$ oxygenates. The selectivity of the $\mathrm{C}_{2}+$ oxygenates to alcohols is relatively low (about $15 \%$ to $25 \%$ ) over this concentration range, but none of the conditions achieved a very good selectivity, with the selectivity ranging from about $15 \%$ to $35 \%$ over the range of temperatures and Ir concentrations evaluated.

The addition of Li to the RhMn catalyst improves the converted carbon selectivity to both the $\mathrm{C}_{2}+$ oxygenates and ethanol but at the expense of a significant decrease in the STYs of both. Consequently, it is not possible to specify an optimum Li concentration. Instead, it becomes an issue as to which parameter, STY or selectivity, is more important within the constraint that too high of a catalyst temperature will cause the catalyst to deactivate.

The presence of $\mathrm{Ir}$ in a catalyst also containing Li does not improve the $\mathrm{C}_{2}+$ oxygenates or ethanol STYs. However, it does appear to modestly improve the converted carbon selectivity to both $\mathrm{C}_{2}+$ oxygenates and ethanol. There also is an indication that alteration of the catalyst containing Ir at higher temperatures (up to $345^{\circ} \mathrm{C}$ ) may improve the catalyst activity and the converted carbon selectivity of the oxygenates to $\mathrm{C}_{2}+$ alcohols, although at the expense of converted carbon selectivity to $\mathrm{C}_{2}+$ oxygenates.

Seven tests were conducted to screen $\mathrm{Mg}, \mathrm{V}, \mathrm{La}, \mathrm{Ce}, \mathrm{B}, \mathrm{W}$, and $\mathrm{Na}$ as possible additives using the baseline $\mathrm{RhMn} / \mathrm{SiO}_{2}$ catalyst composition of $5.56 \mathrm{wt} \% \mathrm{Rh}$ and $1.69 \mathrm{wt} \% \mathrm{Mn}$ on Davisil $645 \mathrm{SiO}_{2}$. Overall, none of the modified catalysts was more active than the $\mathrm{RhMn} / \mathrm{SiO}_{2}$ catalyst. However, the B-, Mg-, and La-promoted catalysts did achieve comparable or better converted carbon selectivity to $\mathrm{C}_{2}+$

oxygenates at both the conditions where they achieved their maximum $\mathrm{C}_{2}+$ oxygenates STYs and at the common testing temperature of $300^{\circ} \mathrm{C}$, with the $\mathrm{Mg}$ - and La-promoted catalysts achieving significantly greater selectivity to alcohols. Based on these results, remaking these three catalysts using two 
impregnations (as was done in the earlier tests) would be warranted to see if this method of adding the promoters could further improve the performance of these catalysts. 


\subsection{References}

Gerber MA, JF White, and DJ Stevens. 2007. Mixed Alcohol Synthesis Catalyst Screening. PNNL-16763, Pacific Northwest National Laboratory, Richland, Washington.

Gerber MA, JF White, MJ Gray and DJ Stevens. 2008. Evaluation of Promoters for Rhodium-Based Catalysts for Mixed Alcohol Synthesis. PNNL-178573, Pacific Northwest National Laboratory, Richland, Washington.

Phillips S, A Aden, J Jechura, D Dayton, and T Eggeman. 2007. Thermochemical Ethanol via Indirect Gasification and Mixed Alcohol Synthesis of Lignocellulosic Biomass. NREL-TP-510-41168, National Renewable Energy Laboratory, Golden, Colorado.

Quarderer GJ. 1986. "Mixed Alcohols from Synthesis Gas.” In Proceedings from the $78^{\text {th }}$ Spring National AIChE Meeting, April 1986, New Orleans, Louisiana.

Quarderer GJ and GA Cochran. 1986. Process for Producing Alcohols from Synthesis Gas. U.S. Patent No. 4,749,724.

Stiles AB, F Chen, JB Harrison, X Hu, DA Storm, and HX Yang. 1991. "Catalytic Conversion of Synthesis Gas to Methanol and Other Oxygenated Products.” Industrial and Engineering Chemistry Research 30:811-821. 

Appendix A

\section{Catalyst Testing Data}





\section{Appendix A}

\section{Catalyst Testing Data}

Table A.1. Summary Catalyst Optimization Test Results

\begin{tabular}{|c|c|c|c|c|c|c|c|c|c|c|c|c|c|c|c|c|c|c|c|}
\hline \multirow[b]{2}{*}{ Parameter } & \multirow[b]{2}{*}{$\begin{array}{c}\text { Catalyst } \\
\text { Concentrations, } \\
\text { wt\% } \\
\mathrm{Rh} / \mathrm{Mn} / \mathrm{Ir} / \mathrm{Li}\end{array}$} & \multirow[b]{2}{*}{\begin{tabular}{|c|} 
Space \\
Velocity \\
L/L/hr
\end{tabular}} & \multirow[b]{2}{*}{$\begin{array}{l}\text { Temp. } \\
{ }^{\circ} \mathrm{C}\end{array}$} & \multirow[b]{2}{*}{\begin{tabular}{|c|} 
Carbon \\
Conv. \\
$\%$
\end{tabular}} & \multirow[b]{2}{*}{$\begin{array}{c}\text { CO } \\
\text { Conv. } \\
\%\end{array}$} & \multirow[b]{2}{*}{$\begin{array}{c}\text { CO } \\
\text { Conv. to } \\
\text { CO2, \% }\end{array}$} & \multicolumn{6}{|c|}{ Carbon Selectivity (C-Mol\%) } & \multicolumn{6}{|c|}{ STY $\left(\mathrm{g} / \mathrm{mL}_{\mathrm{cat}} / \mathrm{hr}\right)$} & \multirow[b]{2}{*}{$\begin{array}{c}\text { Carbon } \\
\text { Balance } \\
\left(\mathrm{C}_{\text {out }} / \mathrm{C}_{\text {in }}\right) \\
\% \\
\%\end{array}$} \\
\hline & & & & & & & $\mathrm{MEOH}$ & \begin{tabular}{|c|} 
Other $\mathrm{C}_{1}$ \\
Oxygenates \\
\end{tabular} & $\begin{array}{l}\mathrm{C}_{2}+ \\
\text { Alc. } \\
\end{array}$ & $\begin{array}{c}\text { Other } \mathrm{C}_{2}+ \\
\text { Oxygenates }\end{array}$ & Methane & $\begin{array}{c}\text { Total } \\
\text { Higher } \\
\text { HCs } \\
\text { (est) } \\
\end{array}$ & $\begin{array}{c}\mathrm{C}_{2}+ \\
\text { Alcohols } \\
\end{array}$ & $\begin{array}{c}\text { Other } \mathrm{C}_{2}+ \\
\text { Oxygenates }\end{array}$ & \begin{tabular}{|c|} 
Total $\mathrm{C}_{2}+$ \\
Oxyggenates
\end{tabular} & $\begin{array}{c}\text { HC } \\
\text { Liquids }\end{array}$ & MEOH & $\begin{array}{c}\text { Total } \\
\text { Liq. }\end{array}$ & \\
\hline \multirow{8}{*}{$\begin{array}{l}\text { Total RhMn } \\
\text { metals } \\
\text { concentration }\end{array}$} & $1.85 / 0.56 / 0 / 0$ & 7500 & 275 & 1.17 & 1.06 & -0.26 & 3.92 & \begin{tabular}{|l|}
0.02 \\
\end{tabular} & 17.41 & 23.79 & 53.96 & 0.90 & 0.006 & 0.009 & \begin{tabular}{|l|}
0.015 \\
\end{tabular} & 0.000 & 0.002 & $\mid 0.016$ & 97.54 \\
\hline & $2.78 / 0.84 / 0 / 0$ & 7500 & 275 & 2.08 & 2.10 & -0.24 & 1.55 & 0.00 & 8.54 & 35.91 & 43.93 & 10.07 & 0.005 & 0.024 & 0.029 & 0.000 & 0.001 & 0.030 & 96.61 \\
\hline & $3.71 / 1.13 / 0 / 0$ & 7500 & 276 & 4.20 & \begin{tabular}{|l|}
4.51 \\
\end{tabular} & -0.21 & 0.86 & 0.00 & 10.65 & 23.74 & 56.54 & 8.21 & 0.013 & 0.031 & 0.043 & 0.001 & 0.001 & 0.046 & 95.77 \\
\hline & $5.56 / 1.69 / 0 / 0$ & 7500 & 275 & 29.99 & 33.47 & -0.51 & 0.65 & 0.00 & \begin{tabular}{|l|}
6.27 \\
\end{tabular} & 35.75 & 30.34 & 27.00 & 0.052 & 0.316 & 0.368 & 0.064 & 0.008 & 0.440 & 99.64 \\
\hline & $1.85 / 0.56 / 0 / 0$ & 11000 & 300 & 3.30 & \begin{tabular}{|l|}
4.52 \\
\end{tabular} & 0.80 & 3.41 & 0.00 & \begin{tabular}{|l|}
19.39 \\
\end{tabular} & 21.69 & 50.82 & 4.69 & 0.026 & 0.033 & 0.059 & 0.000 & \begin{tabular}{|l|}
0.007 \\
\end{tabular} & 0.066 & 103.67 \\
\hline & $2.78 / 0.84 / 0 / 0$ & 11000 & 301 & 4.08 & 4.30 & $\begin{array}{l}-0.33 \\
\end{array}$ & 1.26 & 0.00 & 11.87 & 37.63 & 47.95 & 1.29 & 0.020 & 0.073 & 0.094 & 0.000 & 0.003 & 0.097 & 97.77 \\
\hline & $3.71 / 1.13 / 0 / 0$ & 11000 & 302 & 12.69 & 13.87 & -0.38 & 0.91 & 0.00 & 12.55 & 30.99 & 41.41 & 14.14 & 0.067 & 0.184 & 0.252 & 0.000 & 0.007 & 0.259 & 93.62 \\
\hline & $5.56 / 1.69 / 0 / 0$ & 11000 & 301 & 32.24 & 36.36 & $\begin{array}{l}-0.17 \\
\end{array}$ & 0.29 & 0.00 & 7.04 & 22.20 & 50.41 & 20.07 & 0.095 & 0.311 & 0.407 & 0.029 & 0.006 & 0.441 & 97.69 \\
\hline \multirow{12}{*}{$\begin{array}{l}\text { Manganese } \\
\text { Concentration }\end{array}$} & $5.56 / 0 / 0 / 0$ & 11000 & 301 & 1.76 & 1.34 & -0.63 & 3.68 & 0.00 & 10.53 & 17.61 & 64.23 & 3.95 & 0.008 & 0.015 & 0.023 & 0.000 & 0.004 & 0.027 & 98.09 \\
\hline & $5.56 / 0.28 / 0 / 0$ & 11000 & 300 & 12.66 & 13.93 & -0.23 & 1.45 & 0.00 & 15.52 & 33.54 & 36.94 & 12.55 & 0.085 & 0.202 & 0.287 & 0.000 & 0.011 & 0.298 & 99.31 \\
\hline & $5.56 / 0.56 / 0 / 0$ & 11000 & 298 & 28.71 & 32.56 & 0.10 & 0.71 & 0.01 & 8.22 & 26.62 & 47.62 & 16.83 & 0.093 & 0.319 & 0.413 & 0.000 & 0.011 & 0.424 & 98.03 \\
\hline & $5.56 / 1.13 / 0 / 0$ & 11000 & 297 & 38.32 & 43.35 & -0.02 & 0.68 & 0.00 & 8.31 & 23.63 & 48.90 & 18.48 & 0.129 & 0.381 & 0.511 & 0.022 & 0.015 & 0.547 & 98.49 \\
\hline & $5.56 / 1.69 / 0 / 0$ & 11000 & 301 & 32.24 & 36.36 & -0.17 & 0.29 & 0.00 & 7.04 & 22.20 & 50.41 & 20.07 & 0.095 & 0.311 & 0.407 & 0.029 & 0.006 & 0.441 & 97.69 \\
\hline & $5.56 / 2.25 / 0 / 0$ & 11000 & 298 & 40.72 & 46.58 & 0.44 & 0.49 & 0.00 & 7.47 & 19.31 & 55.02 & 17.71 & 0.122 & 0.328 & 0.451 & 0.007 & 0.011 & 0.469 & 99.80 \\
\hline & $5.56 / 0 / 0 / 0$ & 11000 & 316 & 3.53 & 3.66 & -0.30 & 2.85 & 0.00 & 9.46 & 10.20 & 54.54 & 22.94 & 0.014 & 0.017 & 0.032 & 0.000 & 0.006 & 0.038 & 98.67 \\
\hline & $5.56 / 0.28 / 0 / 0$ & 11000 & 315 & 17.56 & 19.29 & -0.34 & 1.42 & 0.00 & 18.92 & 21.58 & 45.50 & 12.58 & 0.141 & 0.171 & 0.312 & 0.001 & 0.015 & 0.328 & 97.83 \\
\hline & $5.56 / 0.56 / 0 / 0$ & 11000 & 314 & 36.28 & 42.21 & 1.07 & 0.50 & 0.00 & 9.34 & 17.32 & 57.83 & 15.00 & 0.135 & 0.258 & 0.393 & 0.000 & 0.010 & 0.403 & 97.39 \\
\hline & $5.56 / 1.13 / 0 / 0$ & 11000 & 315 & 42.91 & 50.07 & 1.61 & 0.57 & 0.00 & 8.64 & 14.55 & 61.74 & 14.48 & 0.148 & 0.259 & 0.408 & 0.000 & 0.014 & 0.421 & 100.68 \\
\hline & $5.56 / 1.69 / 0 / 0$ & 11000 & 315 & 33.73 & 38.84 & 0.70 & 0.44 & 0.00 & 8.16 & 16.71 & 56.34 & 18.34 & 0.117 & 0.249 & 0.366 & 0.000 & 0.009 & 0.375 & 95.71 \\
\hline & $5.56 / 2.25 / 0 / 0$ & 11000 & 316 & 40.94 & \begin{tabular}{|l|}
47.35 \\
\end{tabular} & 1.07 & 0.51 & 0.00 & 7.89 & 11.89 & 66.39 & 13.32 & 0.128 & 0.199 & 0.327 & 0.000 & 0.012 & 0.339 & 99.66 \\
\hline \multirow{10}{*}{$\begin{array}{c}\text { Iridium } \\
\text { Concentration }\end{array}$} & $5.56 / 1.69 / 0 / 0$ & 7500 & 275 & 29.99 & 33.47 & -0.51 & 0.65 & 0.00 & 6.27 & 35.75 & 30.34 & 27.00 & 0.052 & 0.316 & 0.368 & 0.064 & 0.008 & 0.440 & 99.64 \\
\hline & $5.56 / 1.69 / 0.0172 / 0$ & 7500 & 276 & 11.19 & 12.28 & -0.26 & 1.01 & 0.00 & 10.15 & 32.75 & 33.92 & 22.17 & 0.031 & 0.109 & 0.140 & 0.000 & 0.004 & 0.145 & 95.57 \\
\hline & $5.56 / 1.69 / 0.343 / 0$ & 7500 & 276 & 21.99 & 24.67 & -0.01 & 1.31 & 0.00 & 7.80 & 44.15 & 29.10 & 17.64 & 0.046 & 0.279 & 0.325 & 0.000 & 0.011 & 0.336 & 96.19 \\
\hline & $5.56 / 1.69 / 1.03 / 0$ & 7500 & 275 & 24.03 & 27.18 & 0.38 & 0.90 & 0.00 & 6.90 & 42.78 & 27.24 & 22.18 & 0.046 & 0.309 & 0.355 & 0.000 & 0.009 & 0.364 & 98.71 \\
\hline & $5.56 / 1.69 / 1.37 / 0$ & 7500 & 275 & 39.35 & 43.45 & -0.59 & 0.13 & 0.01 & 3.96 & 21.63 & 29.83 & 44.45 & 0.039 & 0.235 & 0.274 & 0.069 & 0.002 & 0.345 & 95.55 \\
\hline & $5.56 / 1.69 / 1.72 / 0$ & 7500 & 276 & 49.02 & 54.20 & -0.67 & 0.43 & 0.01 & \begin{tabular}{|l|}
6.61 \\
\end{tabular} & 21.81 & 31.00 & 40.15 & 0.085 & 0.301 & 0.386 & 0.146 & 0.008 & 0.541 & 96.45 \\
\hline & $5.56 / 1.69 / 0 / 0$ & 11000 & 301 & 32.24 & 36.36 & -0.17 & 0.29 & 0.00 & \begin{tabular}{|l|}
7.04 \\
\end{tabular} & 22.20 & 50.41 & 20.07 & 0.10 & 0.31 & 0.41 & 0.03 & \begin{tabular}{|l|}
0.01 \\
\end{tabular} & 0.44 & 97.69 \\
\hline & $5.56 / 1.69 / 0.0172 / 0$ & 11000 & 300 & 22.28 & 24.75 & -0.26 & 1.25 & 0.00 & 13.66 & 30.19 & 34.16 & 20.75 & 0.13 & 0.30 & 0.43 & 0.00 & 0.02 & 0.45 & 100.81 \\
\hline & $5.56 / 1.69 / 0.343 / 0$ & 11000 & 299 & 30.24 & 34.10 & 0.13 & 0.94 & 0.00 & 10.64 & 35.60 & 36.86 & 15.96 & 0.13 & 0.47 & 0.60 & 0.00 & 0.02 & 0.61 & 98.29 \\
\hline & $5.56 / 1.69 / 1.03 / 0$ & 11000 & 299 & 32.75 & 36.89 & 0.22 & 0.81 & 0.00 & \begin{tabular}{|l|l|}
9.55 \\
\end{tabular} & 39.91 & 31.59 & 18.14 & 0.13 & 0.57 & 0.70 & 0.00 & 0.02 & \begin{tabular}{|l|} 
\\
\end{tabular} & 100.56 \\
\hline
\end{tabular}


Table A.1. (cont'd)

\begin{tabular}{|c|c|c|c|c|c|c|c|c|c|c|c|c|c|c|c|c|c|c|c|}
\hline \multirow{4}{*}{ Parameter } & \multirow[b]{2}{*}{$\begin{array}{c}\text { Catalyst } \\
\text { Concentrations, } \\
\text { wt\% } \\
\mathrm{Rh} / \mathrm{Mn} / \mathrm{Ir} / \mathrm{Li} \\
\end{array}$} & \multirow[b]{2}{*}{\begin{tabular}{|c} 
Space \\
Velocity \\
L/L/hr \\
\end{tabular}} & \multirow[b]{2}{*}{$\begin{array}{c}\text { Temp. } \\
{ }^{\circ} \mathrm{C}\end{array}$} & \multirow[b]{2}{*}{$\begin{array}{c}\text { Carbon } \\
\text { Conv. } \\
\%\end{array}$} & \multirow[b]{2}{*}{$\begin{array}{c}\text { CO } \\
\text { Conv. } \\
\%\end{array}$} & \multirow[b]{2}{*}{$\begin{array}{c}\mathrm{CO} \\
\text { Conv. to } \\
\mathrm{CO}_{2}, \% \\
\end{array}$} & \multicolumn{6}{|c|}{ Carbon Selectivity (C-Mol\%) } & \multicolumn{6}{|c|}{ STY $\left(\mathrm{g} / \mathrm{mL}_{\mathrm{cat}} / \mathrm{hr}\right)$} & \multirow[b]{2}{*}{$\begin{array}{c}\text { Carbon } \\
\text { Balance } \\
\left(\mathrm{C}_{\text {out }} / \mathrm{C}_{\text {in }}\right) \\
\% \\
\%\end{array}$} \\
\hline & & & & & & & MEOH & $\begin{array}{c}\text { Other } \mathrm{C}_{1} \\
\text { Oxygenates } \\
\end{array}$ & $\begin{array}{l}\mathrm{C}_{2}+ \\
\text { Alc. }\end{array}$ & $\begin{array}{c}\text { Other } \mathrm{C}_{2}+ \\
\text { Oxygenates }\end{array}$ & Methane & $\begin{array}{c}\text { Total } \\
\text { Higher } \\
\text { HCs } \\
\text { (est) } \\
\end{array}$ & \begin{tabular}{|c|}
$\mathrm{C}_{2}{ }^{+}$ \\
Alcohols \\
\end{tabular} & $\begin{array}{l}\text { Other } \mathrm{C}_{2}+ \\
\text { Oxygenates }\end{array}$ & $\begin{array}{c}\text { Total } \mathrm{C}_{2}{ }^{+} \\
\text {Oxygenates }\end{array}$ & $\begin{array}{c}\text { HC } \\
\text { Liquids }\end{array}$ & $\mathrm{MEOH}$ & \begin{tabular}{|c|} 
Total \\
Liq. \\
\end{tabular} & \\
\hline & $5.56 / 1.69 / 1.37 / 0$ & 11000 & 300 & 45.39 & 50.53 & -0.06 & 0.08 & 0.01 & \begin{tabular}{|l|}
6.19 \\
\end{tabular} & 23.57 & 33.12 & 37.03 & 0.109 & 0.443 & 0.552 & 0.062 & 0.002 & 0.616 & 98.87 \\
\hline & $5.56 / 1.69 / 1.72$ & 11000 & 301 & 49.14 & 54.61 & -0.51 & 0.31 & 0.00 & 9.14 & 17.96 & 48.48 & 24.12 & 0.18 & 0.37 & 0.55 & 0.02 & 0.01 & \begin{tabular}{|l|}
0.57 \\
\end{tabular} & 97.62 \\
\hline \multirow{8}{*}{\begin{tabular}{|c} 
Lithium \\
Concentration \\
(RhMn on \\
Catalyst)
\end{tabular}} & $5.56 / 1.69 / 0 / 0$ & 11000 & 301 & 32.24 & 36.36 & -0.17 & 0.29 & 0.00 & \begin{tabular}{|l|}
7.04 \\
\end{tabular} & 22.20 & 50.41 & 20.07 & 0.095 & 0.311 & 0.407 & 0.029 & 0.006 & 0.441 & 97.69 \\
\hline & $5.56 / 1.69 / 0 / 0.113$ & 11000 & 301 & 8.83 & 9.65 & -0.27 & 2.14 & 0.00 & 10.83 & 37.81 & 28.75 & 20.47 & 0.039 & 0.152 & 0.191 & 0.000 & 0.011 & 0.202 & 98.56 \\
\hline & $5.56 / 1.69 / 0 / 00.170$ & 11000 & 300 & 3.47 & 3.24 & -0.69 & 8.29 & 0.00 & 27.01 & 27.37 & 30.28 & 7.05 & 0.037 & 0.044 & 0.081 & 0.000 & 0.016 & 0.097 & 97.57 \\
\hline & $5.56 / 1.69 / 0 / 00.227$ & 11000 & 300 & 0.72 & 0.13 & -0.69 & 26.93 & 0.00 & 35.54 & 37.53 & 0.00 & 0.00 & 0.010 & 0.013 & 0.024 & 0.000 & 0.011 & 0.035 & 98.23 \\
\hline & $5.56 / 1.69 / 0 / 0$ & 11000 & 315 & 33.73 & 38.84 & 0.70 & 0.44 & 0.00 & 8.16 & 16.71 & 56.34 & 18.34 & 0.117 & 0.249 & 0.366 & 0.000 & 0.009 & 0.375 & 95.71 \\
\hline & $\begin{array}{l}5.56 / 1.69 / 0 / 0.113 \\
\end{array}$ & 11000 & 316 & 15.33 & 16.88 & -0.30 & 1.60 & 0.00 & 12.55 & 34.80 & 33.90 & 17.15 & 0.079 & 0.235 & 0.314 & 0.000 & 0.015 & 0.329 & 98.60 \\
\hline & $5.56 / 1.69 / 0 / 00.170$ & 11000 & 316 & 7.17 & 8.05 & -0.03 & 6.09 & 0.00 & 23.28 & 19.80 & 33.13 & 17.71 & 0.068 & 0.062 & 0.130 & 0.000 & 0.025 & 0.155 & 97.12 \\
\hline & $5.56 / 1.69 / 0 / 00.227$ & 11000 & 315 & 1.47 & 1.44 & -0.22 & 22.79 & 0.00 & 40.88 & 36.33 & 0.00 & 0.00 & 0.025 & 0.026 & 0.051 & 0.000 & 0.019 & 0.070 & 97.55 \\
\hline \multirow{8}{*}{\begin{tabular}{|c} 
Lithium \\
Concentration \\
(RhMnIr on \\
Catalyst)
\end{tabular}} & $5.56 / 1.69 / 1.03 / 0$ & 11000 & 299 & 32.75 & 36.89 & 0.22 & 0.81 & 0.00 & 9.55 & 39.91 & 31.59 & 18.14 & 0.128 & 0.574 & 0.702 & 0.000 & 0.016 & 0.718 & 100.56 \\
\hline & $5.56 / 1.69 / 1.03 / 0.170$ & 11000 & 300 & 2.33 & 2.14 & -0.49 & 14.72 & 0.00 & 39.43 & 40.56 & 0.00 & 5.29 & 0.037 & 0.043 & 0.080 & 0.000 & 0.019 & 0.099 & 97.31 \\
\hline & $5.56 / 1.69 / 1.03 / 0.170$ & 11000 & \begin{tabular}{|c|}
300 \\
(repeat)
\end{tabular} & 4.17 & 4.27 & -0.43 & 9.37 & 0.00 & 30.52 & 27.36 & 29.81 & 2.93 & 0.051 & 0.053 & 0.104 & 0.000 & 0.022 & 0.126 & 99.11 \\
\hline & $5.56 / 1.69 / 1.03 / 0.227$ & 11000 & 301 & 1.71 & 1.41 & -0.51 & 23.23 & 0.00 & 40.48 & 36.29 & 0.00 & 0.00 & 0.028 & 0.029 & 0.057 & 0.000 & 0.023 & 0.080 & 97.68 \\
\hline & $5.56 / 1.69 / 1.03 / 0.227$ & 11000 & $\begin{array}{c}301 \\
\text { (Repeat) }\end{array}$ & 3.57 & 3.56 & -0.46 & 11.95 & 0.00 & 29.79 & 26.50 & 29.08 & 2.67 & 0.043 & 0.045 & 0.087 & 0.000 & 0.024 & 0.112 & 99.15 \\
\hline & $5.56 / 1.69 / 1.03 / 0$ & 11000 & 314 & 34.16 & 38.52 & 0.28 & 0.66 & 0.00 & 12.47 & 26.89 & 42.28 & 17.71 & 0.179 & 0.404 & 0.582 & 0.000 & 0.013 & 0.596 & 98.86 \\
\hline & $5.56 / 1.69 / 1.03 / 0.170$ & 11000 & \begin{tabular}{|c|}
315 \\
(after \\
repeat)
\end{tabular} & 6.36 & 6.63 & -0.57 & 8.59 & 0.00 & 28.47 & 18.93 & 40.09 & 3.91 & 0.073 & 0.052 & 0.125 & 0.000 & 0.031 & 0.156 & 97.14 \\
\hline & $5.56 / 1.69 / 1.03 / 0.227$ & 11000 & \begin{tabular}{|c|}
315 \\
(after \\
Repeat)
\end{tabular} & 5.51 & 5.76 & -0.47 & 9.41 & 0.00 & 28.70 & 18.32 & 39.83 & 3.74 & 0.064 & 0.045 & 0.108 & 0.000 & 0.029 & 0.138 & 97.50 \\
\hline
\end{tabular}


Table A.2. Summary of Catalyst Screening Test Results

\begin{tabular}{|c|c|c|c|c|c|c|c|c|c|c|c|c|c|c|c|c|c|c|}
\hline \multirow[b]{2}{*}{ Catalyst } & \multirow[b]{2}{*}{$\begin{array}{c}\text { Space } \\
\text { Velocity, } \\
\mathrm{L} / \mathrm{L} / \mathrm{hr}\end{array}$} & \multirow[b]{2}{*}{$\underset{\text { Temp. }}{\text { Tem }}$} & \multirow[b]{2}{*}{$\begin{array}{c}\text { Carbon } \\
\text { Conv. } \\
\%\end{array}$} & \multirow[b]{2}{*}{$\begin{array}{c}\text { CO } \\
\text { Conv. } \\
\%\end{array}$} & \multirow[b]{2}{*}{$\left|\begin{array}{c}\mathrm{CO} \\
\text { Conv. } \\
\mathrm{To} \mathrm{CO}_{2}\end{array}\right|$} & \multicolumn{6}{|c|}{ Carbon Selectivity (C-Mole\%) } & \multicolumn{6}{|c|}{ STY $\left(g / \mathrm{mL}_{\mathrm{cat}} / \mathrm{hr}\right)$} & \multirow{2}{*}{$\begin{array}{c}\text { Carbon } \\
\text { Balance } \\
\left(\mathrm{C}_{\text {out }} / \mathrm{C}_{\text {in }}\right) \\
\%\end{array}$} \\
\hline & & & & & & $\mathrm{MeOH}$ & $\begin{array}{c}\text { Other } \mathrm{C}_{1} \\
\text { Oxygenates }\end{array}$ & $\begin{array}{l}\mathrm{C}_{2}+ \\
\text { Alc. }\end{array}$ & $\begin{array}{c}\text { Other } \mathrm{C}_{2}+ \\
\text { Oxygenates }\end{array}$ & Methane & \begin{tabular}{|c|} 
Total \\
Higher \\
HCs (est)
\end{tabular} & $\begin{array}{c}\mathrm{C}_{2}+ \\
\text { Alcohols }\end{array}$ & $\begin{array}{l}\text { Other } \mathrm{C}_{2}+ \\
\text { Oxygenates }\end{array}$ & $\begin{array}{c}\text { Total } \mathrm{C}_{2}+ \\
\text { Oxygenates }\end{array}$ & \begin{tabular}{|c|} 
HC \\
Liquids
\end{tabular} & $\mathrm{MeOH}$ & $\begin{array}{l}\text { Total } \\
\text { Liq. }\end{array}$ & \\
\hline \multirow{5}{*}{$\mathrm{RhMnV} / \mathrm{SiO}_{2}$} & 7500 & 256 & 0.82 & 0.64 & -0.29 & 10.11 & 0.01 & 36.79 & 53.08 & 0.00 & 0.00 & 0.01 & 0.02 & 0.02 & 0.00 & 0.00 & 0.03 & 98.87 \\
\hline & 7500 & 276 & 0.40 & -0.39 & -0.84 & 8.80 & 0.00 & 36.73 & 54.48 & 0.00 & 0.00 & 0.00 & 0.01 & 0.01 & 0.00 & 0.00 & 0.01 & 96.62 \\
\hline & 11000 & 300 & 2.89 & 2.47 & -0.78 & 3.96 & 0.00 & 23.02 & 22.29 & 46.98 & 3.75 & 0.03 & 0.04 & 0.07 & 0.00 & 0.01 & 0.08 & 97.64 \\
\hline & 11000 & 325 & 6.93 & 6.99 & -0.83 & 3.20 & 0.00 & 23.95 & 10.38 & 49.39 & 13.08 & 0.07 & 0.05 & 0.12 & 0.00 & 0.01 & 0.13 & 97.55 \\
\hline & 11000 & 343 & 11.22 & 12.03 & -0.70 & 3.49 & 0.00 & 27.36 & 9.91 & 49.32 & 9.92 & 0.13 & 0.07 & 0.20 & 0.00 & 0.02 & 0.22 & 99.20 \\
\hline \multirow{6}{*}{$\mathrm{RhMnMg} / \mathrm{SiO}_{2}$} & 7500 & 257 & 3.72 & 3.86 & -0.34 & 4.22 & 0.01 & 20.39 & 39.15 & 32.00 & 4.23 & 0.02 & 0.06 & 0.08 & 0.00 & 0.01 & 0.09 & 98.44 \\
\hline & 7500 & 276 & 6.87 & 6.92 & -0.85 & 2.08 & 0.00 & 13.17 & 17.23 & 49.07 & 18.45 & 0.02 & 0.05 & 0.08 & 0.00 & 0.01 & 0.08 & 95.54 \\
\hline & 11000 & 300 & 13.91 & 14.81 & -0.86 & 1.98 & 0.00 & 16.68 & 21.50 & 46.22 & 13.61 & 0.10 & 0.20 & 0.30 & 0.00 & 0.02 & 0.31 & 96.84 \\
\hline & 11000 & 315 & 19.36 & 21.05 & -0.80 & 2.01 & 0.00 & 18.14 & 16.06 & 56.59 & 7.20 & 0.14 & 0.22 & 0.36 & 0.00 & 0.02 & 0.38 & 95.15 \\
\hline & 11000 & 323 & 24.64 & 27.35 & -0.60 & 1.98 & 0.00 & 17.17 & 13.38 & 55.20 & 12.26 & 0.17 & 0.23 & 0.40 & 0.00 & 0.03 & 0.43 & 98.12 \\
\hline & 11000 & 302 & 11.82 & 11.94 & -1.43 & 2.42 & 0.00 & 15.10 & 17.80 & 499.78 & 14.90 & 0.07 & 0.15 & 0.22 & 0.00 & 0.02 & 0.24 & 96.66 \\
\hline \multirow{10}{*}{$\mathrm{RhMnLa} / \mathrm{SiO}_{2}$} & 7500 & 256 & 0.69 & 0.93 & 0.16 & 11.29 & 0.00 & 36.88 & 44.79 & 0.00 & 7.04 & 0.01 & 0.01 & 0.02 & 0.00 & 0.00 & 0.02 & 97.70 \\
\hline & 7500 & 276 & 3.76 & 4.09 & -0.12 & 3.43 & 0.00 & 15.27 & 15.95 & 42.11 & 23.23 & 0.02 & 0.03 & 0.04 & 0.00 & 0.00 & 0.05 & 97.46 \\
\hline & 11000 & 301 & 7.96 & 8.38 & -0.55 & 3.93 & 0.00 & 21.53 & 17.46 & 42.16 & 14.93 & 0.07 & 0.09 & 0.16 & 0.00 & 0.02 & 0.18 & 98.36 \\
\hline & 11000 & 315 & 10.95 & 11.74 & -0.53 & 3.94 & 0.00 & 24.40 & 10.43 & 47.65 & 13.58 & 0.11 & 0.08 & 0.19 & 0.00 & 0.03 & 0.21 & 97.76 \\
\hline & 11000 & 325 & 14.21 & 15.16 & -0.87 & 4.55 & 0.00 & 26.56 & 9.12 & 48.96 & 10.81 & 0.16 & 0.09 & 0.25 & 0.00 & 0.04 & 0.28 & 98.30 \\
\hline & 11000 & 301 & 6.48 & 7.13 & -0.15 & 5.34 & 0.00 & 25.51 & 14.49 & 40.99 & 13.67 & 0.07 & 0.06 & 0.13 & 0.00 & 0.02 & 0.15 & 98.92 \\
\hline & 7500 & 325 & 17.21 & $\begin{array}{l}19.52 \\
\end{array}$ & 0.16 & 4.24 & 0.00 & 24.58 & 6.71 & 53.91 & 10.55 & 0.12 & 0.05 & 0.17 & 0.00 & 0.03 & 0.20 & 96.84 \\
\hline & 7500 & 344 & 26.63 & 31.12 & 1.07 & 3.80 & 0.00 & 22.18 & 4.68 & 61.33 & 8.01 & 0.17 & 0.06 & 0.22 & 0.00 & 0.04 & 0.26 & 98.14 \\
\hline & 11000 & 345 & 19.44 & 23.48 & 1.51 & 4.10 & 0.00 & 21.65 & 3.47 & 62.53 & 8.25 & 0.17 & 0.05 & 0.22 & 0.00 & 0.05 & 0.27 & 100.54 \\
\hline & 11000 & 301 & 4.49 & 4.14 & -0.90 & 6.55 & 0.00 & 30.66 & 10.97 & 48.58 & 3.24 & 0.06 & 0.03 & 0.09 & 0.00 & 0.02 & 0.11 & 98.61 \\
\hline \multirow{5}{*}{$\mathrm{RhMnCe} / \mathrm{SiO}_{2}$} & 7500 & 257 & 0.31 & 0.47 & 0.13 & 16.85 & 0.00 & 36.66 & 46.49 & 0.00 & 0.00 & 0.00 & 0.00 & 0.01 & 0.00 & 0.00 & 0.01 & 99.05 \\
\hline & 7500 & 276 & 0.28 & 0.19 & -0.12 & 26.69 & 0.00 & 42.60 & 30.70 & 0.00 & 0.00 & 0.00 & 0.00 & 0.01 & 0.00 & 0.00 & 0.01 & 97.79 \\
\hline & 11000 & 301 & 2.17 & 1.92 & -0.52 & 11.95 & 0.00 & 24.34 & 14.82 & 45.21 & 3.68 & 0.02 & 0.02 & 0.04 & 0.00 & 0.02 & 0.05 & 98.71 \\
\hline & 11000 & 315 & 3.39 & 3.19 & -0.61 & 11.39 & 0.00 & 26.02 & 11.51 & 49.39 & 1.69 & 0.04 & 0.02 & 0.05 & 0.00 & 0.02 & 0.08 & 97.83 \\
\hline & 11000 & 327 & 5.31 & 4.99 & -1.00 & 11.02 & 0.00 & 27.28 & 8.69 & 49.97 & 3.03 & 0.06 & 0.02 & 0.08 & 0.00 & 0.03 & 0.12 & 97.87 \\
\hline \multirow{8}{*}{$\mathrm{RhMn} / \mathrm{SiO} 2$} & 7500 & 257 & 14.57 & 15.29 & -1.20 & 0.88 & 0.00 & 5.90 & 45.77 & 29.14 & 18.31 & 0.02 & 0.20 & 0.23 & 0.00 & 0.01 & 0.23 & 91.44 \\
\hline & 7500 & 275 & 29.99 & 33.47 & -0.51 & 0.65 & 0.00 & 6.27 & 35.75 & 30.34 & 27.00 & 0.05 & 0.32 & 0.37 & 0.06 & 0.01 & 0.44 & 99.64 \\
\hline & 11000 & 301 & 31.22 & 35.73 & 0.30 & 0.26 & 0.00 & 6.23 & 20.77 & 53.88 & 18.86 & 0.08 & 0.29 & 0.37 & 0.00 & 0.00 & 0.38 & 96.13 \\
\hline & 11000 & 301 & 32.24 & 36.36 & -0.17 & 0.29 & 0.00 & 7.04 & 22.20 & 50.41 & 20.07 & 0.10 & 0.31 & 0.41 & 0.03 & 0.01 & 0.44 & 97.69 \\
\hline & 11000 & 315 & 33.73 & 38.84 & 0.70 & 0.44 & 0.00 & 8.16 & 16.71 & 56.34 & 18.34 & 0.12 & 0.25 & 0.37 & 0.00 & 0.01 & 0.38 & 95.71 \\
\hline & 15000 & 315 & 26.98 & 31.69 & 1.05 & 0.54 & 0.00 & 7.76 & 13.98 & 64.41 & 13.31 & 0.12 & 0.22 & 0.34 & 0.00 & 0.01 & 0.35 & 103.25 \\
\hline & 11000 & 326 & 41.96 & 53.16 & 5.35 & 0.10 & 0.00 & 2.92 & 5.18 & 84.71 & 7.08 & 0.05 & 0.09 & 0.15 & 0.00 & 0.00 & 0.15 & 105.23 \\
\hline & 11000 & 303 & 18.65 & 20.26 & -0.86 & 0.58 & 0.00 & 7.82 & 21.74 & 54.37 & 15.48 & 0.06 & 0.17 & 0.23 & 0.00 & 0.01 & 0.24 & 91.86 \\
\hline \multirow{6}{*}{$\mathrm{Rh} / \mathrm{SiO}_{2}$} & 7500 & 257 & 0.12 & 0.15 & 0.02 & 7.54 & 0.00 & 22.98 & 69.48 & 0.00 & 0.00 & 0.00 & 0.00 & 0.00 & 0.00 & 0.00 & 0.00 & 99.15 \\
\hline & 7500 & 275 & 0.29 & 0.19 & -0.13 & 9.80 & 0.00 & 26.56 & 63.64 & 0.00 & 0.00 & 0.00 & 0.01 & 0.01 & 0.00 & 0.00 & 0.01 & 97.78 \\
\hline & 11000 & 301 & 1.76 & 1.34 & $\begin{array}{ll}-0.63 \\
\end{array}$ & 3.68 & 0.00 & 10.53 & 17.61 & 64.23 & 3.95 & 0.01 & 0.01 & 0.02 & 0.00 & 0.00 & 0.03 & $\begin{array}{l}98.09 \\
\end{array}$ \\
\hline & 11000 & 316 & 3.53 & 3.66 & \begin{tabular}{|l|}
-0.30 \\
\end{tabular} & 2.85 & 0.00 & 9.46 & 10.20 & 54.54 & 22.94 & 0.01 & 0.02 & 0.03 & 0.00 & 0.01 & 0.04 & 98.67 \\
\hline & 11000 & 326 & 5.07 & 5.18 & -0.50 & $\begin{array}{l}3.77 \\
\end{array}$ & 0.00 & 13.14 & 11.43 & 53.76 & 17.91 & 0.03 & 0.03 & 0.06 & 0.00 & 0.01 & $\begin{array}{l}0.07 \\
\end{array}$ & $\begin{array}{l}98.90 \\
\end{array}$ \\
\hline & 11000 & 345 & 8.25 & 9.14 & -0.12 & 3.17 & 0.00 & 11.53 & 5.97 & 65.14 & 14.19 & 0.04 & 0.02 & 0.06 & 0.00 & 0.02 & 0.08 & 99.34 \\
\hline
\end{tabular}


Table A.2. (contd)

\begin{tabular}{|c|c|c|c|c|c|c|c|c|c|c|c|c|c|c|c|c|c|c|}
\hline \multirow[b]{2}{*}{ Catalyst } & \multirow[b]{2}{*}{$\begin{array}{c}\text { Space } \\
\text { Velocity, } \\
\text { L/L/hr }\end{array}$} & \multirow[b]{2}{*}{$\begin{array}{c}\text { Temp. } \\
{ }^{\circ} \mathrm{C}\end{array}$} & \multirow[b]{2}{*}{$\begin{array}{c}\text { Carbon } \\
\text { Conv. } \\
\%\end{array}$} & \multirow[b]{2}{*}{$\begin{array}{c}\text { CO } \\
\text { Conv. } \\
\% \\
\end{array}$} & \multirow[b]{2}{*}{$\begin{array}{c}\mathrm{CO} \\
\text { Conv. } \\
\text { To } \mathrm{CO}_{2}\end{array}$} & \multicolumn{6}{|c|}{ Carbon Selectivity (C-Mole\%) } & \multicolumn{6}{|c|}{$\mathrm{STY}\left(\mathrm{g} / \mathrm{mL}_{\mathrm{cat}} / \mathrm{hr}\right)$} & \multirow{2}{*}{$\begin{array}{c}\text { Carbon } \\
\text { Balance } \\
\left(\mathrm{C}_{\text {out }} / \mathrm{C}_{\text {in }}\right) \\
\% \\
\end{array}$} \\
\hline & & & & & & $\mathrm{MeOH}$ & $\begin{array}{c}\text { Other } \mathrm{C}_{1} \\
\text { Oxygenates }\end{array}$ & $\begin{array}{l}\mathrm{C}_{2}+ \\
\text { Alc. }\end{array}$ & $\begin{array}{c}\text { Other } \mathrm{C}_{2}+ \\
\text { Oxygenates }\end{array}$ & Methane & \begin{tabular}{|c|} 
Total \\
Higher \\
HCs (est)
\end{tabular} & $\begin{array}{c}\mathrm{C}_{2}+ \\
\text { Alcohols } \\
\end{array}$ & $\begin{array}{c}\text { Other } \mathrm{C}_{2}{ }^{+} \\
\text {Oxygenates }\end{array}$ & \begin{tabular}{|c|} 
Total $\mathrm{C}_{2}+$ \\
Oxygenates \\
\end{tabular} & $\begin{array}{c}\text { HC } \\
\text { Liquids }\end{array}$ & $\mathrm{MeOH}$ & $\begin{array}{l}\text { Total } \\
\text { Liq. }\end{array}$ & \\
\hline \multirow{6}{*}{$\mathrm{RhMnNa} / \mathrm{SiO}_{2}$} & 7500 & 256 & 0.00 & 0.03 & 0.03 & \#DIV/0! & \#DIV/0! & \#DIV/0! & \#DIV/0! & \#DIV/0! & \#DIV/0! & 0.00 & 0.00 & 0.00 & 0.00 & 0.00 & 0.00 & 99.59 \\
\hline & 7500 & 276 & 0.00 & \begin{tabular}{|l|}
-0.43 \\
\end{tabular} & $\begin{array}{l}-0.43 \\
\end{array}$ & \#DIV/0! & \#DIV/0! & \#DIV/0! & \#DIV/0! & \#DIV/0! & \#DIV/0! & 0.00 & 0.00 & 0.00 & 0.00 & 0.00 & 0.00 & 98.45 \\
\hline & 11000 & 301 & 0.33 & 0.07 & $\begin{array}{l}-0.30 \\
\end{array}$ & 34.71 & 0.00 & 21.13 & 35.40 & 0.00 & 8.76 & 0.00 & 0.01 & 0.01 & 0.00 & 0.01 & 0.02 & 98.22 \\
\hline & 11000 & 316 & 0.87 & 0.65 & $\begin{array}{l}-0.32 \\
\end{array}$ & 34.85 & 0.00 & 27.01 & 38.13 & 0.00 & 0.00 & 0.01 & 0.02 & 0.03 & 0.00 & 0.02 & 0.04 & 98.04 \\
\hline & 11000 & 326 & 1.38 & 1.08 & $\begin{array}{ll}-0.48 \\
\end{array}$ & 32.36 & 0.00 & 29.98 & 37.66 & 0.00 & 0.00 & 0.02 & 0.03 & 0.04 & 0.00 & 0.03 & 0.07 & 97.40 \\
\hline & 11000 & 345 & 4.32 & 5.61 & 0.78 & 15.25 & 0.00 & 21.84 & 17.70 & 41.06 & 4.15 & 0.04 & 0.04 & 0.07 & 0.00 & 0.04 & 0.11 & 97.68 \\
\hline \multirow{6}{*}{$\mathrm{RhMnB} / \mathrm{SiO}_{2}$} & 7500 & 257 & 3.98 & 4.53 & 0.08 & 1.12 & 0.00 & 7.63 & 41.01 & 34.75 & 15.48 & 0.01 & 0.05 & 0.06 & 0.00 & 0.00 & 0.06 & 98.25 \\
\hline & 7500 & 276 & 11.62 & 12.69 & -0.34 & 0.86 & 0.00 & 5.82 & 22.60 & 37.59 & 33.13 & 0.02 & 0.08 & 0.10 & 0.02 & 0.00 & 0.12 & 96.37 \\
\hline & 11000 & 301 & 21.45 & 23.73 & -0.27 & 1.03 & 0.00 & 9.14 & 29.21 & 41.52 & 19.10 & 0.08 & 0.29 & 0.37 & 0.01 & 0.01 & 0.39 & 98.48 \\
\hline & 11000 & 316 & 30.60 & 34.24 & $\begin{array}{l}-0.07 \\
\end{array}$ & 0.97 & 0.00 & 9.82 & 20.68 & 50.90 & 17.63 & 0.12 & 0.28 & 0.40 & 0.01 & 0.02 & 0.43 & 98.35 \\
\hline & 11000 & 325 & 31.44 & \begin{tabular}{|l|}
34.96 \\
\end{tabular} & -0.35 & 0.93 & 0.00 & 10.01 & 18.96 & 53.54 & 16.57 & 0.13 & 0.27 & 0.40 & 0.01 & 0.02 & 0.43 & 99.23 \\
\hline & 11000 & 302 & 13.79 & 15.31 & -0.11 & 1.12 & 0.00 & 8.39 & 22.34 & 46.46 & 21.69 & 0.05 & 0.13 & 0.18 & 0.01 & 0.01 & 0.20 & 98.05 \\
\hline \multirow{6}{*}{$\mathrm{RhMnW} / \mathrm{SiO}_{2}$} & 7500 & 256 & 5.92 & 6.08 & -0.53 & 2.94 & 0.00 & 23.09 & 40.44 & 20.74 & 12.79 & 0.04 & 0.07 & 0.11 & 0.00 & 0.01 & 0.12 & 101.44 \\
\hline & 7500 & 275 & 17.88 & \begin{tabular}{|l|}
23.57 \\
\end{tabular} & 3.58 & 0.00 & 0.00 & 9.69 & 9.96 & 45.79 & 34.57 & 0.05 & 0.05 & 0.10 & 0.01 & 0.00 & 0.11 & $\begin{array}{l}93.13 \\
\end{array}$ \\
\hline & 11000 & 299 & 25.26 & \begin{tabular}{|l|}
31.32 \\
\end{tabular} & 2.98 & 0.95 & 0.00 & 8.94 & 17.61 & 41.46 & 31.04 & 0.09 & 0.20 & 0.29 & 0.02 & 0.01 & 0.33 & 97.70 \\
\hline & 11000 & 311 & 28.46 & \begin{tabular}{|l|}
34.99 \\
\end{tabular} & 2.99 & 0.88 & 0.00 & 8.77 & 16.94 & 44.30 & 29.11 & 0.10 & 0.21 & 0.31 & 0.02 & 0.01 & 0.35 & 97.56 \\
\hline & 11000 & 314 & 30.06 & 37.05 & 3.30 & 0.88 & 0.00 & 8.44 & 16.59 & 45.67 & 28.42 & 0.10 & 0.22 & 0.32 & 0.02 & 0.02 & 0.36 & 97.65 \\
\hline & 11000 & 301 & 26.25 & 34.34 & 5.00 & 0.74 & 0.00 & 5.94 & 15.31 & 47.50 & 30.50 & 0.07 & 0.18 & 0.24 & 0.02 & 0.01 & 0.28 & 94.72 \\
\hline
\end{tabular}


Appendix B

\section{Summary of Individual Test Results}





\section{Appendix B}

\section{Summary of Individual Test Results}

A total of seven tests were performed to examine $\mathrm{V}, \mathrm{La}, \mathrm{Ce}, \mathrm{Mg}, \mathrm{B}, \mathrm{W}$, and $\mathrm{Na}$ as promoters on the $\mathrm{RhMn} / \mathrm{SiO}_{2}$ catalyst. We also tested the unpromoted $\mathrm{RhMn} / \mathrm{SiO}_{2}$ and the $\mathrm{Rh} / \mathrm{SiO}_{2}$ catalyst.

All of the catalysts were prepared used Davisil 645 high-surface-area $\mathrm{SiO}_{2}$ as the support. Catalyst preparation consisted of a single-step impregnation procedure using the incipient wetness technique. This procedure is different than that reported in previous reports (Gerber et. al. 2007, Gerber el. al. 2008). The $\mathrm{SiO}_{2}$ was pretreated by calcining at $500^{\circ} \mathrm{C}$ for 2 hours (ramping up at a rate of $5^{\circ} \mathrm{C} /$ min during heating and ramping down at a rate of $10^{\circ} \mathrm{C} / \mathrm{min}$ during cooling). The appropriate quantities of a rhodium nitrate solution (10 wt\% Rh concentration in solution) and manganese nitrate tetrahydrate and a soluble compound (usually a nitrate salt) of the selected promoter were combined with enough deionized water to bring the total volume of the impregnation solution to the water adsorption pore volume of the support. The solution was impregnated onto the $\mathrm{SiO}_{2}$ in drop-wise fashion, dried under an infrared lamp while being shaken until a steady weight was achieved, and then dried overnight at $110^{\circ} \mathrm{C}$ in a drying oven. The dried catalyst was calcined at $400^{\circ} \mathrm{C}$ in air using a muffle furnace.

Prior to conducting the tests, the calcined catalysts were loaded into the reactor and reduced using a $10 \% \mathrm{H}_{2}$-in- $\mathrm{N}_{2}$ gas mixture. All catalysts were heated in the reducing atmosphere to $220^{\circ} \mathrm{C}$ at a rate of $2.5^{\circ} \mathrm{C} / \mathrm{min}$ and held that temperature for 1 hour, heated from $220^{\circ} \mathrm{C}$ to $260^{\circ} \mathrm{C}$ at a rate of $1^{\circ} \mathrm{C} / \mathrm{min}$ and held at that temperature for 8 hours, and heated to approximately $350^{\circ} \mathrm{C}$ at a rate of $1.5^{\circ} \mathrm{C} / \mathrm{min}$ and held at that temperature for 2 hours.

The testing sequence for the catalysts was generally the same except where noted. All catalyst were tested at sequentially higher temperatures with test conditions of approximately $256^{\circ} \mathrm{C}$ and $275^{\circ} \mathrm{C}$ at $7500 \mathrm{~L} / \mathrm{L}_{\text {cat }} / \mathrm{hr}$ GHSV and approximately $300^{\circ} \mathrm{C}, 315^{\circ} \mathrm{C}$, and $325^{\circ} \mathrm{C}$ at $11,000 \mathrm{~L} / \mathrm{L}_{\text {cat }} / \mathrm{hr}$ GHSV (the Vpromoted catalyst was not tested at $315^{\circ} \mathrm{C}$ ). A repeat of the test condition at approximately $300^{\circ} \mathrm{C}$ was performed for the more active promoters $\mathrm{La}, \mathrm{Ce}, \mathrm{Mg}, \mathrm{B}$, and $\mathrm{W}$, and the baseline RhMn catalyst. The Naand V-promoted catalysts and the Rh catalyst were tested at approximately $345^{\circ} \mathrm{C}$ in lieu of testing at a repeat condition. Additional test conditions from certain catalysts are discussed below.

\section{B.1 Unmodified $\mathrm{RhMn} / \mathrm{SiO}_{2}$ Catalyst}

The unmodified $\mathrm{Rh}-\mathrm{Mn} / \mathrm{SiO}_{2}$ catalyst was tested at all of the standard conditions up to approximately $325^{\circ} \mathrm{C}$, and with a repeat condition at approximately $300^{\circ} \mathrm{C}$. In addition, the test conducted at $315^{\circ} \mathrm{C}$ was repeated using a GHSV of $15,000 \mathrm{~L} / \mathrm{L}_{\text {cat }} / \mathrm{hr}$, prior to testing at the standard condition at $325^{\circ} \mathrm{C}$. There were problems with catalyst temperature control when setting the catalyst temperature at $300^{\circ} \mathrm{C}$. It took nearly 5 hours to reach the desired set point without experiencing a significant thermal runaway of the catalyst bed and an additional 2 hours to stabilize at $300^{\circ} \mathrm{C}$ (catalyst temperature fluctuating between $298^{\circ} \mathrm{C}$ and $305^{\circ} \mathrm{C}$ during this period). The test condition was repeated to ensure that the data collected was representative of the condition. Temperature control was not a problem at the other test conditions. 
Figure B.1 shows the carbon conversion for the unmodified Rh- $\mathrm{Mn} / \mathrm{SiO}_{2}$ catalyst. The Rh-Mn/SiO catalyst achieves a regular increase in carbon conversion with temperature and a lower conversion at higher space velocities, as would be expected. The repeat condition suggests that there was some deactivation of the catalyst with respect to carbon conversion over the duration of the tests.

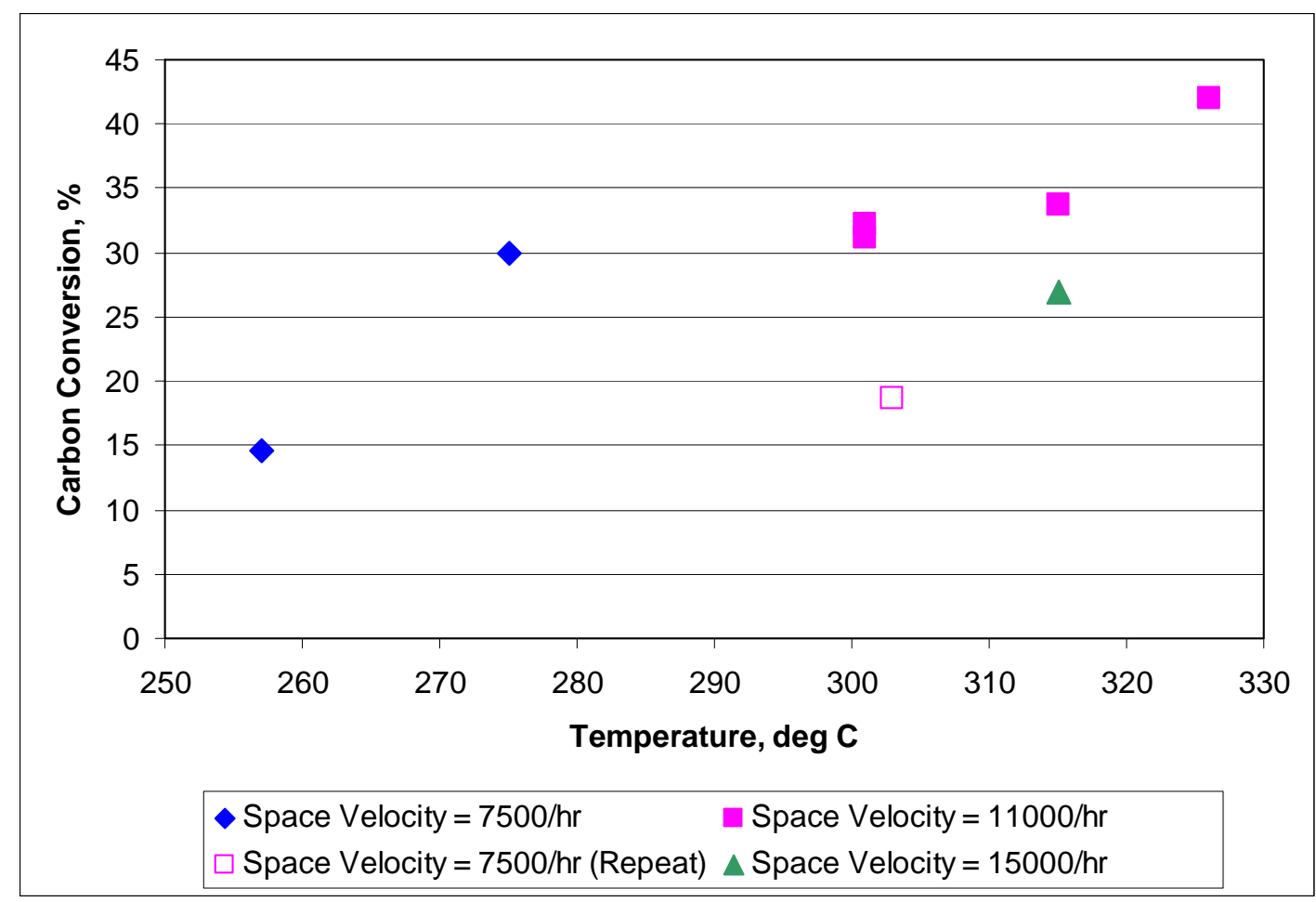

Figure B.1. Carbon Conversions for the $\mathrm{Rh} / \mathrm{Mn} / \mathrm{SiO}_{2}$ Catalyst

Figure B.2 shows the $\mathrm{C}_{2}+$-oxygenates STYs for both catalysts. It appears that while the STYs increased with increasing temperature up to about between $275^{\circ} \mathrm{C}$ and $300^{\circ} \mathrm{C}$ and then decreased at higher temperatures. Increasing the space velocity at $315^{\circ} \mathrm{C}$ to reduce carbon conversion did not improve the STY at that temperature, suggesting an overall deactivation of the catalyst at this temperature. Repeat of test conditions at lower temperatures for both catalysts confirmed this hypothesis.

Figure B.3 shows a regular decrease in the carbon selectivity to $\mathrm{C}_{2}+$ oxygenates with increasing temperature. This trend did not appear to be affected by either the space velocity or deactivation of the catalyst.

Figure B.4 also shows a regular increase in carbon selectivity of all oxygenates to $\mathrm{C}_{2}+$ alcohols with increasing temperature. Again, this behavior did not appear to be affected by either the space velocity or deactivation of the catalyst. 


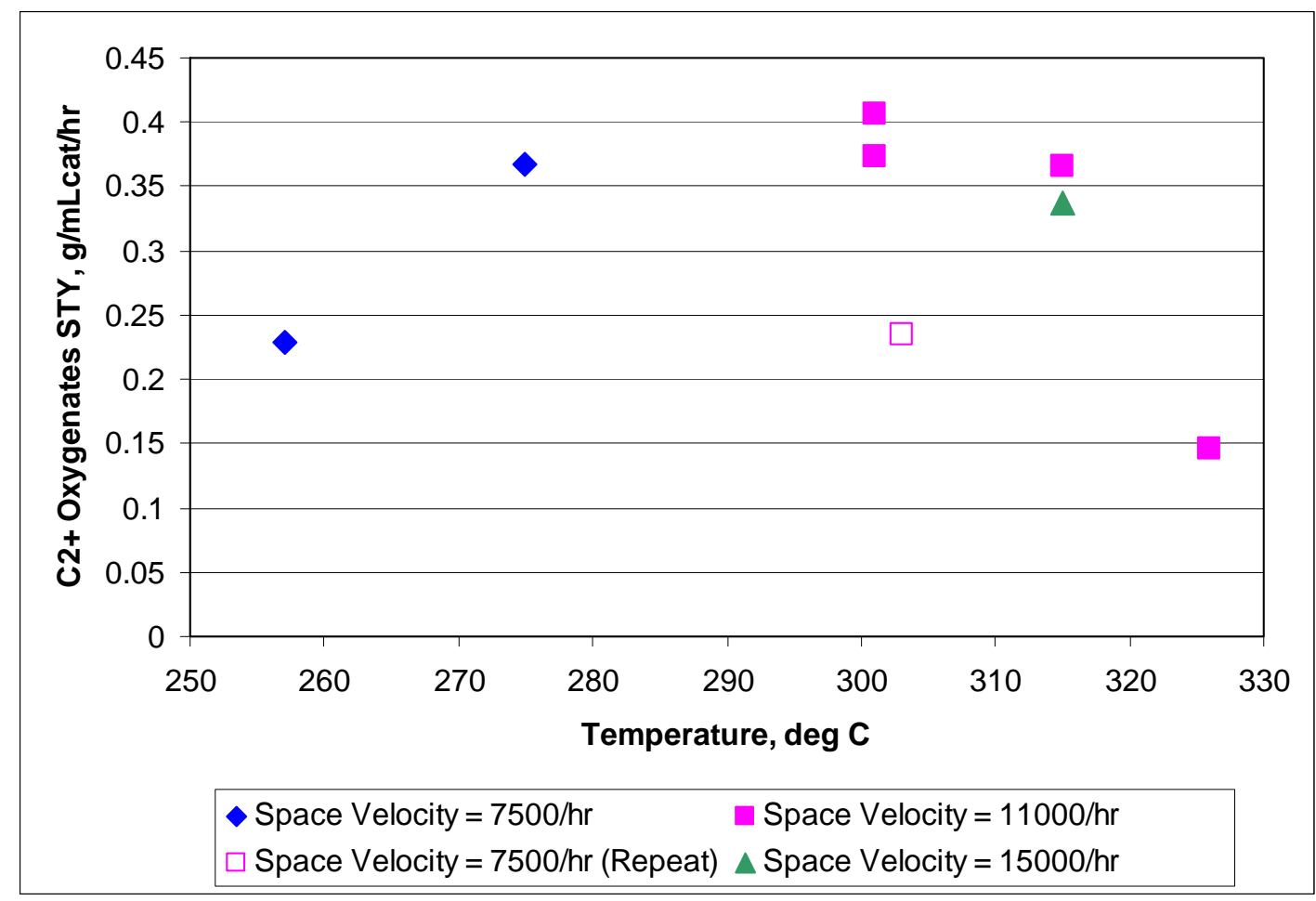

Figure B.2. $\mathrm{C}_{2}+$ Oxygenate STYs for the $\mathrm{Rh} / \mathrm{Mn} / \mathrm{SiO}_{2}$ Catalyst

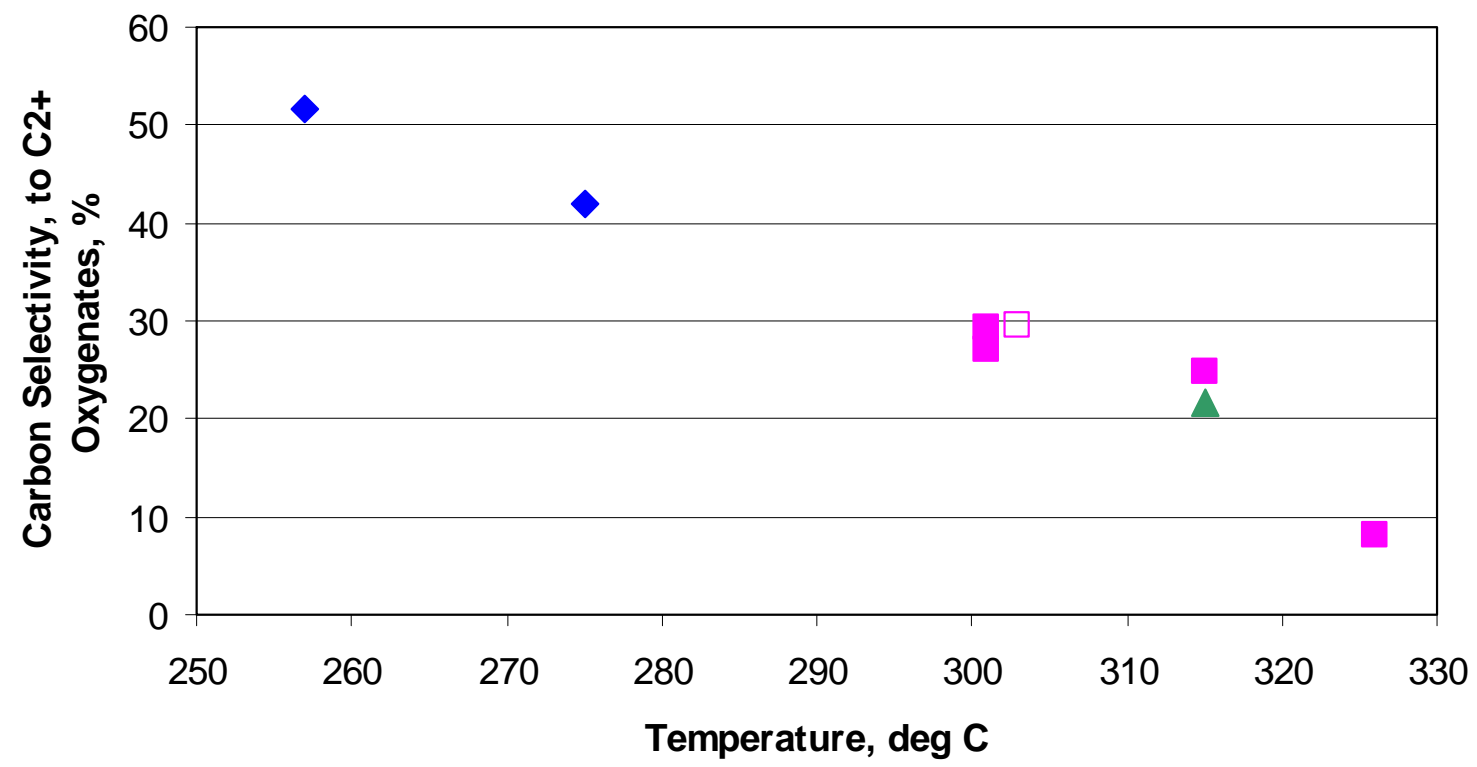

Space Velocity $=7500 / \mathrm{hr} \quad$ Space Velocity $=11000 / \mathrm{hr}$

$\square$ Space Velocity $=11000 / \mathrm{hr}$ Repeat $\Delta$ Space Velocity $=15000 / \mathrm{hr}$

Figure B.3. Carbon Selectivity to $\mathrm{C}_{2}+$ Oxygenates for the $\mathrm{Rh} / \mathrm{Mn} / \mathrm{SiO}_{2}$ Catalyst 


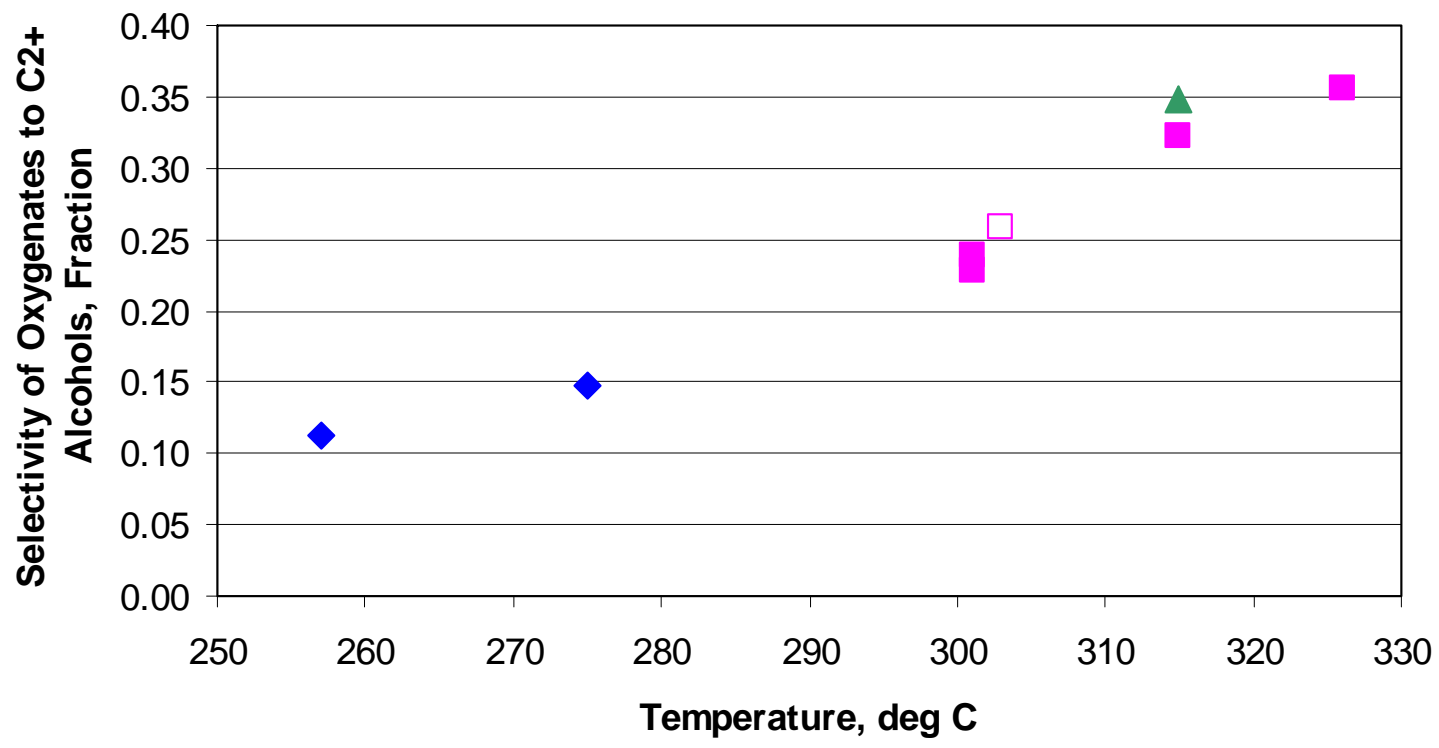

\section{Space Velocity $=7500 / \mathrm{hr} \quad$ Space Velocity $=11000 / \mathrm{hr}$}

$\square$ Space Velocity $=11000 / \mathrm{hr}$ Repeat $\Delta$ Space Velocity $=15000 / \mathrm{hr}$

Figure B.4. Selectivity of the All Oxygenates to $\mathrm{C}_{2}+$ Alcohols for the $\mathrm{Rh} / \mathrm{Mn} / \mathrm{SiO}_{2}$ Catalyst

Figure B.5 shows the carbon selectivity of the catalyst to hydrocarbons. It appears that deactivation of the catalyst at about $300^{\circ} \mathrm{C}$ and at higher temperatures resulted in a greater selectivity to methane at the expense of the higher hydrocarbons. However, the repeat condition suggests that the overall selectivity to hydrocarbons was not significantly affected.

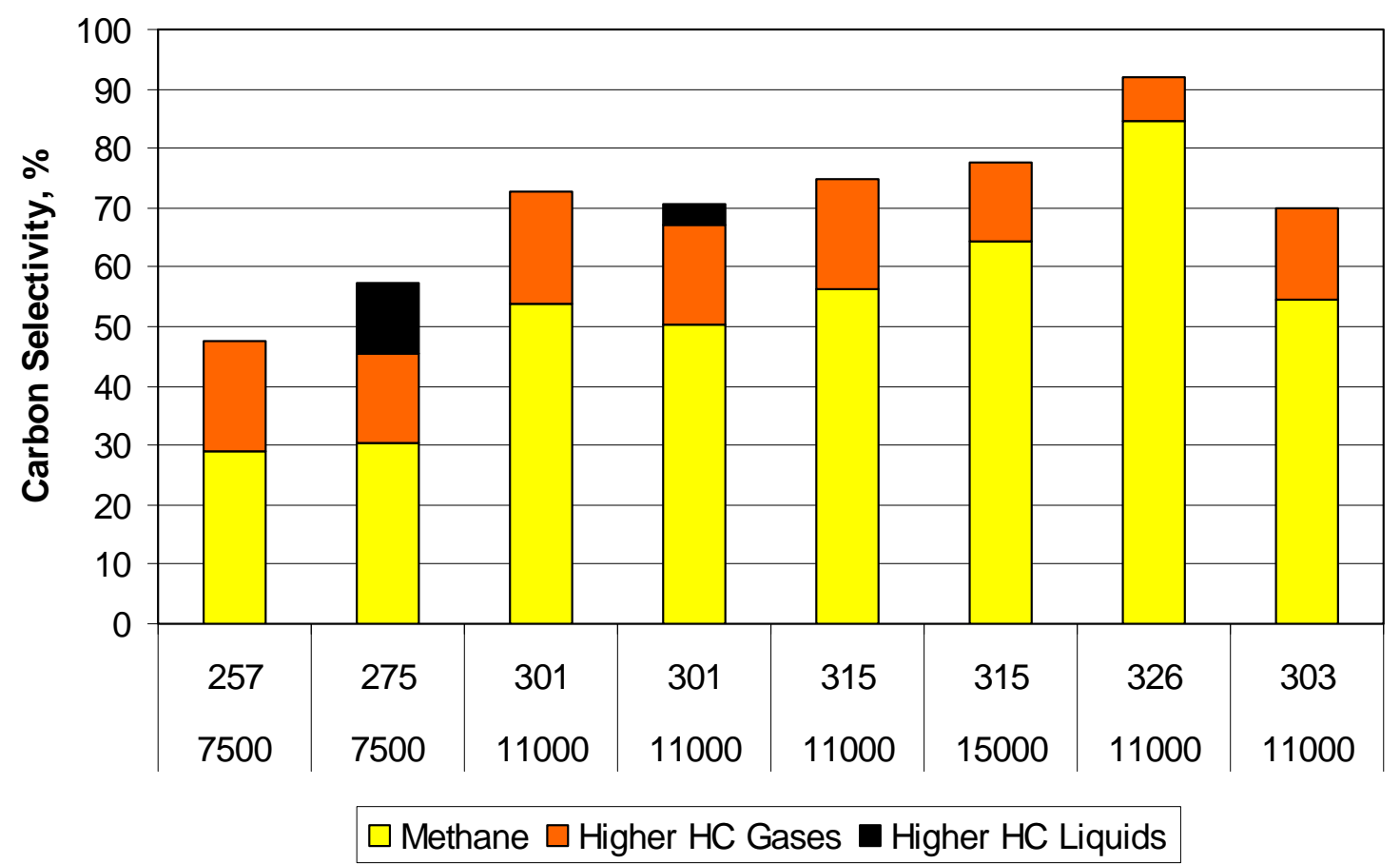

Figure B.5. Comparison of Hydrocarbon Selectivity for the Rh- $\mathrm{Mn} / \mathrm{SiO}_{2}$ Catalyst 


\section{B.2 $\mathrm{Rh} / \mathrm{SiO}_{2}$ Catalyst}

The unmodified $\mathrm{Rh} / \mathrm{SiO}_{2}$ catalyst was tested at all of the standard condition. However, because the catalyst was not very active, it also was tested at approximately $345^{\circ} \mathrm{C}$ in lieu of a repeat test condition at $300^{\circ} \mathrm{C}$. There were no problems with temperature control during the testing.

Figure B.6 shows that carbon conversion was less than $2 \%$ until the catalyst temperature was increased to $315^{\circ} \mathrm{C}$. Carbon conversion achieved a maximum of about $8 \%$ at approximately $345^{\circ} \mathrm{C}$.

Figures B.7, B.8, and B.9 show the $\mathrm{C}_{2}+$ oxygenates STYs and carbon selectivity to $\mathrm{C}_{2}+$ oxygenates and the selectivity of the $\mathrm{C}_{2}+$ oxygenates to alcohols, respectively. Figure B.7 shows that there were small, but measurable, quantities of $\mathrm{C}_{2}+$ oxygenates produced at temperatures as low as $255^{\circ} \mathrm{C}$, but the STY only reached a maximum of $0.06 \mathrm{~g} / \mathrm{L}_{\mathrm{cat}} / \mathrm{hr}$ at $345^{\circ} \mathrm{C}$, which is very low. The carbon selectivity to the $\mathrm{C}_{2}+$ oxygenates at the lower temperatures are misleading in Figure B.7 because the hydrocarbon concentrations in the product gas were below the detection limit and reported as zero concentrations. The low carbon selectivity to $\mathrm{C}_{2}+$ oxygenates of about $25 \%$ at $300^{\circ} \mathrm{C}$ strongly suggests that comparable selectivity was probably occurring at the lower temperatures. Figure B.9 shows that the selectivity of the $\mathrm{C}_{2}+$ oxygenates to alcohols increased significantly with temperature.

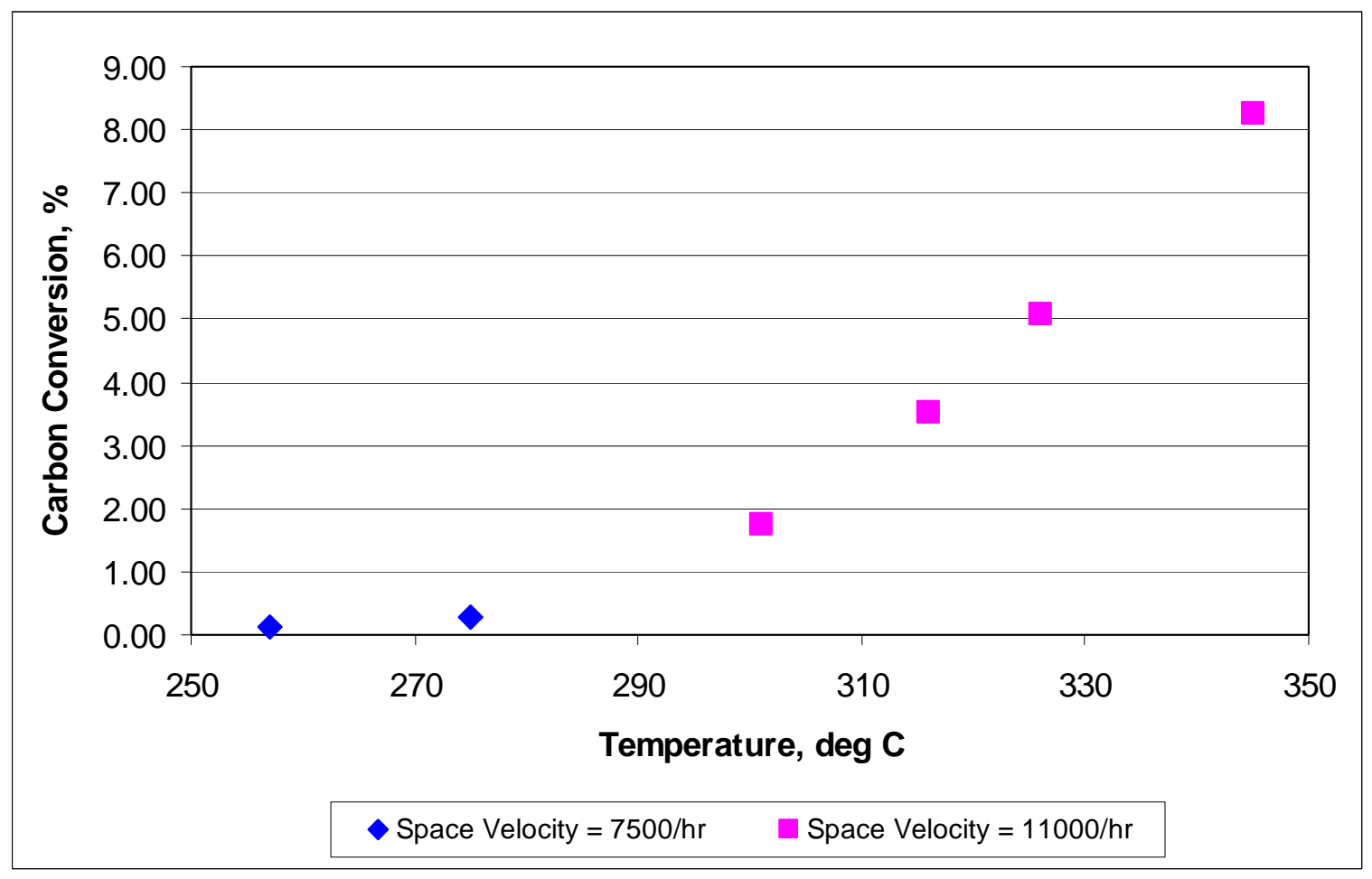

Figure B.6. Carbon Conversion for the $\mathrm{Rh} / \mathrm{SiO}_{2}$ Catalysts 


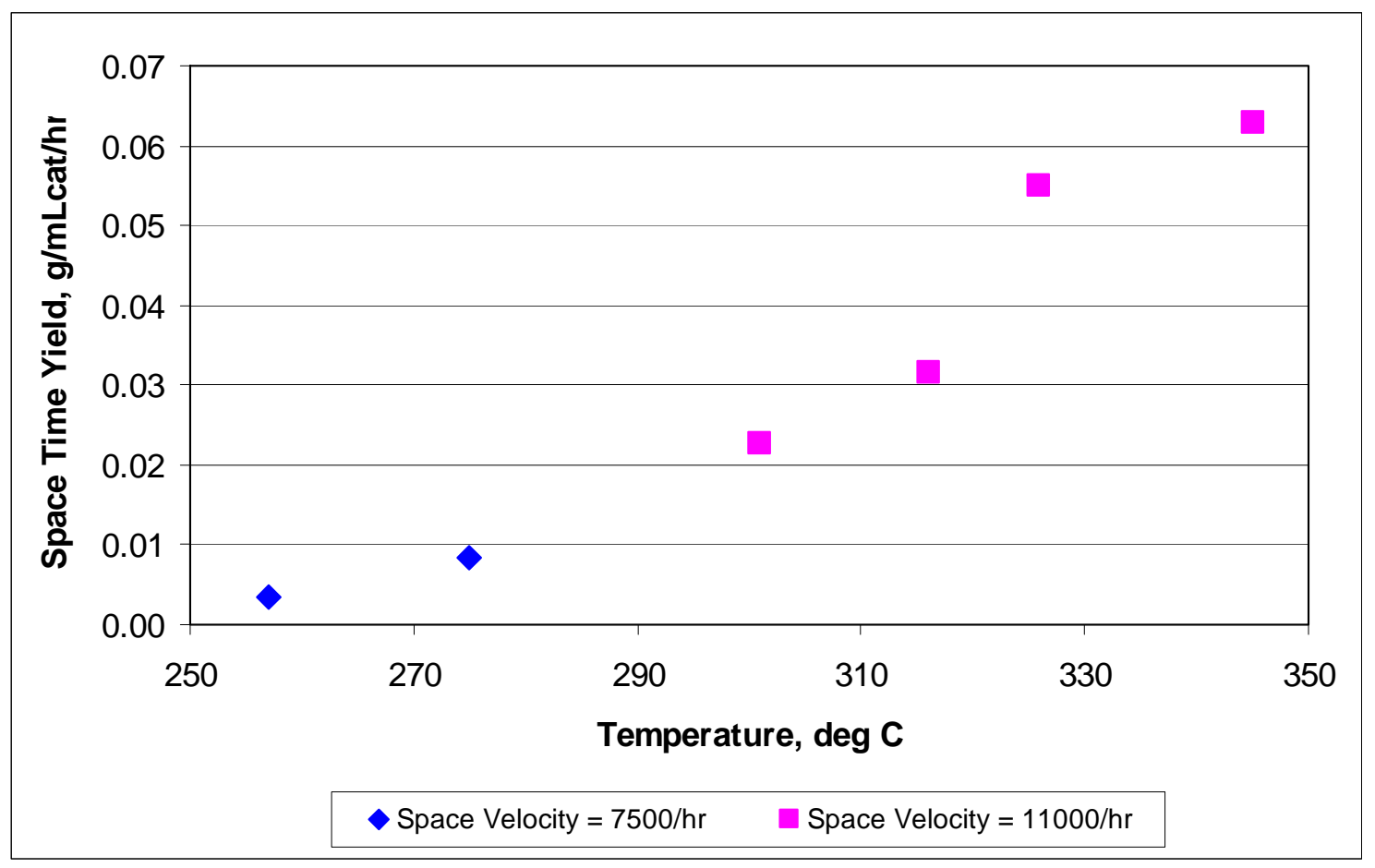

Figure B.7. $\mathrm{C}_{2}+$ Oxygenate STYs for the $\mathrm{Rh} / \mathrm{SiO}_{2}$ Catalysts

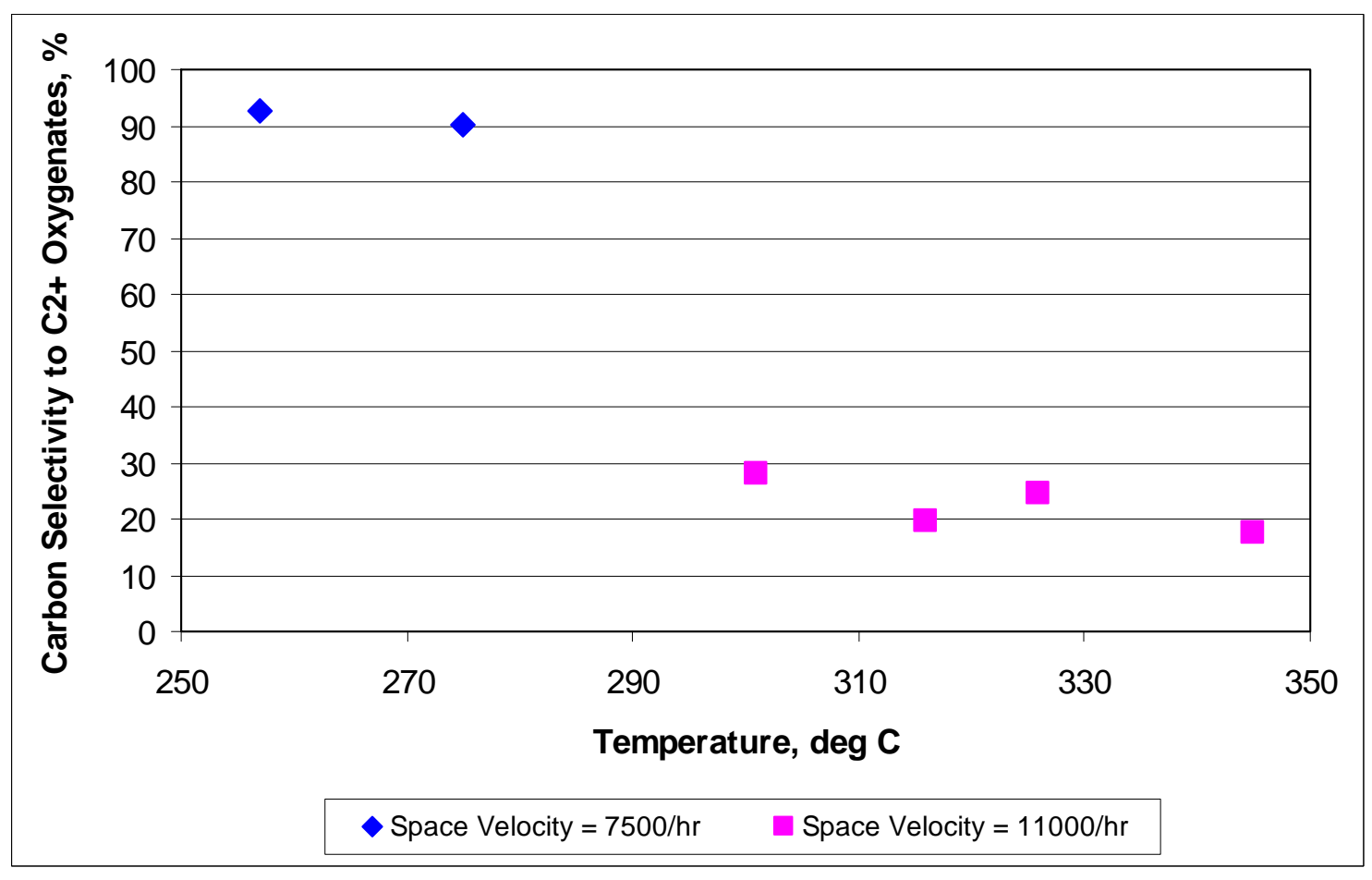

Figure B.8. Carbon Selectivity to $\mathrm{C}_{2}+$ Oxygenates for the $\mathrm{Rh} / \mathrm{SiO}_{2}$ Catalysts 


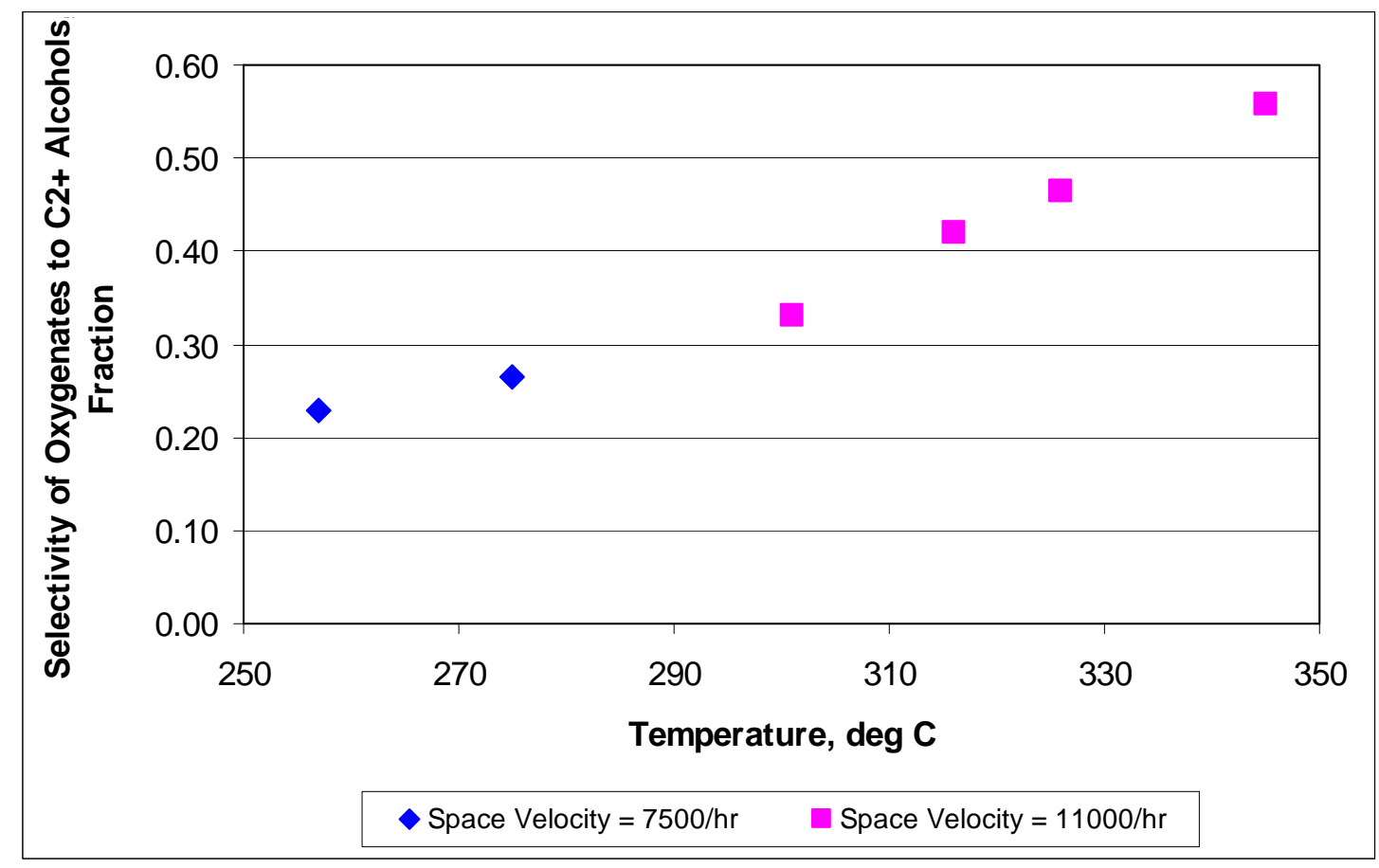

Figure B.9. Carbon Selectivity of All Oxygenates to $\mathrm{C}_{2}+$ Alcohols for the $\mathrm{Rh} / \mathrm{SiO}_{2}$ Catalysts

Figure B.10 shows the selectivity of the $\mathrm{Rh} / \mathrm{SiO}_{2}$ catalyst to hydrocarbons. The selectivity of the catalyst to hydrocarbons was high at all temperatures where hydrocarbons were at concentrations above the detection limit. There also appears to be some deactivation of the catalyst at temperatures above $315^{\circ} \mathrm{C}$. This deactivation resulted in a slight decrease in the selectivity to hydrocarbons.

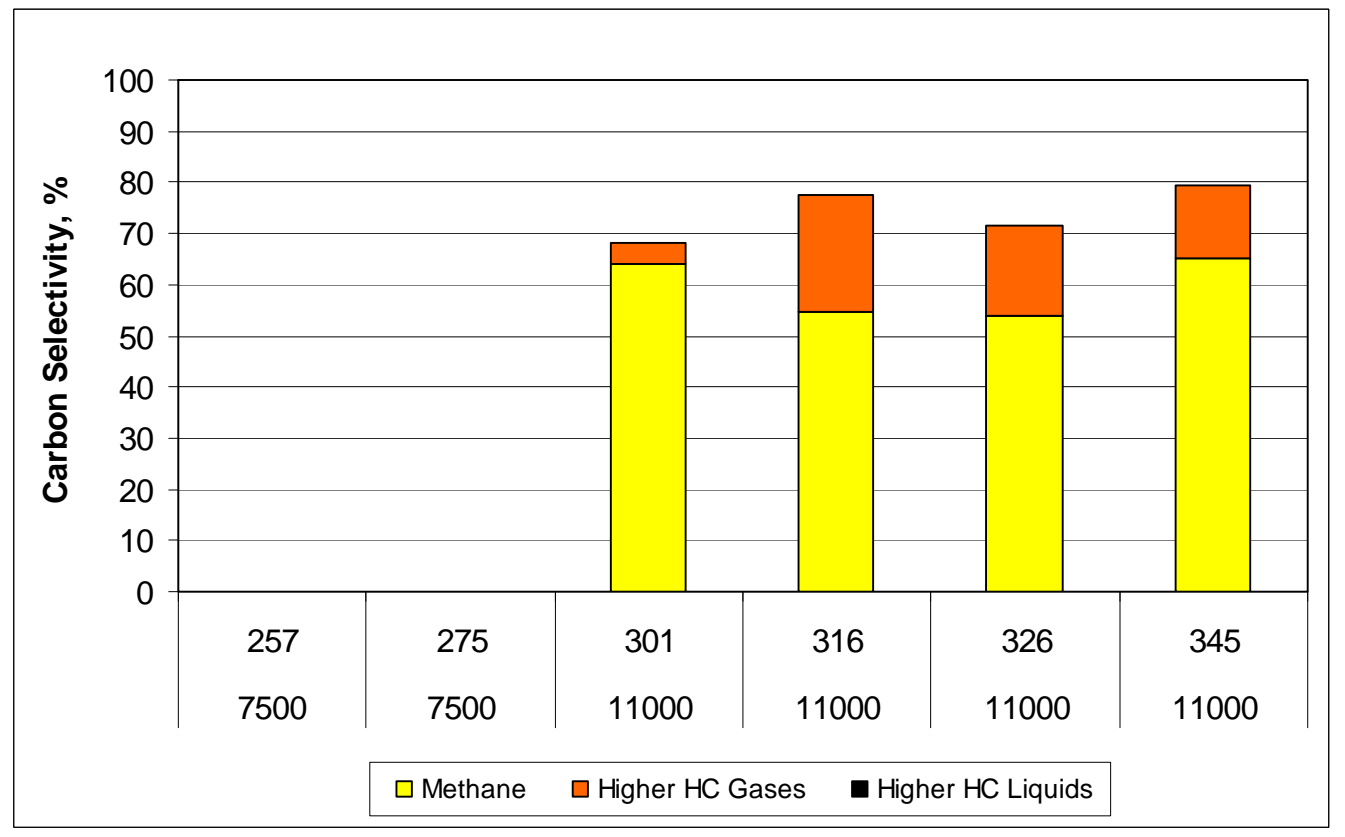

Figure B.10. Comparison of Hydrocarbon Selectivity for the $\mathrm{Rh} / \mathrm{SiO}_{2}$ Catalysts 


\section{B.3 La-Promoted Catalyst}

The La-promoted catalyst ( $\left.\mathrm{RhMnLa} / \mathrm{SiO}_{2}\right)$ was tested at all of the standard conditions up to approximately $325^{\circ} \mathrm{C}$, and with a repeat condition at approximately $300^{\circ} \mathrm{C}$. Further tests were conducted at $325^{\circ} \mathrm{C}$ (at both 7500 and $11,000 \mathrm{~L} / \mathrm{L}_{\text {cat }} / \mathrm{hr}$ ) and at $345^{\circ} \mathrm{C}$ (at $11,000 \mathrm{~L} / \mathrm{L}_{\text {cat }} / \mathrm{hr}$ ). A second repeat condition at $300^{\circ} \mathrm{C}$ to track deactivation of the catalyst also was run. There were no problems with temperature control during the tests.

According to Figure B.11, carbon conversion increased with increasing temperature and lower space velocities, as expected. There was some deactivation of the catalyst over time, however, as indicated by the repeat conditions.

The $\mathrm{C}_{2}+$ oxygenates STYs also increased with increasing temperature up to $325^{\circ} \mathrm{C}$, but decreased at $345^{\circ} \mathrm{C}$ as shown in Figure B.12. The first and second repeat conditions suggest that the catalyst deactivated at the higher temperatures. Catalyst deactivation masked any effect of the space velocity on the STY.

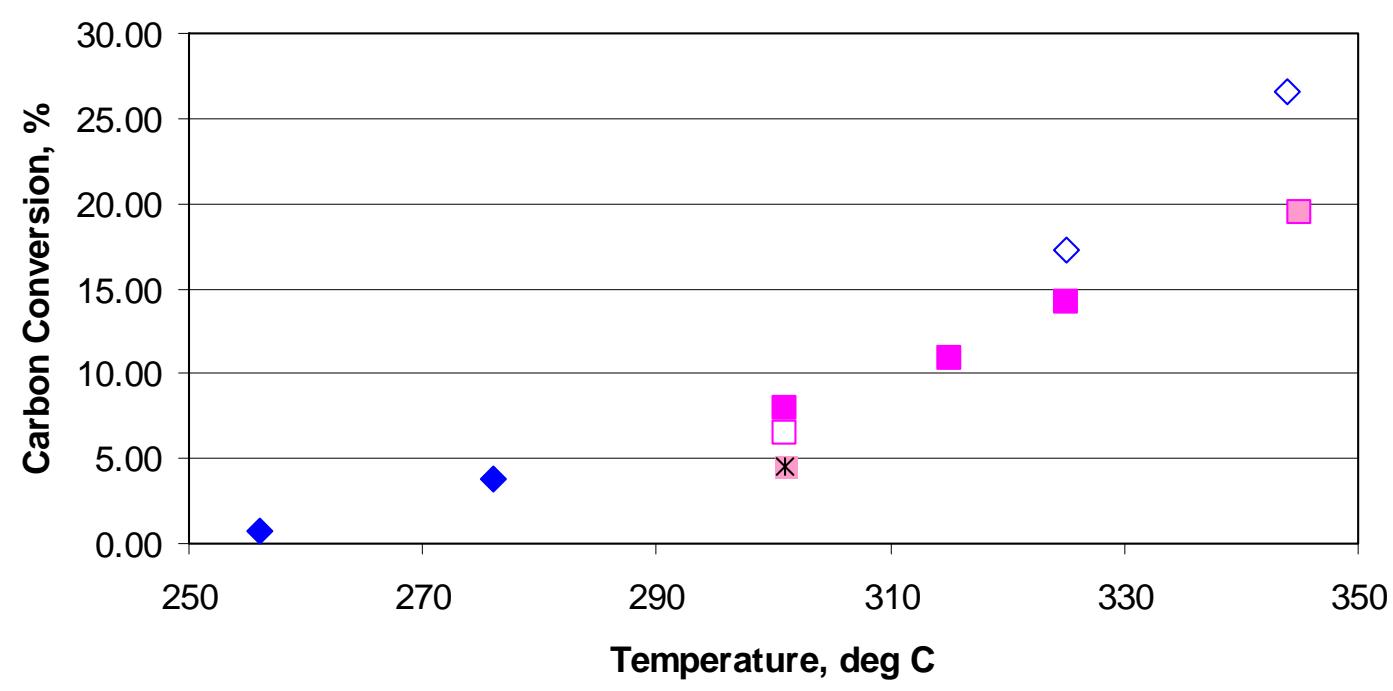

$$
\begin{array}{ll}
\diamond \text { Space Velocity }=7500 / \mathrm{hr} & \square \text { Space Velocity }=11000 / \mathrm{hr} \\
\square \text { Space Velocity }=11000 / \mathrm{hr} \text { (Repeat) } & \diamond \text { Space Velocity }=7500 / \mathrm{hr} \text { (After Repeat) } \\
\square \text { Space Velocity }=11000 / \mathrm{hr} \text { (After Repeat) } & * \text { Space Velocity }=11000 / \mathrm{hr} \text { (2nd Repeat) }
\end{array}
$$

Figure B.11. Carbon Conversion for the La-Promoted Catalyst 


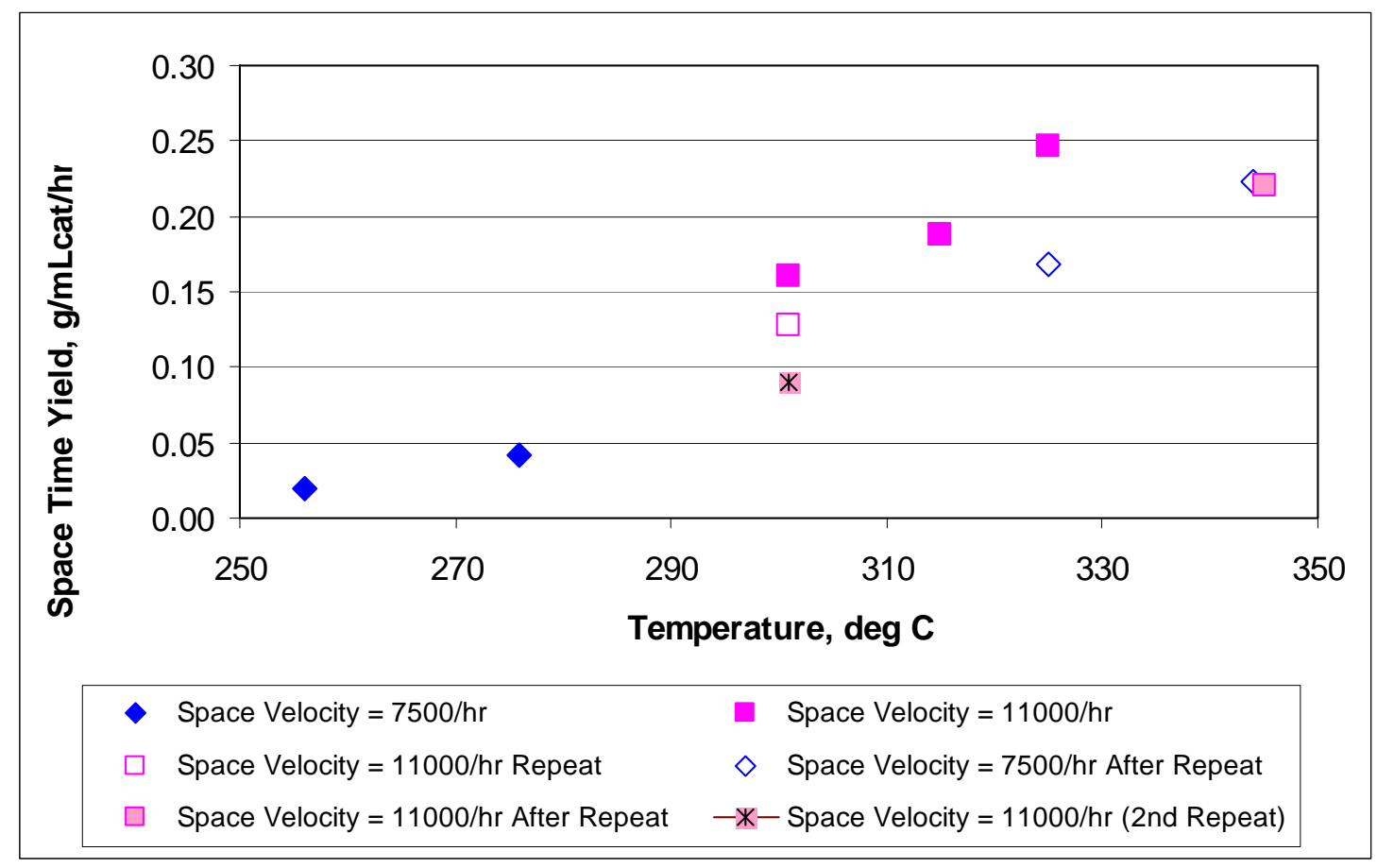

Figure B.12. $\mathrm{C}_{2}+$ Oxygenate STYs for the La-Promoted Catalyst

The effects, of space velocity on carbon selectivity to $\mathrm{C}_{2}+$ oxygenates and to $\mathrm{C}_{2}+$ alcohols, are shown in figures B.13and B.14. The apparent high selectivity to $\mathrm{C}_{2}+$ oxygenates at $256^{\circ} \mathrm{C}$ is misleading because there was a small quantity of $\mathrm{C}_{2}+$ hydrocarbon gases measured in the product gas, but the methane concentration was below detection and reported as zero. Between $275^{\circ} \mathrm{C}$ and $325^{\circ} \mathrm{C}$, carbon selectivity to $\mathrm{C}_{2}+$ oxygenates remained relatively constant between $30 \%$ and $40 \%$, possibly reaching a maximum at $300^{\circ} \mathrm{C}$. The repeat conditions suggest that catalyst deactivation had little if any effect on the selectivity. The selectivity of oxygenates to alcohols was fairly high for this catalyst, and increased with increasing temperature. Results from tests performed at the repeat conditions suggest that the selectivity to alcohols increased as the catalyst deactivated.

Figure B.15 compares the carbon selectivity to hydrocarbons for the La-promoted catalyst. As previously discussed, there was no methane detected at $256^{\circ} \mathrm{C}$, although it was likely present. Results from tests at the repeat conditions at $300^{\circ} \mathrm{C}$ suggest that the carbon selectivity to hydrocarbons decreased slightly as the catalyst deactivated, and the selectivity to methane increased at the expense of the higher hydrocarbon gases. 


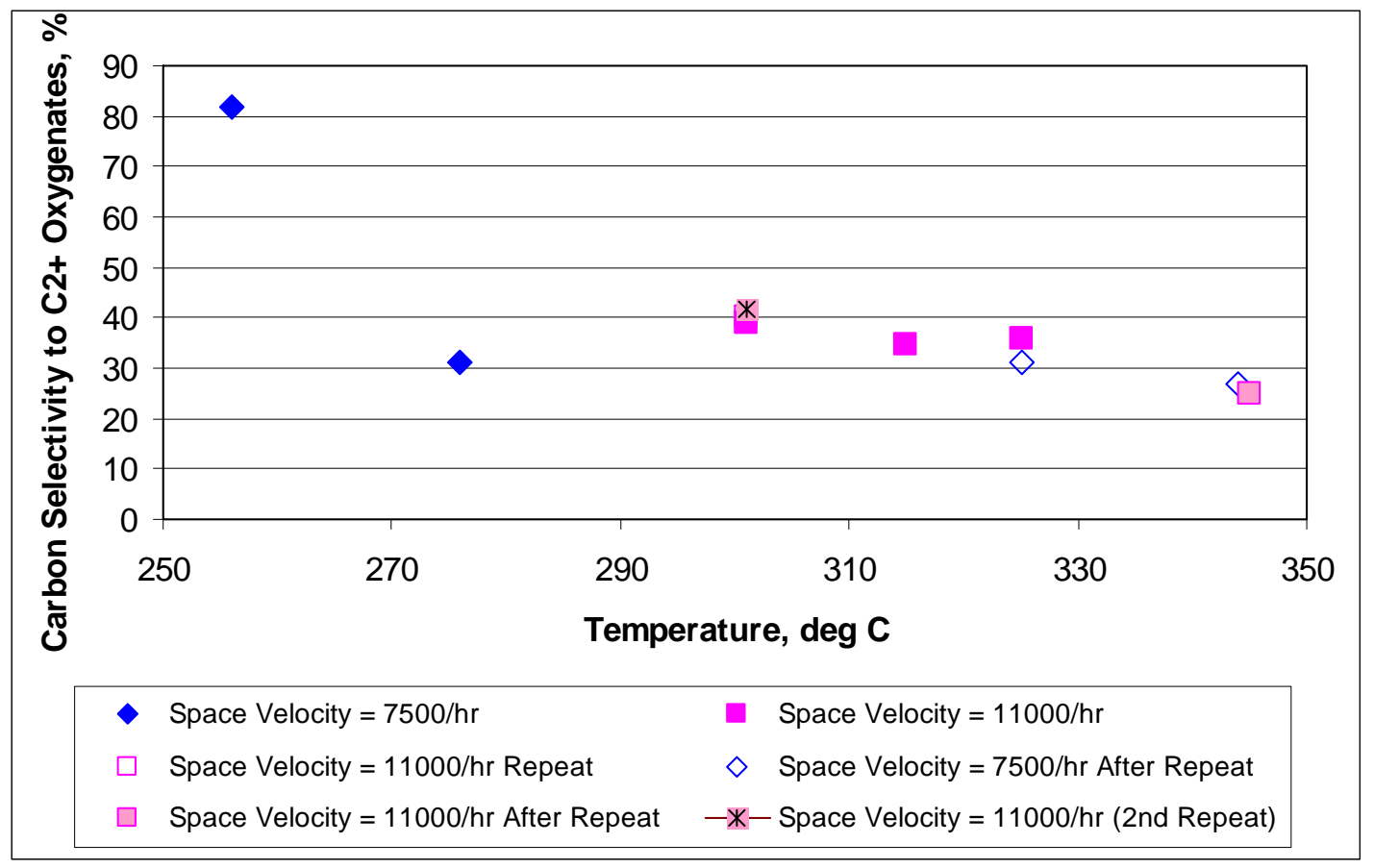

Figure B.13. Converted Carbon Selectivity to $\mathrm{C}_{2}+$ Oxygenates for the La-Promoted Catalyst



Figure B.14. Carbon Selectivity of All Oxygenates to $\mathrm{C}_{2}+$ Alcohols for the La-Promoted Catalyst 


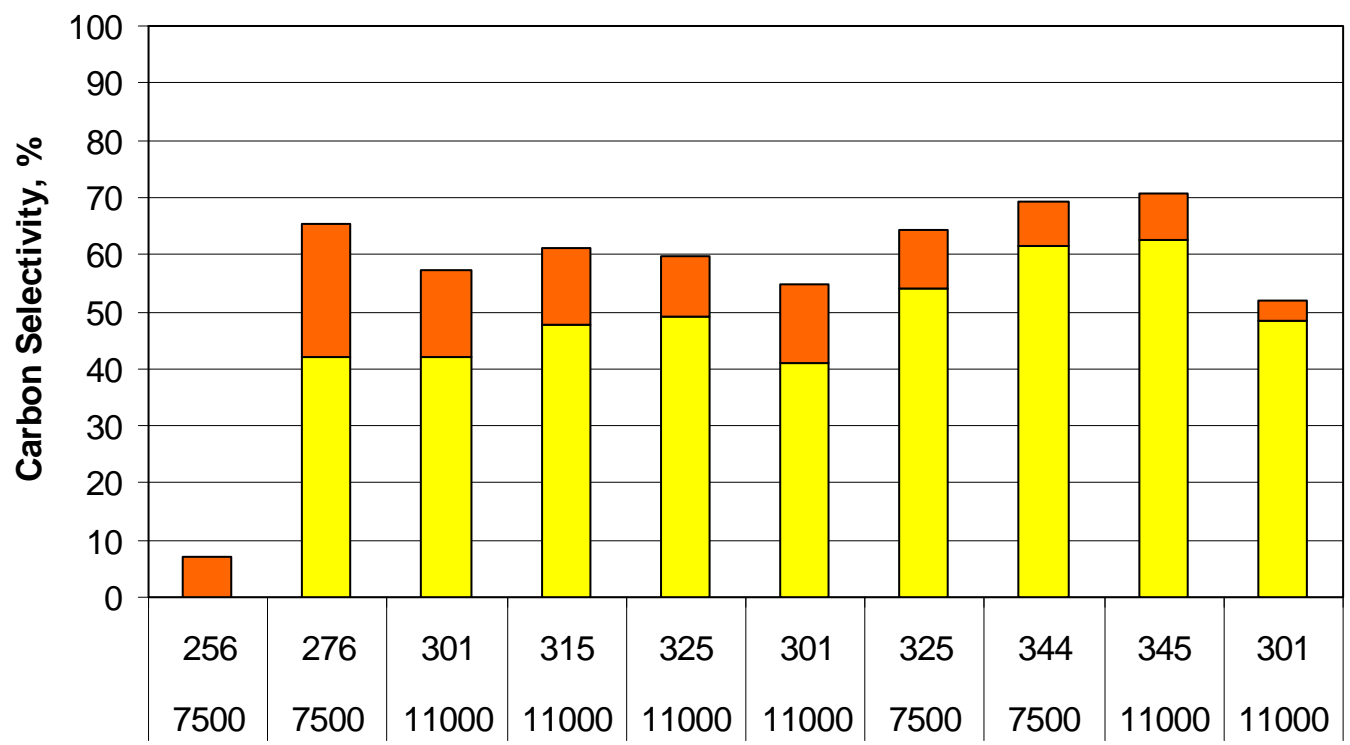

$\square$ Methane $\square$ Higher HC Gases $\square$ Higher HC Liquids

Figure B.15. Comparison of Hydrocarbon Selectivity for the La-Promoted Catalyst

\section{B.4 V-Promoted Catalyst}

The V-promoted catalyst ( $\mathrm{RhMnV} / \mathrm{SiO}_{2}$ ) was tested at the standard conditions up to approximately $325^{\circ} \mathrm{C}$ except for the condition at $315^{\circ} \mathrm{C}$. It was skipped because carbon conversion and the $\mathrm{C}_{2}+$ oxygenates STY were still relatively low at $300^{\circ} \mathrm{C}$. Also, because the catalyst was still not very active at $325^{\circ} \mathrm{C}$, it was also tested at approximately $345^{\circ} \mathrm{C}$ in lieu of a repeat test condition at $300^{\circ} \mathrm{C}$. There were no problems with temperature control during the testing.

Figure B.16 shows that carbon conversion was less than $2 \%$ until the catalyst temperature was increased to $300^{\circ} \mathrm{C}$. It reached a maximum of about $11 \%$ at approximately $345^{\circ} \mathrm{C}$.

Figure B.17 shows that there were small, but measurable, quantities of $\mathrm{C}_{2}+$ oxygenates produced at temperatures as low as $255^{\circ} \mathrm{C}$, and the $\mathrm{C}_{2}+$ oxygenates STY was only $0.10 \mathrm{~g} / \mathrm{L}_{\mathrm{cat}} / \mathrm{hr}$ at $325^{\circ} \mathrm{C}$, which was relatively low. The maximum STY achieved was $0.20 \mathrm{~g} / \mathrm{L}_{\text {cat }} / \mathrm{hr}$ at $345^{\circ} \mathrm{C}$.

Carbon selectivity to the $\mathrm{C}_{2}+$ oxygenates at the lower temperatures are misleading in Figure B.18 because the hydrocarbon concentrations in the product gas were below the detection limit and were reported as zero concentrations. A carbon selectivity to $\mathrm{C}_{2}+$ oxygenates of about $45 \%$ at $300^{\circ} \mathrm{C}$ strongly suggests that the carbon selectivity were less than $90 \%$ at $275^{\circ} \mathrm{C}$. Carbon selectivity to $\mathrm{C}_{2}+$ oxygenates appeared to reach a minimum of about $35 \%$ at $325^{\circ} \mathrm{C}$, and then remained about the same at $345^{\circ} \mathrm{C}$. This behavior is different than most of the other catalysts tested, in which the selectivity continued to decrease as temperature increased. This phenomenon is consistent with the continually increasing $\mathrm{C}_{2}+$ oxygenates STY at $345^{\circ} \mathrm{C}$ and suggests that the catalyst did not undergo significant deactivation at the higher temperatures. The selectivity of the oxygenates to $\mathrm{C}_{2}+$ alcohols also appeared to reach a plateau at $325^{\circ} \mathrm{C}$ to $345^{\circ} \mathrm{C}$ at between $60 \%$ and $70 \%$ as shown in Figure B.19. Figure B.20 shows that there was a slight decrease in the carbon selectivity to hydrocarbons and, specifically, a lower selectivity to the $\mathrm{C}_{2}+$ 
hydrocarbon gases as the temperature increased from $325^{\circ} \mathrm{C}$ to $345^{\circ} \mathrm{C}$. Taken together, it appears that the catalyst is fairly stable up to $325^{\circ} \mathrm{C}$ and then undergoes minor deactivation at $345^{\circ} \mathrm{C}$ that results in improvements in the catalyst with respect to the selectivity to $\mathrm{C}_{2}+$ oxygenates and possibly an accompanying increase in the $\mathrm{C}_{2}+$ oxygenates STY. The latter is inferred mainly because the carbon conversion and the $\mathrm{C}_{2}+$ oxygenates STY show no sign of reaching a maximum at $345^{\circ} \mathrm{C}$, while the selectivity to the $\mathrm{C}_{2}+$ oxygenates remains almost constant at the higher temperature.

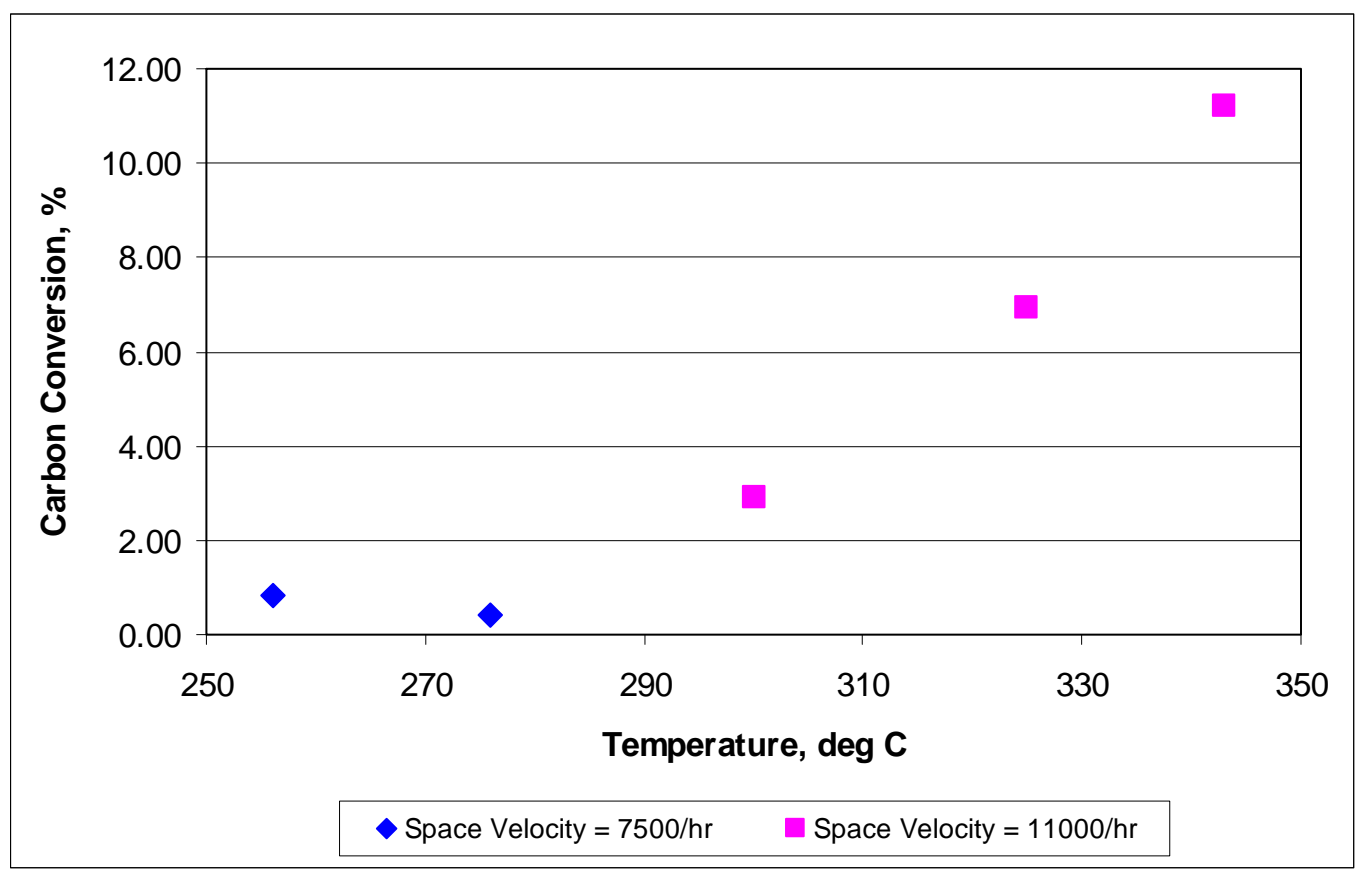

Figure B.16. Carbon Conversion for the V-Promoted Catalyst

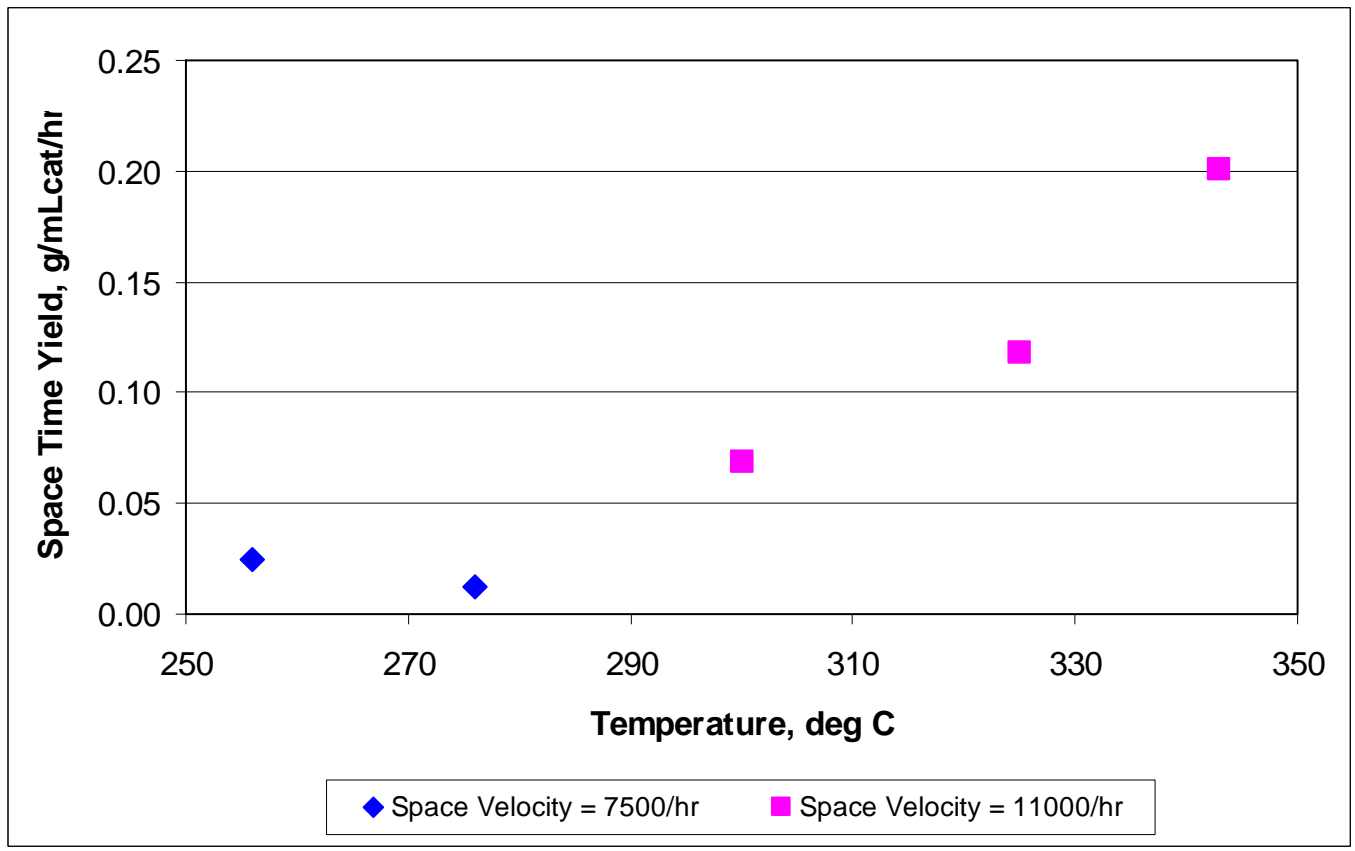

Figure B.17. $\mathrm{C}_{2}+$ Oxygenate STYs for the V-Promoted Catalyst 




Figure B.18. Converted Carbon Selectivity to $\mathrm{C}_{2}+$ Oxygenates for the V-Promoted Catalyst

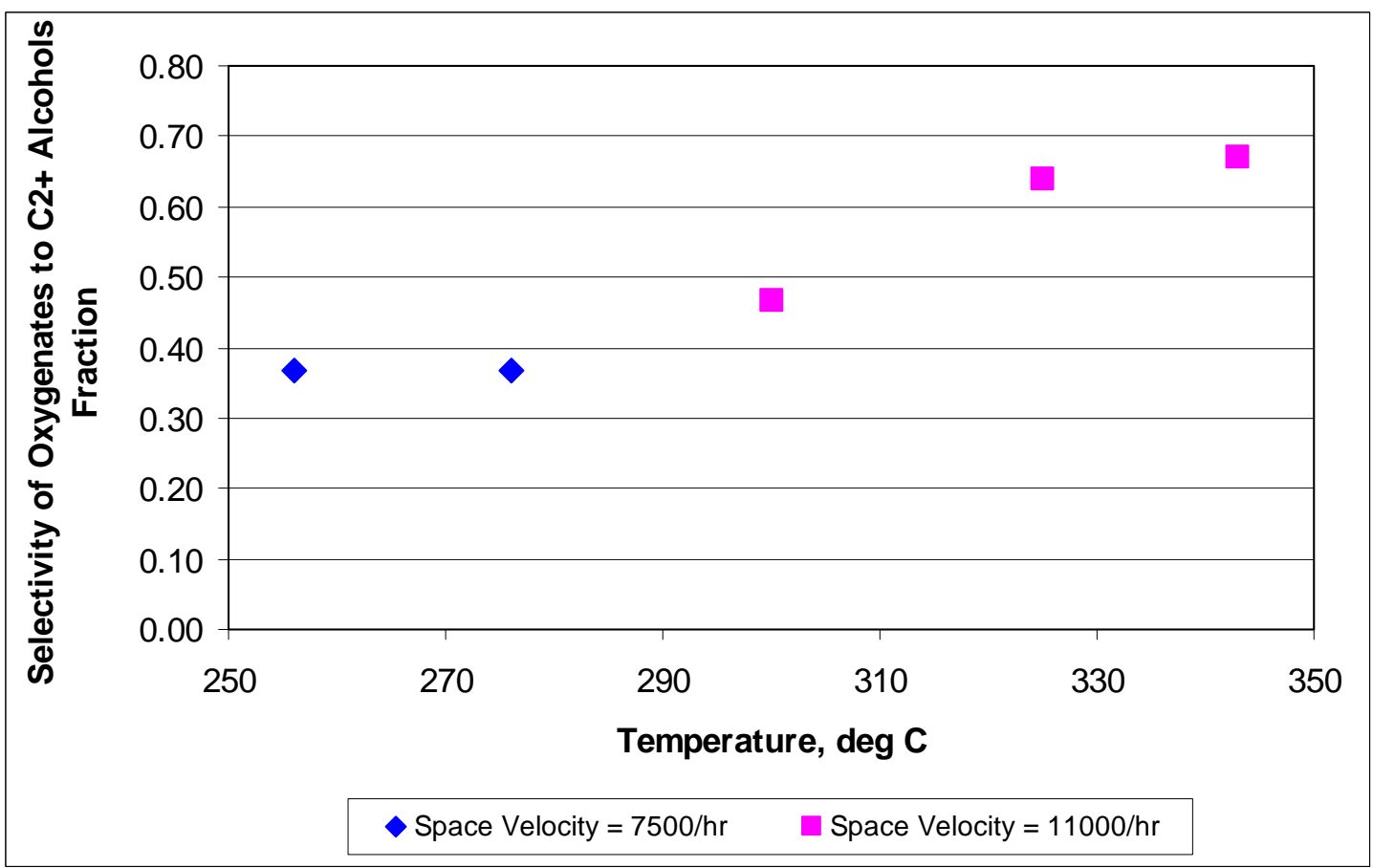

Figure B.19. Carbon Selectivity of All Oxygenates to $C_{2}+$ Alcohols for the V-Promoted Catalyst 


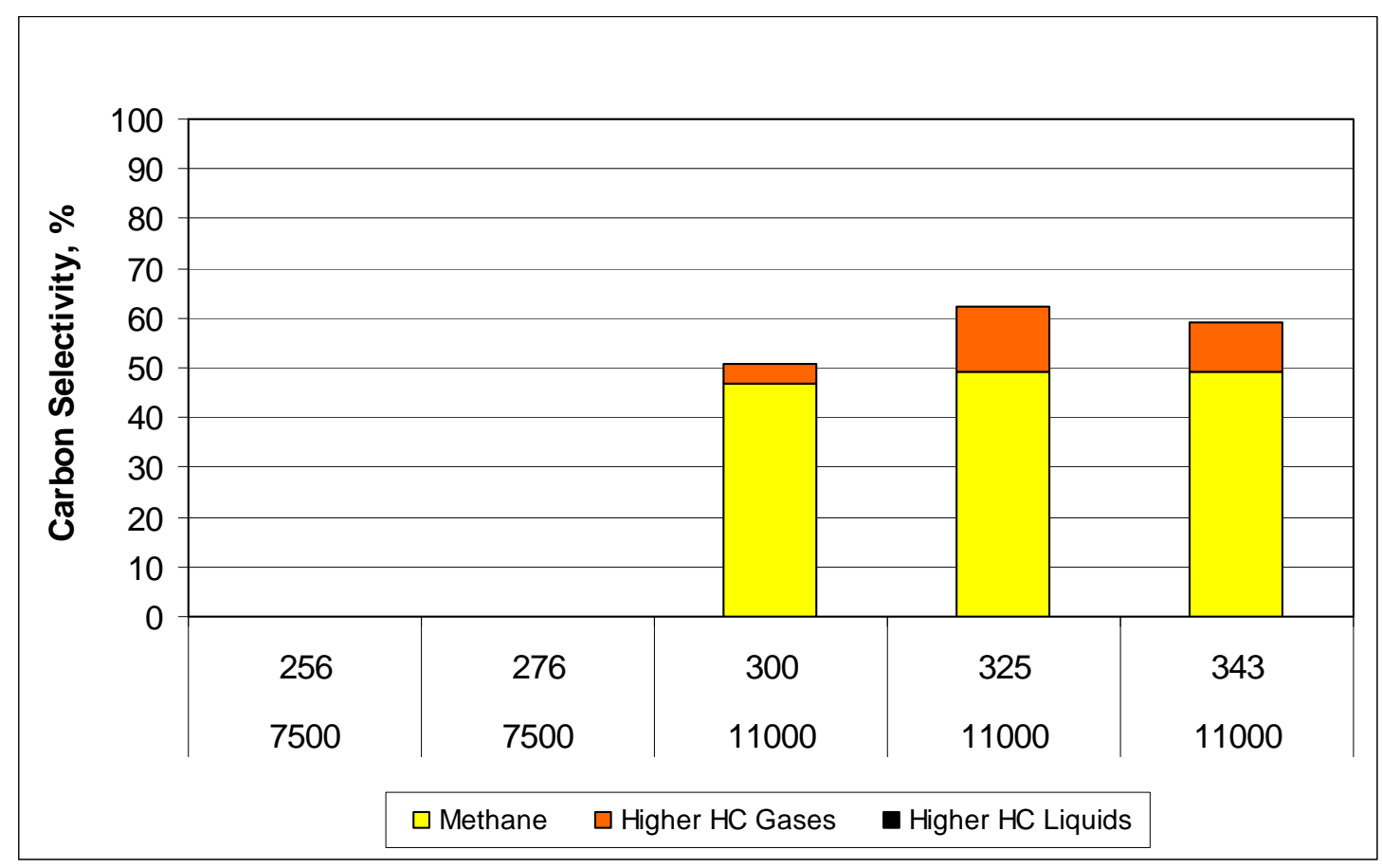

Figure B.20. Comparison of Hydrocarbon Selectivity for the V-Promoted Catalyst

\section{B.5 Mg-Promoted Catalyst}

The Mg-promoted catalyst $\left(\mathrm{RhMnMg} / \mathrm{SiO}_{2}\right)$ was tested at all of the standard conditions up to approximately $325^{\circ} \mathrm{C}$, and with a repeat condition at approximately $300^{\circ} \mathrm{C}$. There were no problems with temperature control during the tests.

Figure B.21 shows that carbon conversion increases with increasing temperature up to the maximum test temperature of $325^{\circ} \mathrm{C}$. The repeat condition indicates that there was a slight deactivation of the catalyst at the higher temperatures.

The $\mathrm{C}_{2}+$ oxygenates STY behaved in a similar manner as the carbon conversion except at $275^{\circ} \mathrm{C}$, where the STY was slightly lower than it was at $256^{\circ} \mathrm{C}$ as shown in Figure B.22. This is attributed to a significant decrease in the carbon selectivity to $\mathrm{C}_{2}+$ oxygenates when the temperature was increased from $256^{\circ} \mathrm{C}$ to $275^{\circ} \mathrm{C}$ as shown in Figure B.23. While the decrease in selectivity could have resulted at least in part to the detection limit of the GC to the various hydrocarbons, they were there in measureable quantities at $256^{\circ} \mathrm{C}$, and the carbon conversion at this temperature was nearly $4 \%$. However, the decrease in the $\mathrm{C}_{2}+$ oxygenates STY does not depend on the amount of hydrocarbons measured, indicating that the catalyst behavior changed to making more hydrocarbons instead of oxygenates as the catalyst temperature was increased. At temperatures above $275^{\circ} \mathrm{C}$, the selectivity to $\mathrm{C}_{2}+$ oxygenates remained in a band between $30 \%$ and $40 \%$ even as the catalyst further deactivated as indicated by the results from the repeat condition shown in Figure B.23. 
Figure B.24 shows that the selectivity of oxygenates to $\mathrm{C}_{2}+$ alcohols increased with increasing temperature. The maximum selectivity obtained at $325^{\circ} \mathrm{C}$ was intermediate between that achieved with the $\mathrm{RhMn} / \mathrm{SiO}_{2}$ and the La- and V-promoted catalysts.

Figure B.25 further illustrates the change in selectivity towards more hydrocarbons as the temperature increased from $256^{\circ} \mathrm{C}$ to $275^{\circ} \mathrm{C}$. There also appears to be some further changes occurring between $275^{\circ} \mathrm{C}$ and $300^{\circ} \mathrm{C}$. However, all of the total selectivity to hydrocarbons for the temperature range of $275^{\circ} \mathrm{C}$ to $325^{\circ} \mathrm{C}$, including the repeat condition, remained within a band between $60 \%$ and $68 \%$, suggesting that the catalyst selectivity was not particularly sensitive to temperatures above $275^{\circ} \mathrm{C}$.

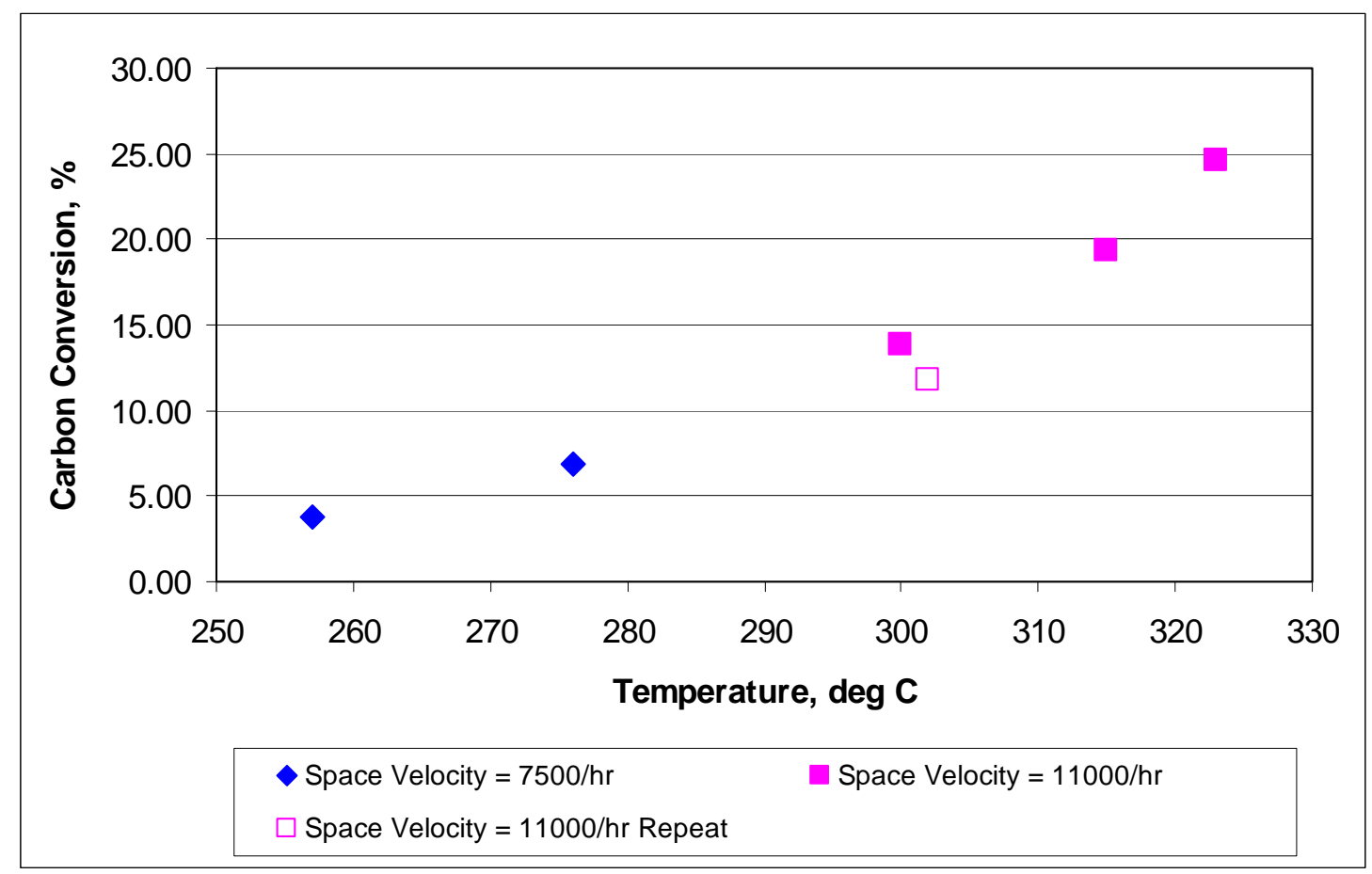

Figure B.21. Carbon Conversion for the Mg-Promoted Catalyst 


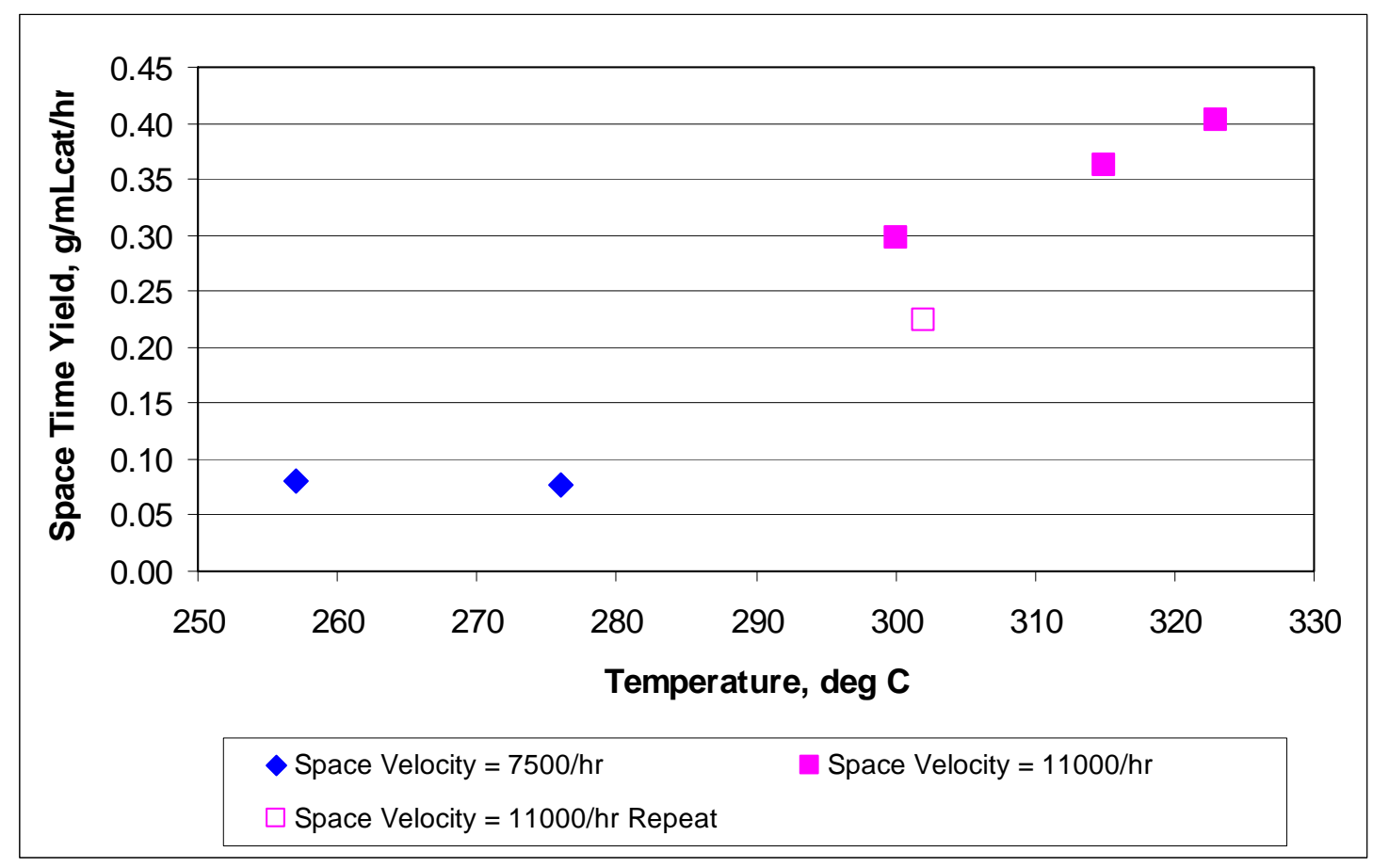

Figure B.22. $C_{2}+$ Oxygenate STYs for the Mg-Promoted Catalyst

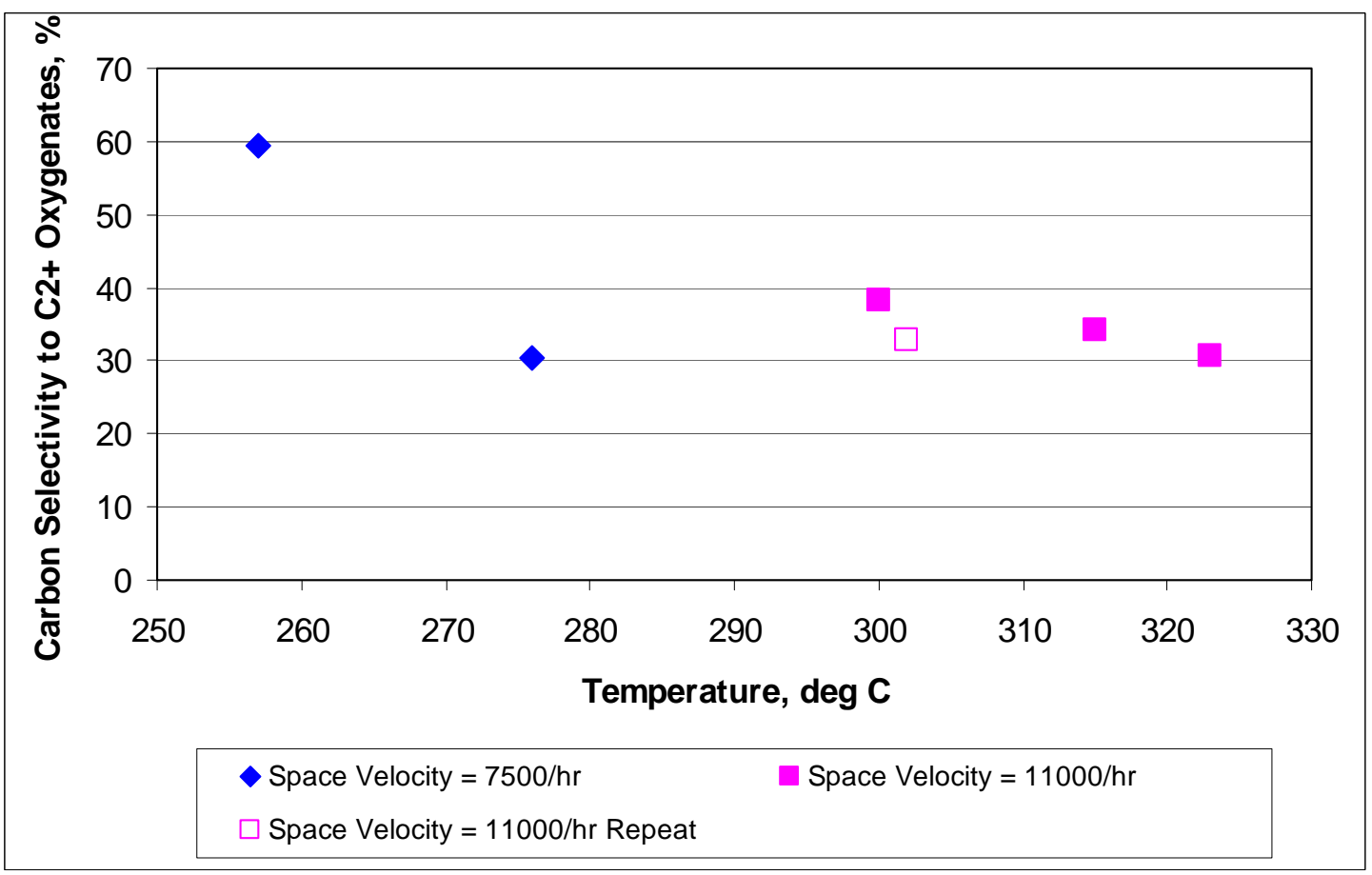

Figure B.23. Converted Carbon Selectivity to $\mathrm{C}_{2}+$ Oxygenates for the Mg-Promoted Catalyst 


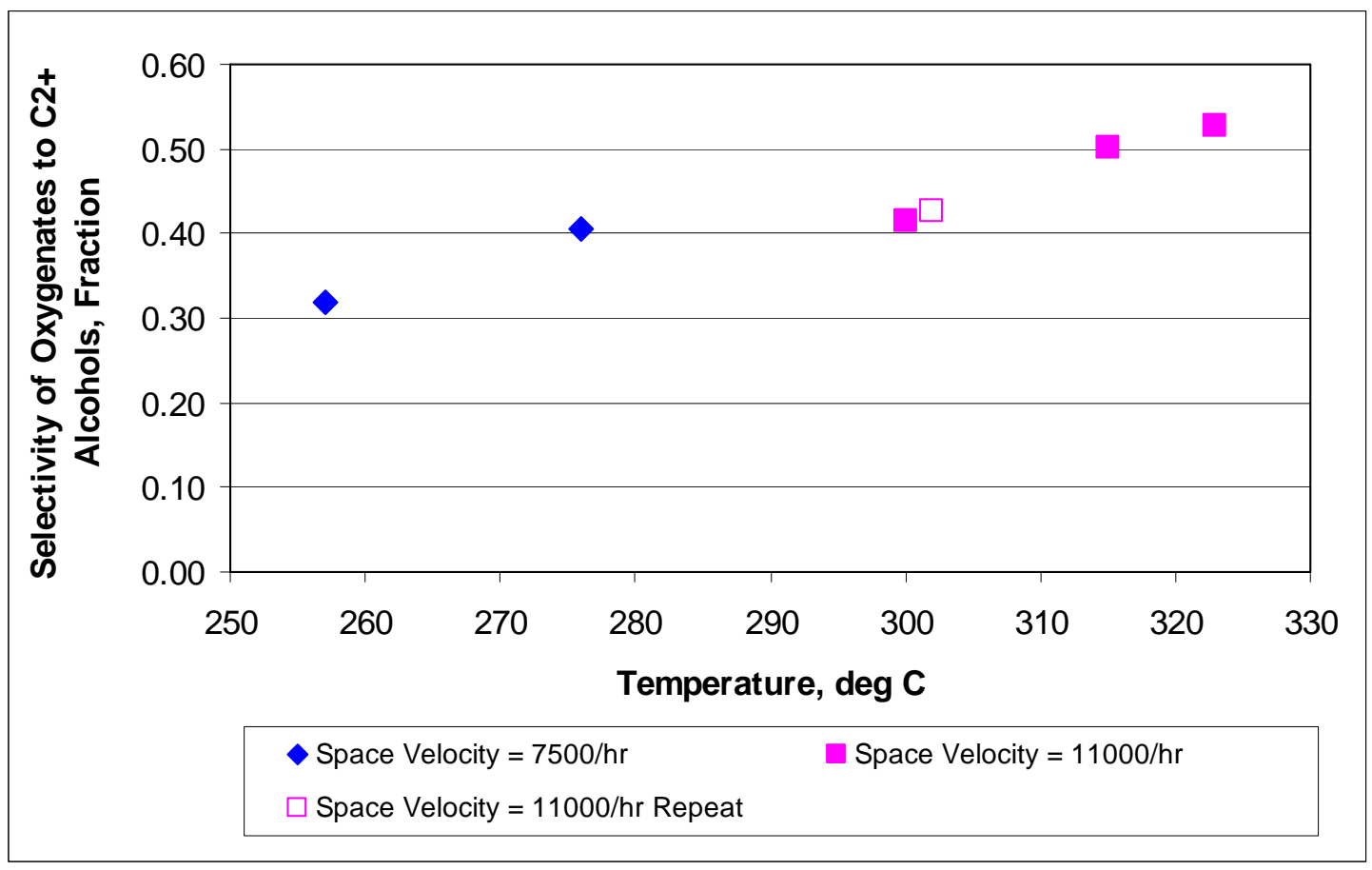

Figure B.24. Carbon Selectivity of All Oxygenates to $\mathrm{C}_{2}+$ Alcohols for the Mg-Promoted Catalyst

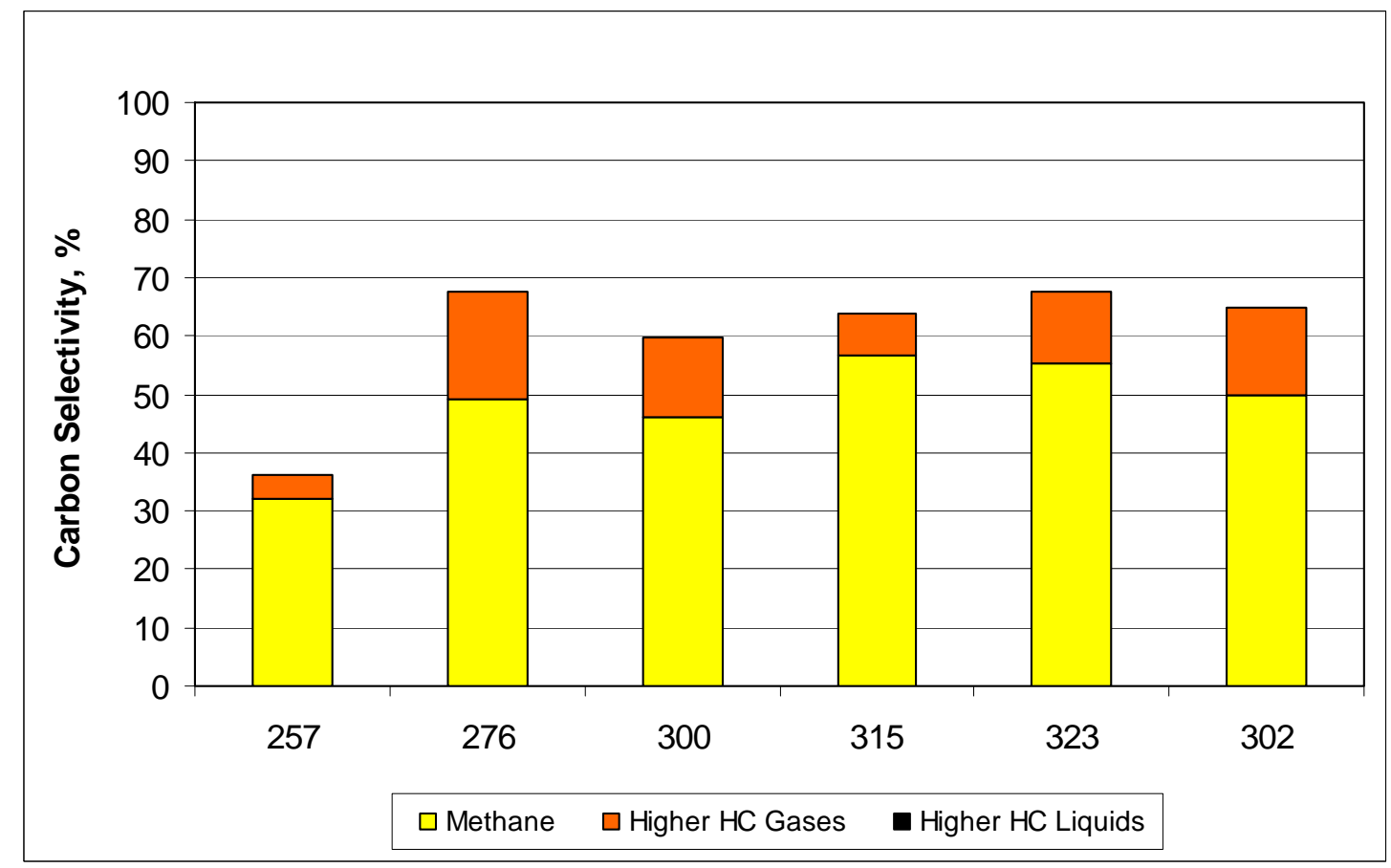

Figure B.25. Comparison of Hydrocarbon Selectivity for the Mg-Promoted Catalyst 


\section{B.6 Ce-Promoted Catalyst}

The Ce-promoted catalyst $\left(\mathrm{RhMnCe} / \mathrm{SiO}_{2}\right)$ was tested at all of the standard conditions up to approximately $325^{\circ} \mathrm{C}$, but no repeat condition was performed. There were no problems with temperature control during the tests.

The Ce-promoted catalyst was not very active at all conditions tested, achieving a maximum carbon conversion of a little over 5\% (Figure B.26) and a $\mathrm{C}_{2}+$ oxygenates STY of $82 \mathrm{~g} / \mathrm{L}_{\text {cat }} / \mathrm{hr}$ (Figure B.27) at the maximum temperature of $325^{\circ} \mathrm{C}$. The carbon selectivity to $\mathrm{C}_{2}+$ oxygenates shown in Figure B.28 are misleading at the two lowest temperatures tested because the hydrocarbon concentrations were below the detection limit and reported as zero as shown in Figure B.29. The selectivity to $\mathrm{C}_{2}+$ oxygenates was relatively constant between $36 \%$ and $39 \%$ over the temperature range of $300^{\circ} \mathrm{C}$ to $325^{\circ} \mathrm{C}$ as shown in Figure 28. Similarly, the carbon selectivity to hydrocarbons was relatively constant at between $49 \%$ and $53 \%$ over the same temperature range. The selectivity of oxygenates to $\mathrm{C}_{2}+$ alcohols increased with increasing temperature, reaching a maximum of about $58 \%$ as shown in Figure B. 30 .

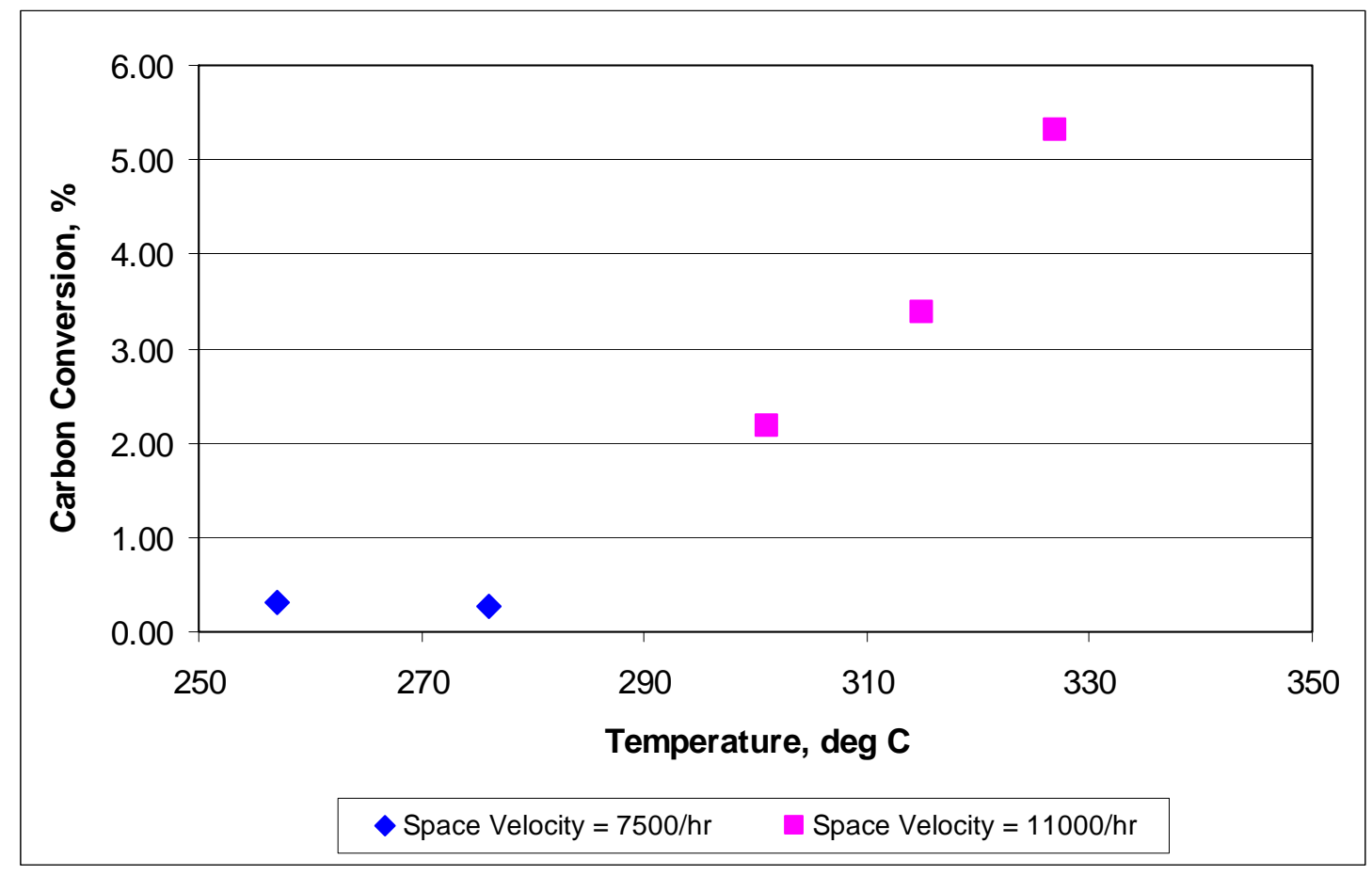

Figure B.26. Carbon Conversion for the Ce-Promoted Catalyst 


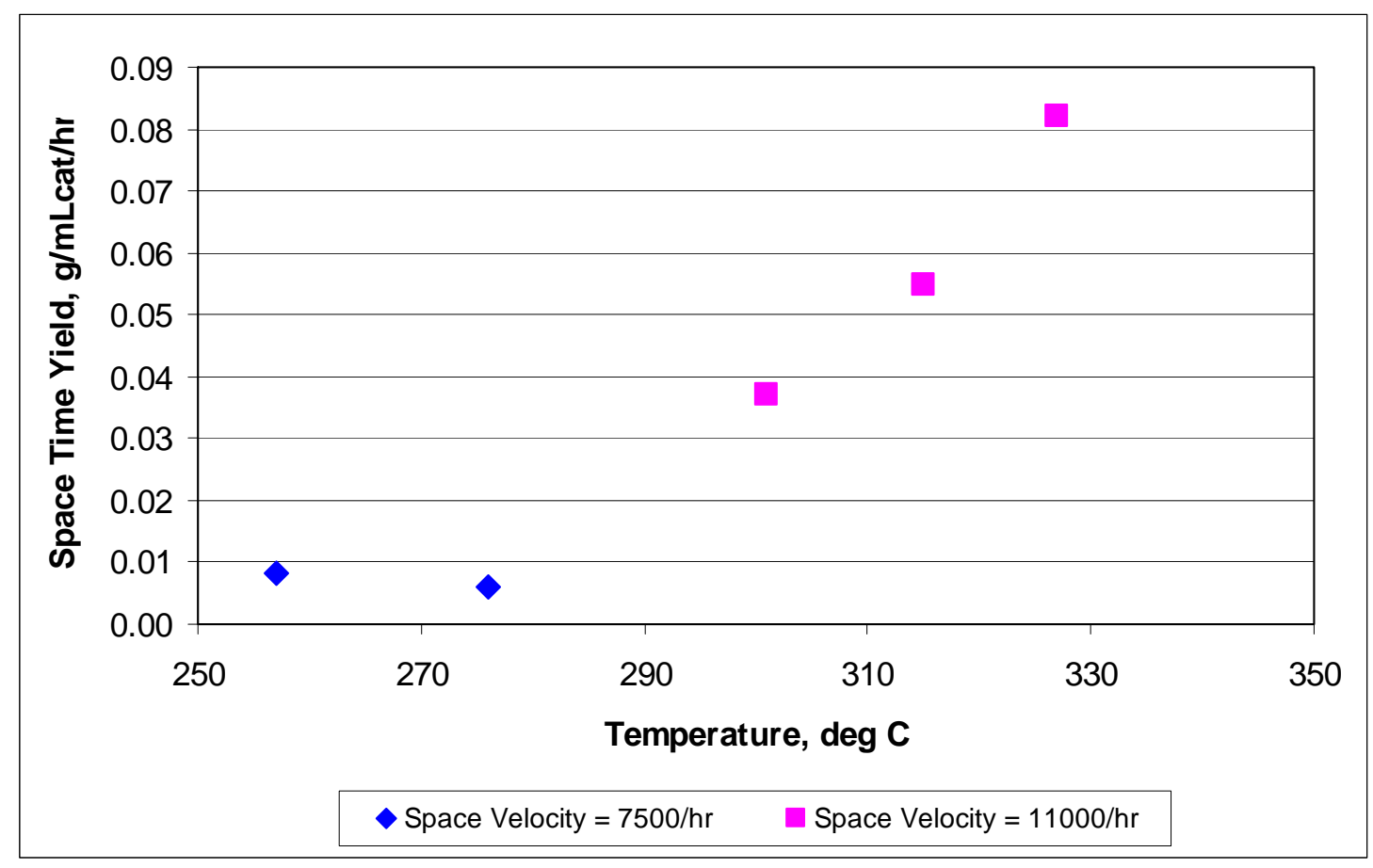

Figure B.27. $\mathrm{C}_{2}+$ Oxygenate STYs for the Ce-Promoted Catalyst

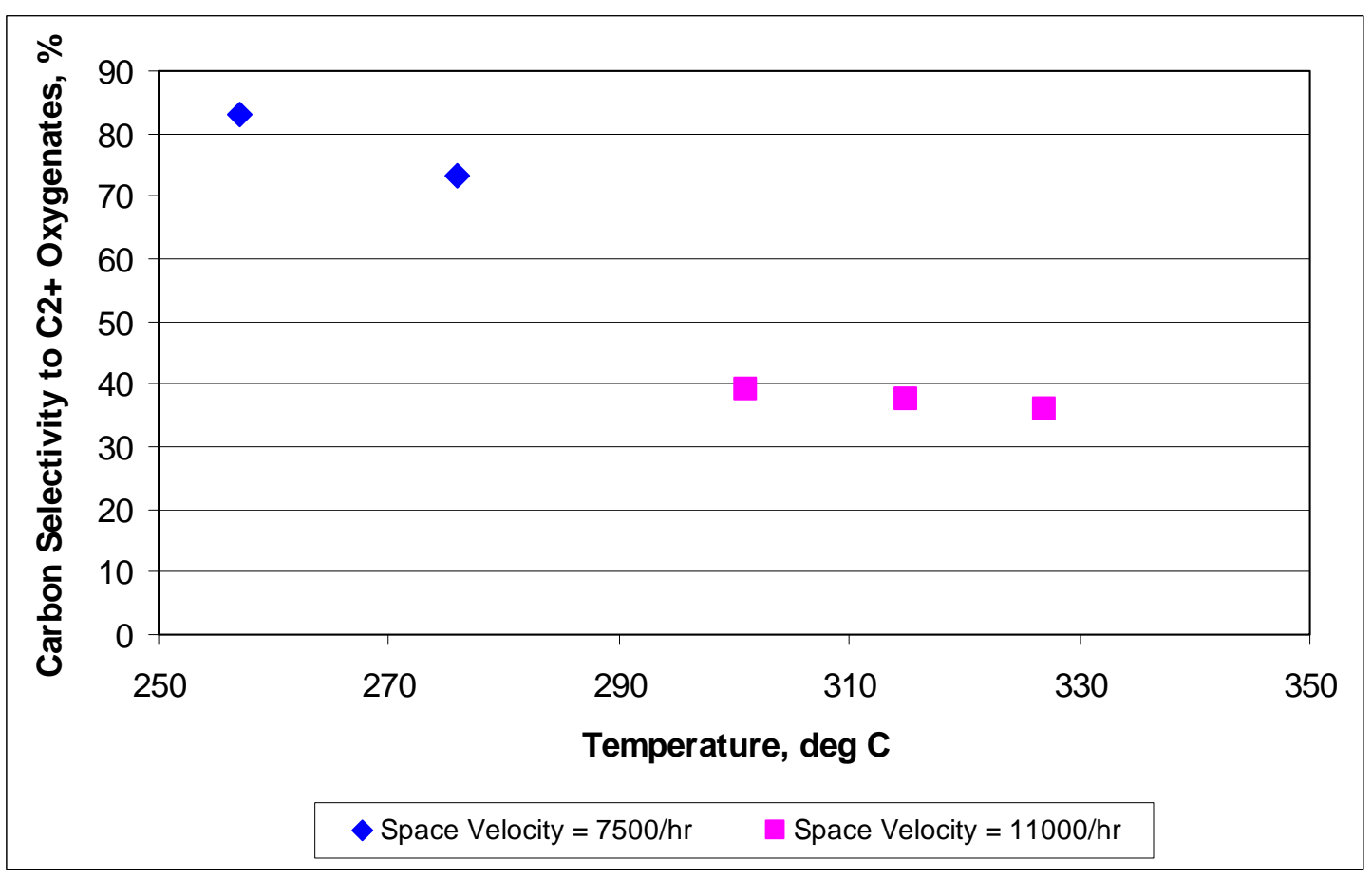

Figure B.28. Converted Carbon Selectivity to $\mathrm{C}_{2}+$ Oxygenates for the Ce-Promoted Catalyst 




Figure B.29. Comparison of Hydrocarbon Selectivity for the Ce-Promoted Catalyst



Figure B.30. Carbon Selectivity of All Oxygenates to $\mathrm{C}_{2}+$ Alcohols for the Ce-Promoted Catalyst 


\section{B.7 Na-Promoted Catalyst}

The Na-promoted catalyst $\left(\mathrm{RhMnNa} / \mathrm{SiO}_{2}\right)$ was tested at all of the standard conditions up to approximately $345^{\circ} \mathrm{C}$, but no repeat condition was performed. There were no problems with temperature control during the tests.

The Na-promoted catalyst was not active at temperatures up to $275^{\circ} \mathrm{C}$ and was barely active at the higher temperatures, achieving a maximum carbon conversion of a little over $4 \%$ (Figure B.31) and a $\mathrm{C}_{2}+$ oxygenates STY of $74 \mathrm{~g} / \mathrm{L}_{\text {cat }} / \mathrm{hr}$ (Figure B.32) at the maximum temperature of $345^{\circ} \mathrm{C}$. The carbon selectivity to $\mathrm{C}_{2}+$ oxygenates shown in Figure B.33 are misleading at all but the highest temperatures tested because the methane concentrations were below the detection limit and were reported as zero as shown in Figure B.34 (some higher hydrocarbon gases were detected at the $300^{\circ} \mathrm{C}$ test condition).

Selectivity of oxygenates to $\mathrm{C}_{2}+$ alcohols increased with increasing temperature as shown in Figure B.35, but were slightly lower than those achieved with the $\mathrm{RhMn} / \mathrm{SiO}_{2}$ catalyst at comparable temperatures.

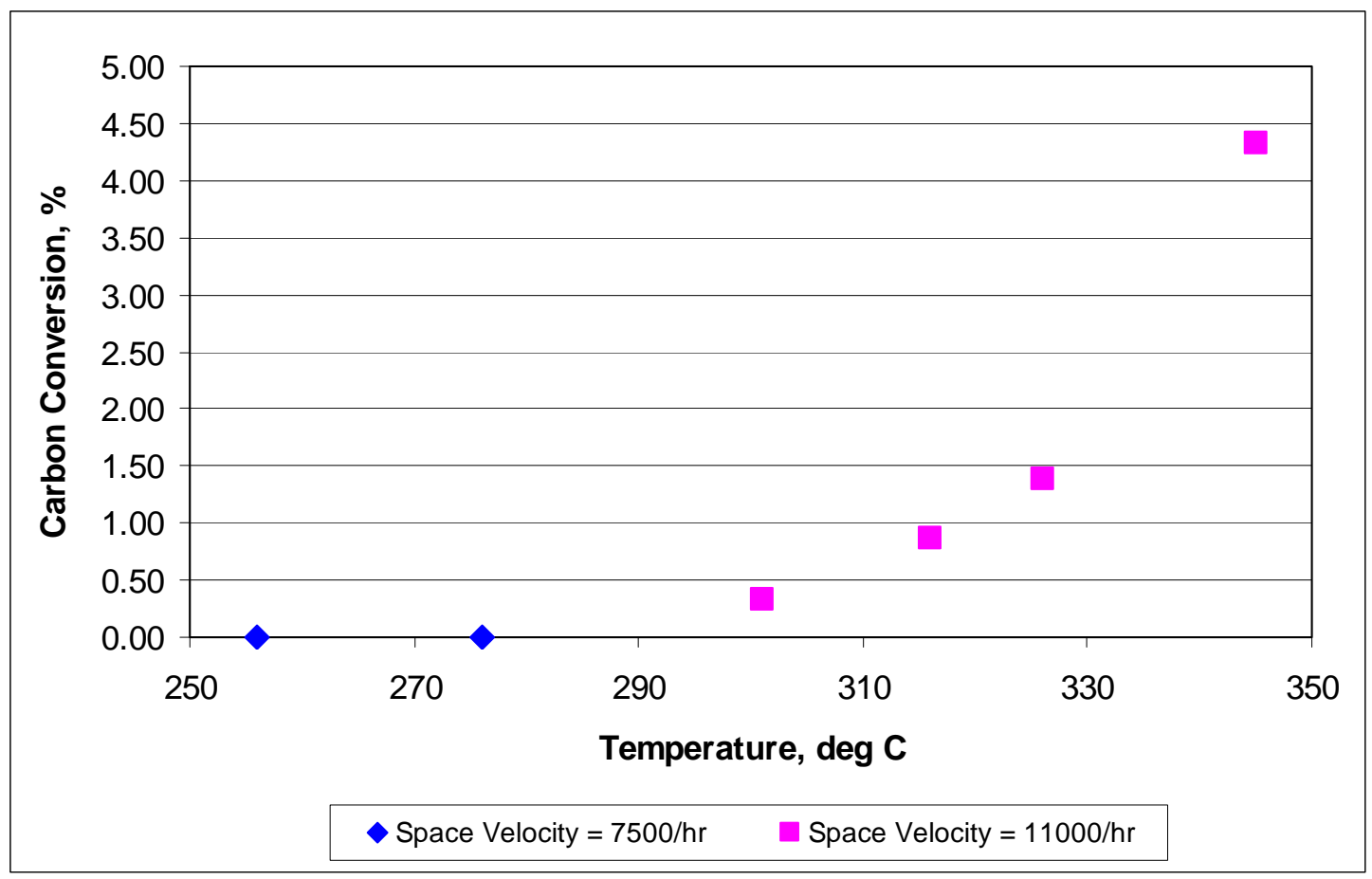

Figure B.31. Carbon Conversion for the Na-Promoted Catalyst 


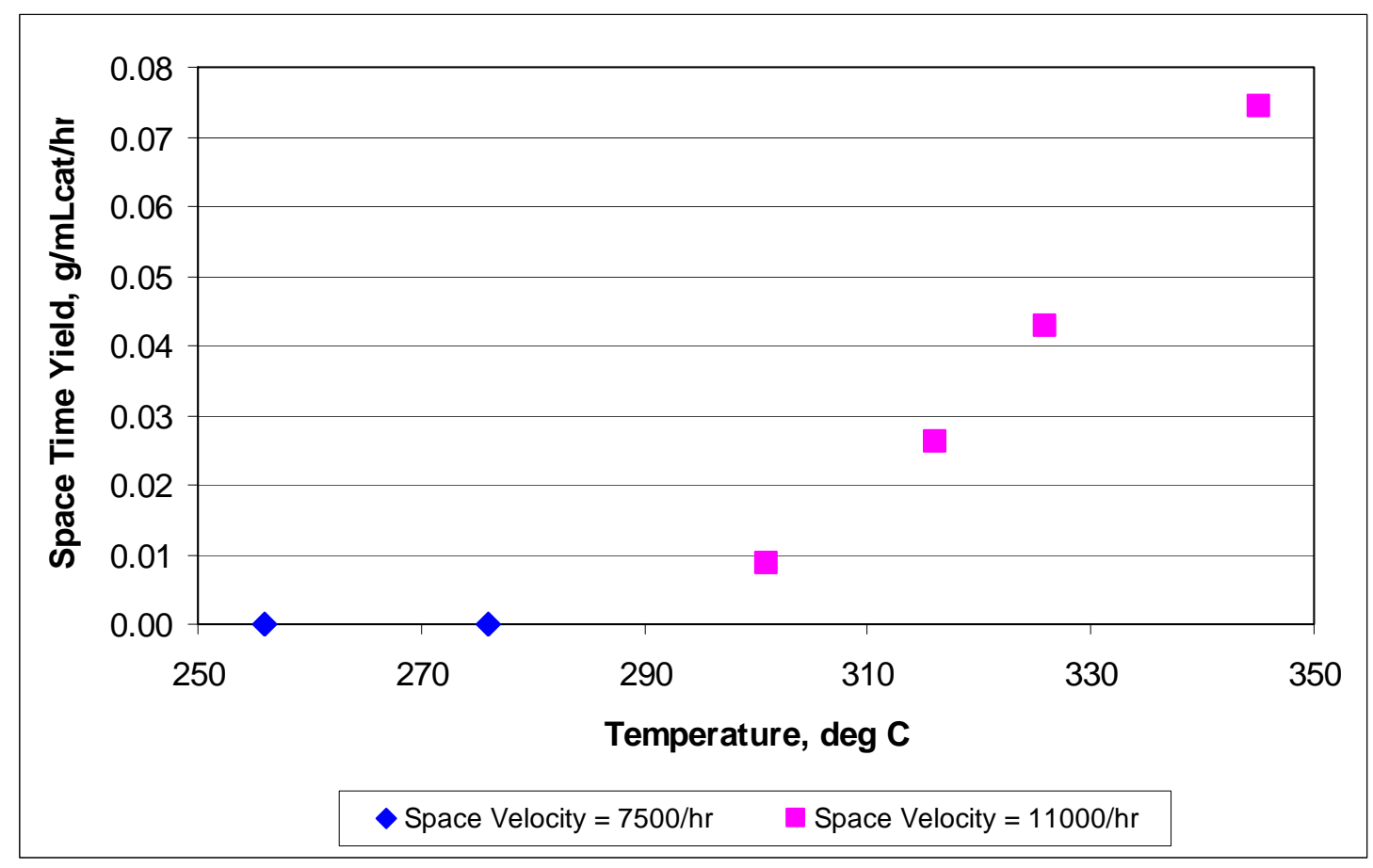

Figure B.32. $\mathrm{C}_{2}+$ Oxygenate STYs for the Na-Promoted Catalyst

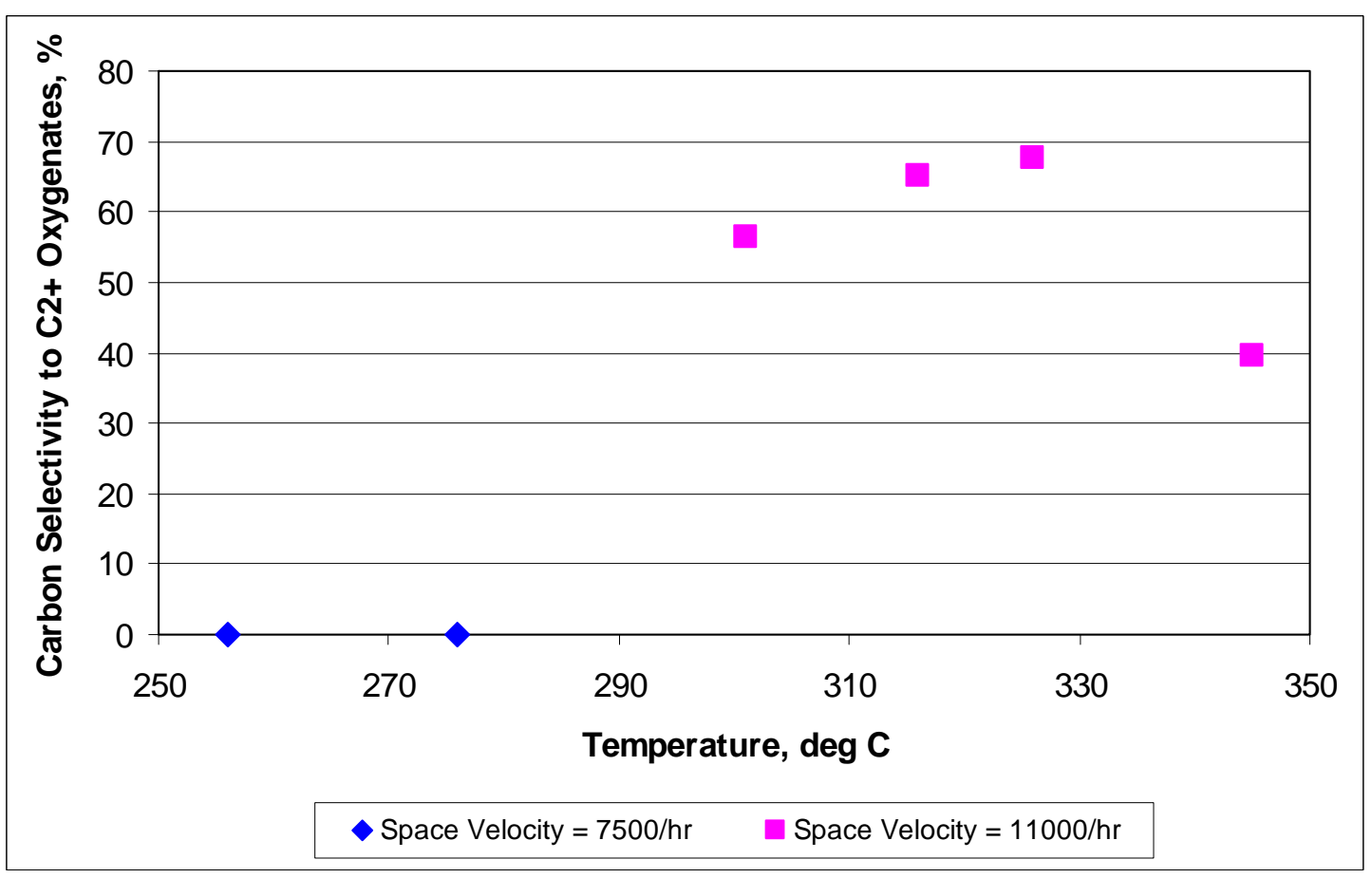

Figure B.33. Converted Carbon Selectivity to $\mathrm{C}_{2}+$ Oxygenates for the Na-Promoted Catalyst 


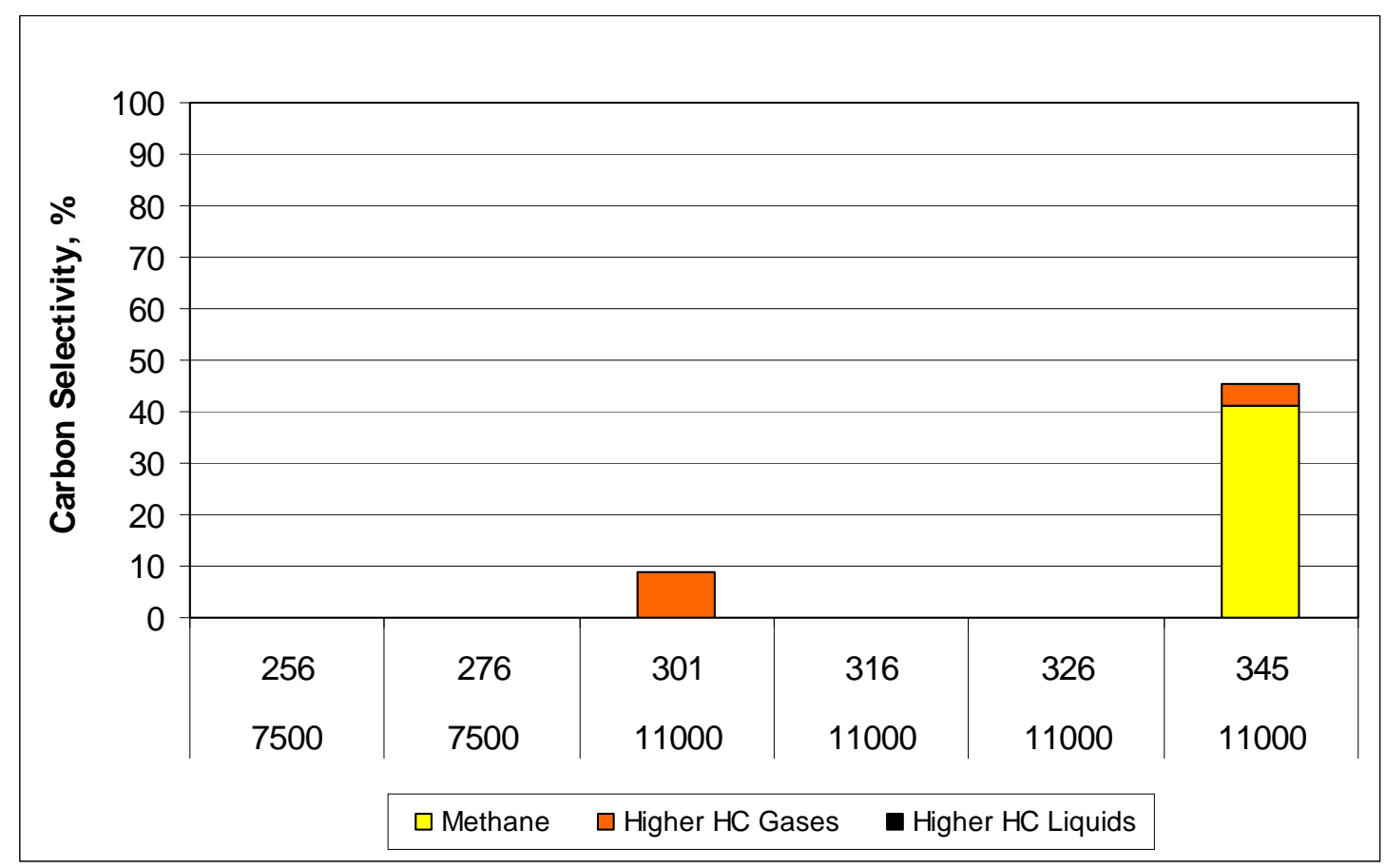

Figure B.34. Comparison of Hydrocarbon Selectivity for the Na-Promoted Catalyst

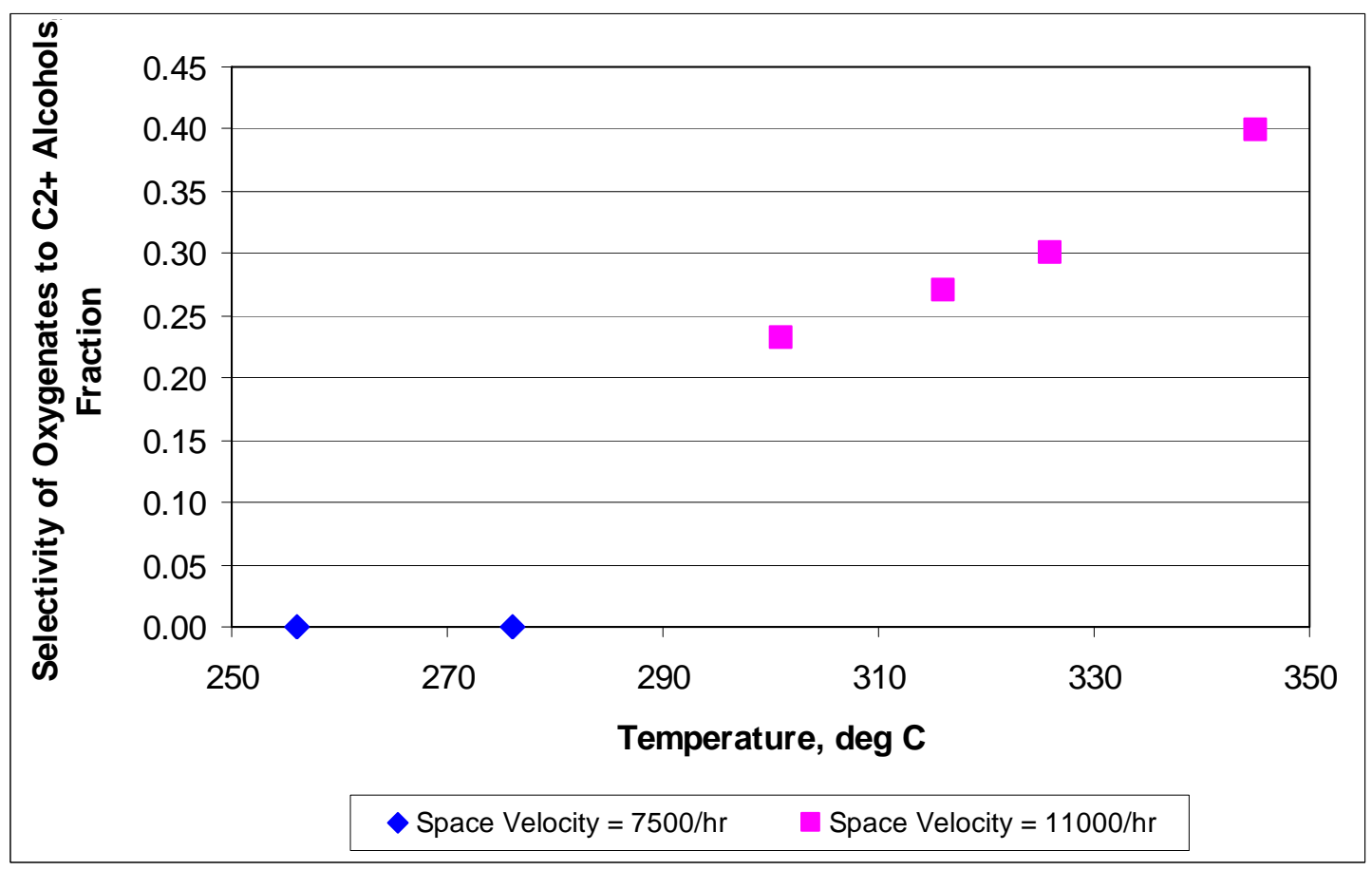

Figure B.35. Carbon Selectivity of All Oxygenates to $\mathrm{C}_{2}+$ Alcohols for the Na-Promoted Catalyst 


\section{B.8 B-Promoted Catalyst}

The B-promoted catalyst $\left(\mathrm{RhMnB} / \mathrm{SiO}_{2}\right)$ was tested at all of the standard conditions up to approximately $325^{\circ} \mathrm{C}$, and with a repeat condition at approximately $300^{\circ} \mathrm{C}$. There were no problems with temperature control during the tests.

Figure B.36 shows that the carbon conversion increased with increasing temperature up to the maximum test temperature of $325^{\circ} \mathrm{C}$. The repeat condition indicates that there was a significant deactivation of the catalyst at the higher temperatures.

The $\mathrm{C}_{2}+$ oxygenates STYs behaved in a fairly similar manner with as the carbon conversion except that there was slight decrease in the STY as temperatures increased from $300^{\circ} \mathrm{C}$ to $325^{\circ} \mathrm{C}$ as shown in Figure B.37. This is attributed to the decrease in the carbon selectivity to $\mathrm{C}_{2}+$ oxygenates when the temperature was increased (Figure B.38). The decrease in carbon selectivity offset any gains resulting from increased carbon conversion. Again, the repeat condition shows that there was considerable decrease in the activity of the catalyst. Data from the repeat conditions shown in Figure B.38 and Figure 39 also show that catalyst deactivation at the higher temperatures affected both the carbon selectivity to $\mathrm{C}_{2}+$ oxygenates (selectivity decrease) and the fraction of oxygenates that were $\mathrm{C}_{2}+$ alcohols (selectivity increase). Carbon selectivity to the various hydrocarbons shown in Figure B.40 suggests that the catalyst began deactivation between $275^{\circ} \mathrm{C}$ and $315^{\circ} \mathrm{C}$. There was very little further effect of the higher temperatures on the selectivity to hydrocarbons.

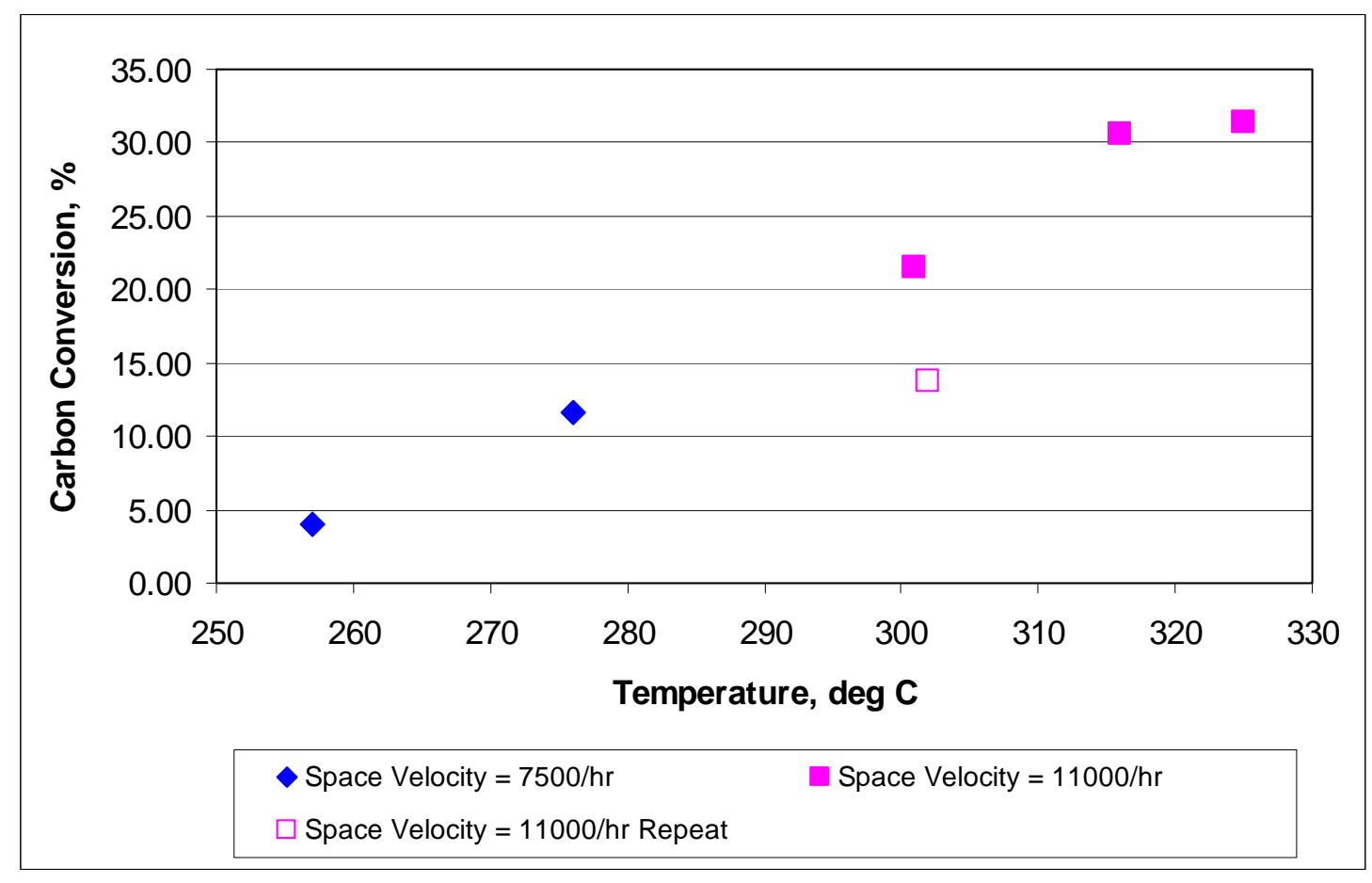

Figure B.36. Carbon Conversion for the B-Promoted Catalyst 




Figure B.37. $\mathrm{C}_{2}+$ Oxygenate STYs for the B-Promoted Catalyst

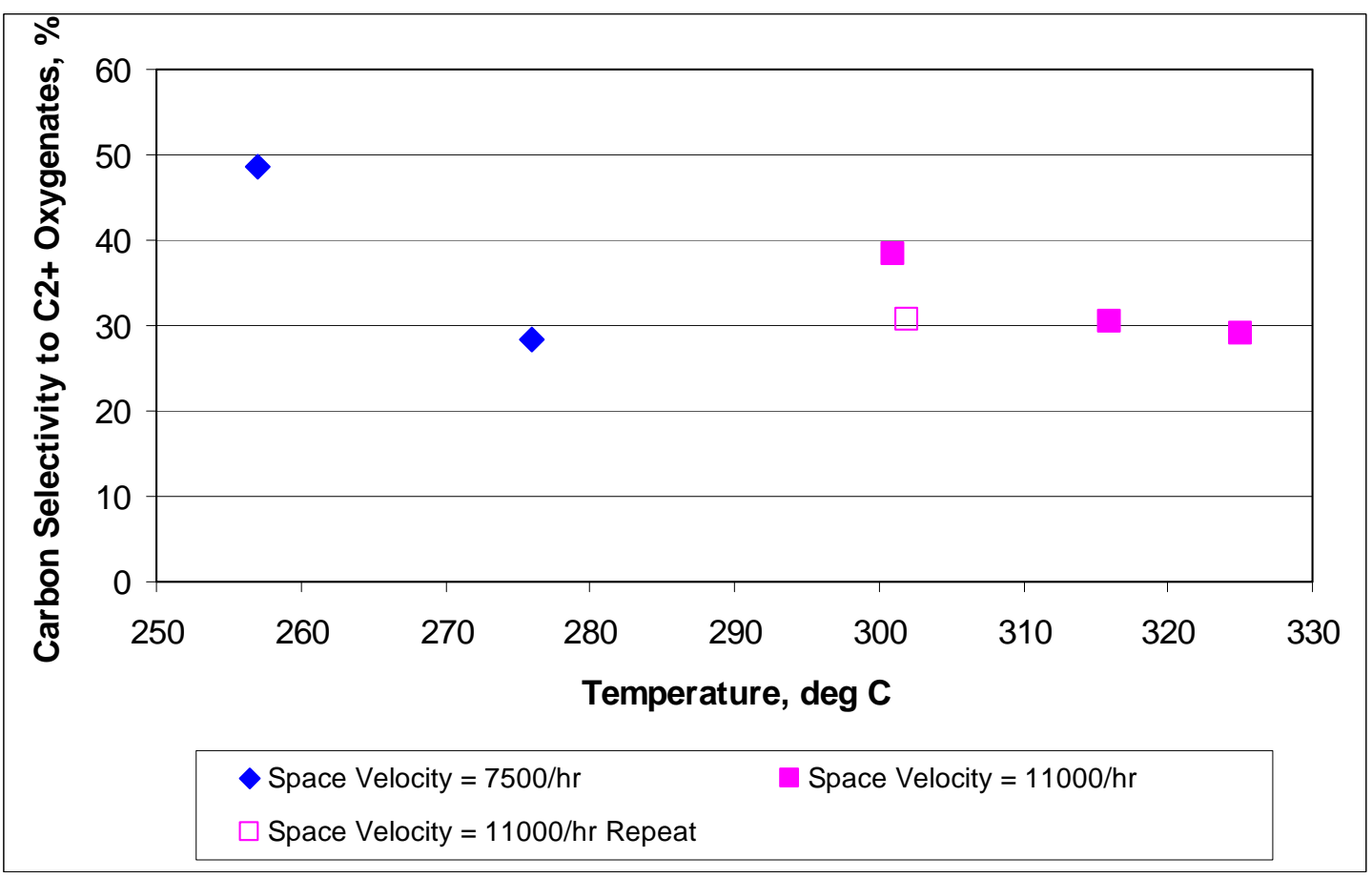

Figure B.38. Converted Carbon Selectivity to $\mathrm{C}_{2}+$ Oxygenates for the B-Promoted Catalyst 


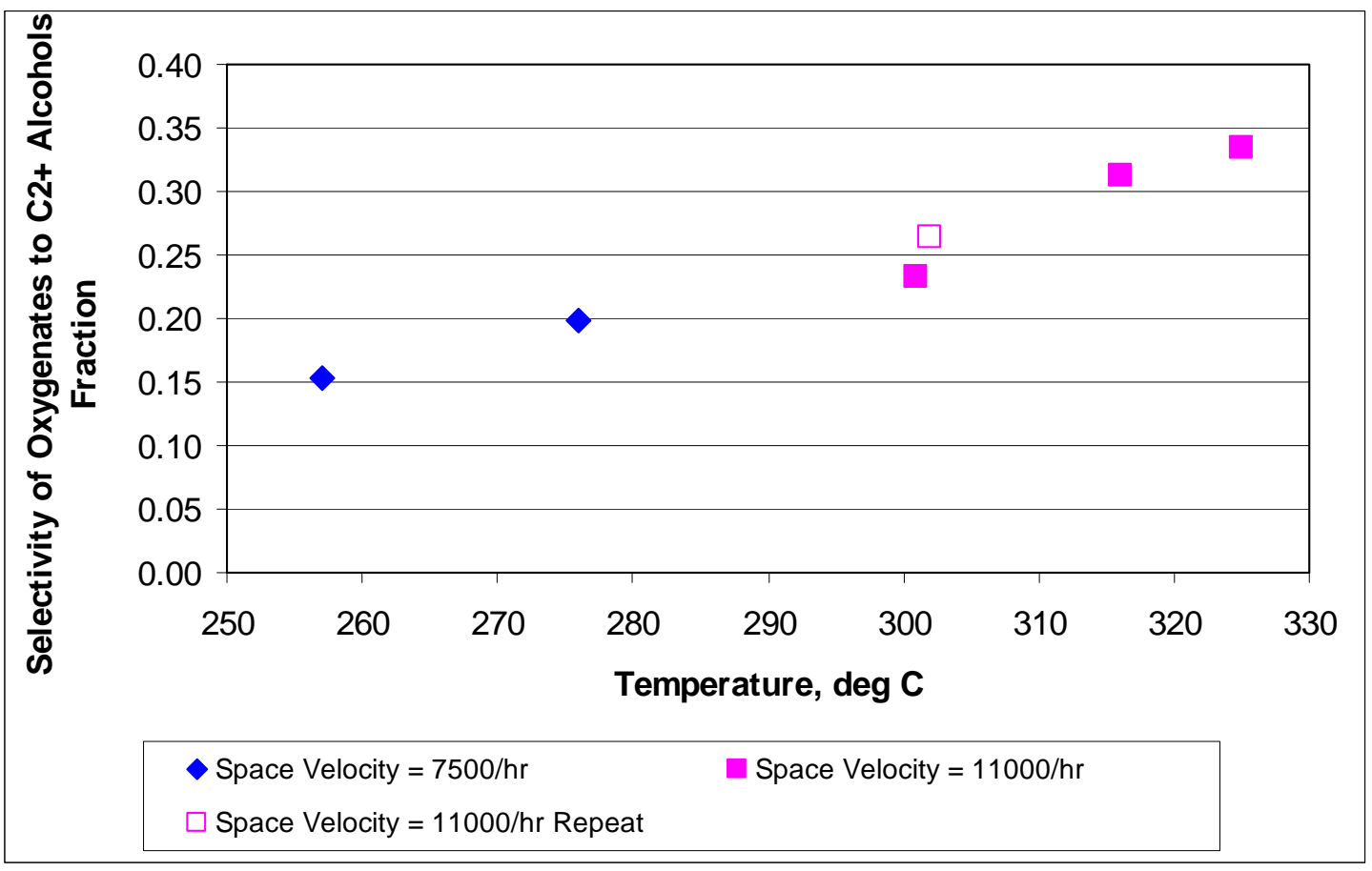

Figure B.39. Carbon Selectivity of All Oxygenates to $\mathrm{C}_{2}+$ Alcohols for the B-Promoted Catalyst

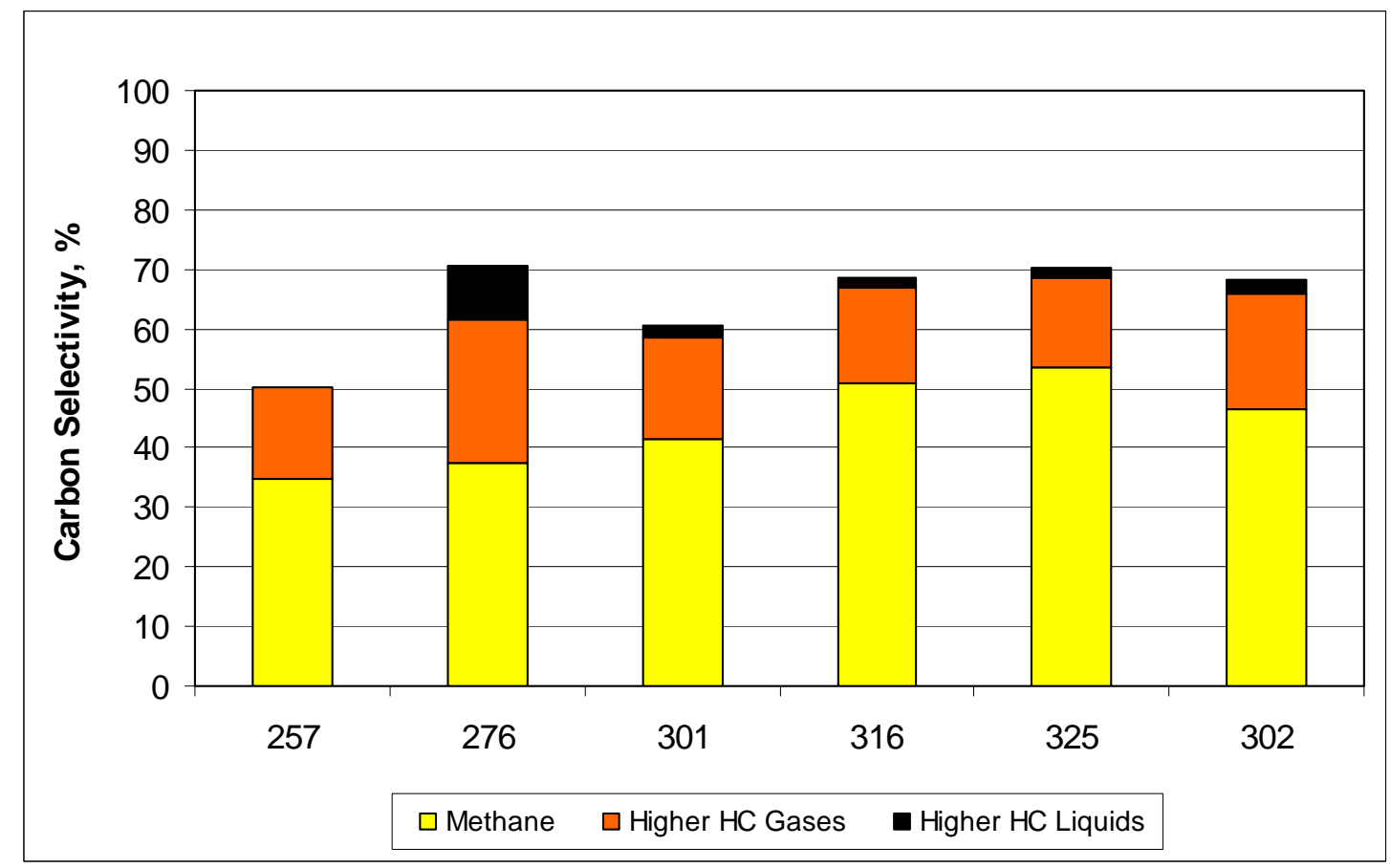

Figure B.40. Comparison of Hydrocarbon Selectivity for the B-Promoted Catalyst 


\section{B.9 W-Promoted Catalyst}

The W-promoted catalyst ( $\mathrm{RhMnW/SiO}$ ) was tested at all of the standard conditions up to approximately $315^{\circ} \mathrm{C}$, and with a repeat condition at approximately $300^{\circ} \mathrm{C}$. Higher temperatures were not investigated because of the poor selectivity to $\mathrm{C}_{2}+$ oxygenates at the lower temperatures. The catalyst also was difficult to control when first attempting to conduct a run at $315^{\circ} \mathrm{C}$. The catalyst temperature spiked several times while increasing the temperature from $275^{\circ} \mathrm{C}$ to $316^{\circ} \mathrm{C}$ and then it cooled $7^{\circ} \mathrm{C}$ overnight. The condition was repeated with a $4.5^{\circ} \mathrm{C}$ temperature drop overnight. No problems were encountered at repeated condition at $300^{\circ} \mathrm{C}$.

This catalyst was fairly active with carbon conversion reaching about $30 \%$ at $314^{\circ} \mathrm{C}$ as shown in Figure B.41. However, carbon selectivity to $\mathrm{C}_{2}+$ oxygenates was relatively low and constant ( 20\% to $27 \%$ ) during tests at $275^{\circ} \mathrm{C}$ and higher as shown in Figure B.43). The resulting $\mathrm{C}_{2}+$ oxygenates STYs appeared to reach a relatively constant level at $300^{\circ} \mathrm{C}$, reaching a maximum of $320 \mathrm{~g} / \mathrm{L}_{\text {cat }} / \mathrm{hr}$ at $314^{\circ} \mathrm{C}$ as shown in Figure B.42. The STY at the repeat condition of $300^{\circ} \mathrm{C}$ was significantly lower, indicating catalyst deactivation at the higher temperatures. Figure B.44 shows that, with the exception of the test condition at $275^{\circ} \mathrm{C}$, the selectivity of oxygenates to $\mathrm{C}_{2}+$ alcohols was relatively constant between $27 \%$ and $33 \%$. Figure B. 45 shows that the selectivity to hydrocarbons was fairly unaffected from $275^{\circ} \mathrm{C}$ to $315^{\circ} \mathrm{C}$.

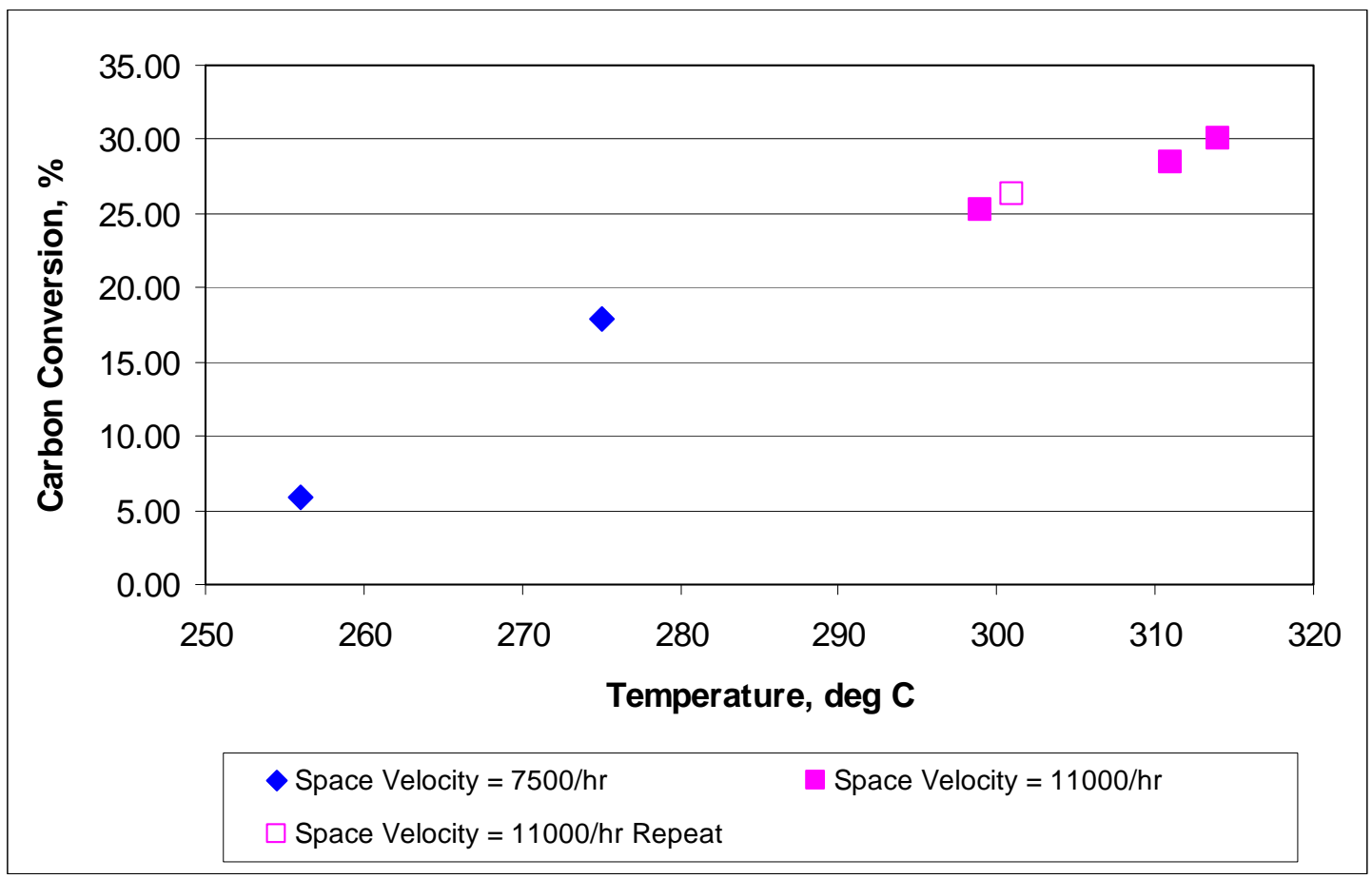

Figure B.41. Carbon Conversion for the W-Promoted Catalyst 




Figure B.42. $\mathrm{C}_{2}+$ Oxygenate STYs for the W-Promoted Catalyst

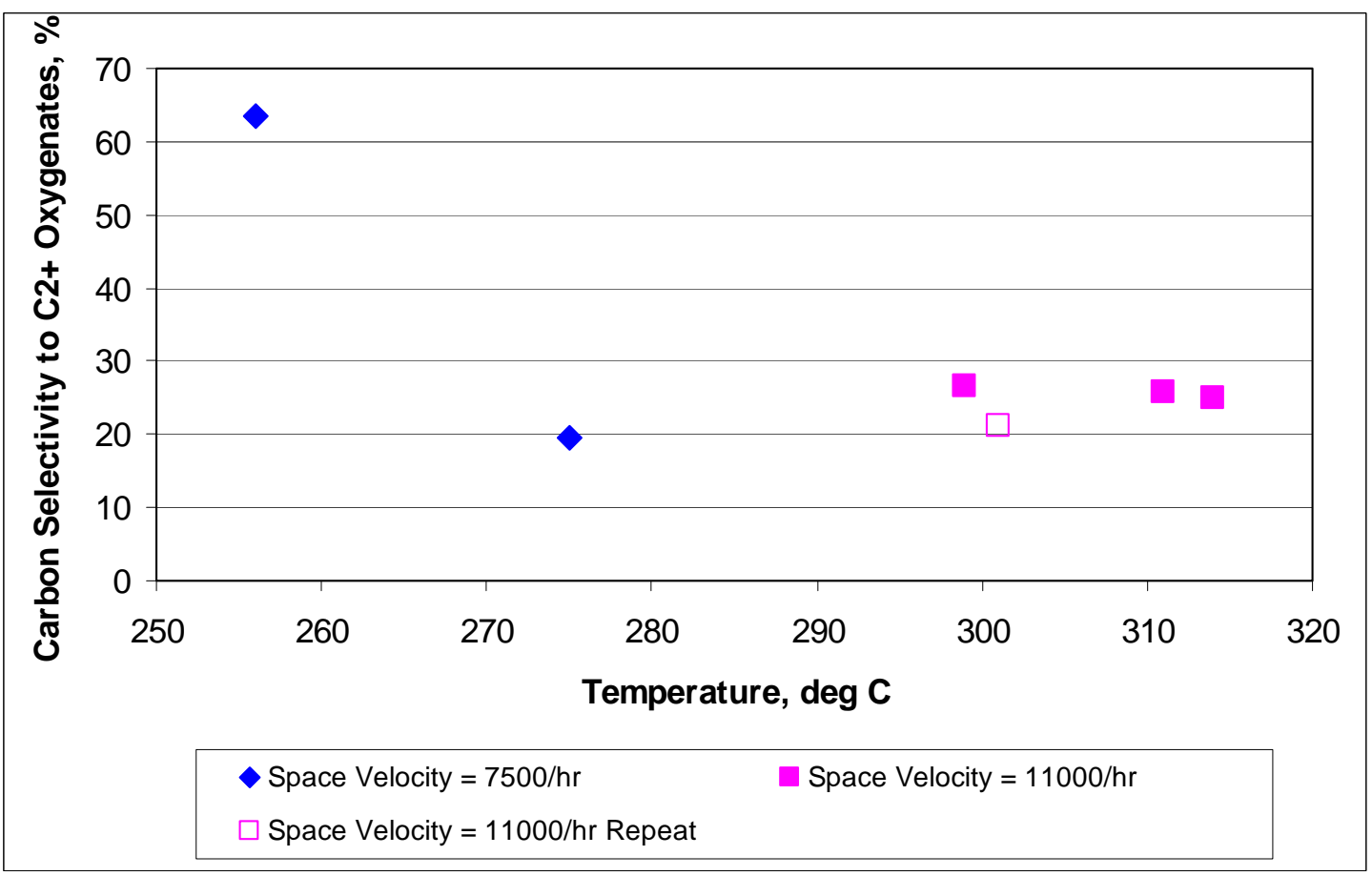

Figure B.43. Converted Carbon Selectivity to $\mathrm{C}_{2}+$ Oxygenates for the W-Promoted Catalyst 


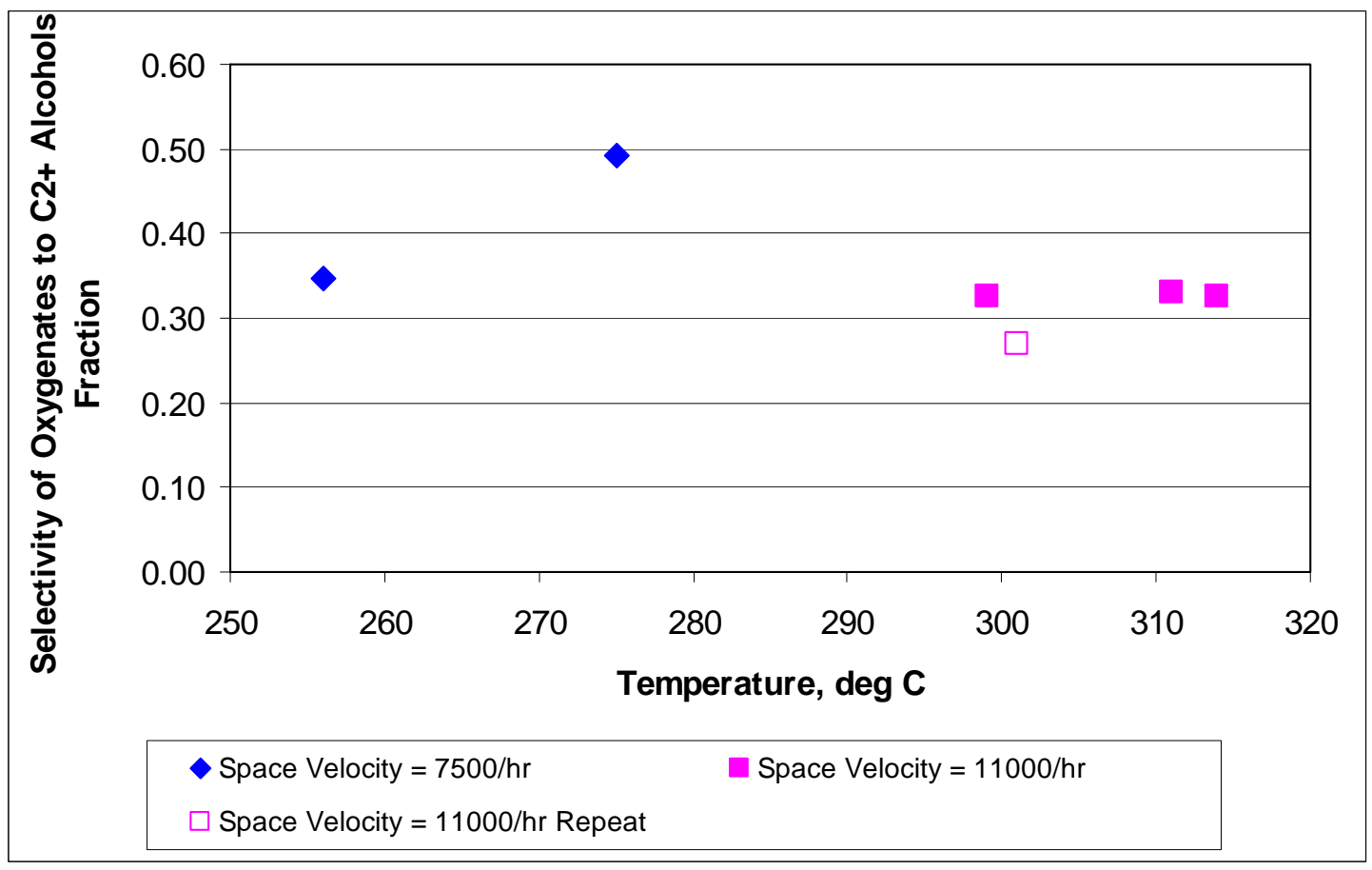

Figure B.44. Carbon Selectivity of All Oxygenates to $\mathrm{C}_{2}+$ Alcohols for the W-Promoted Catalyst

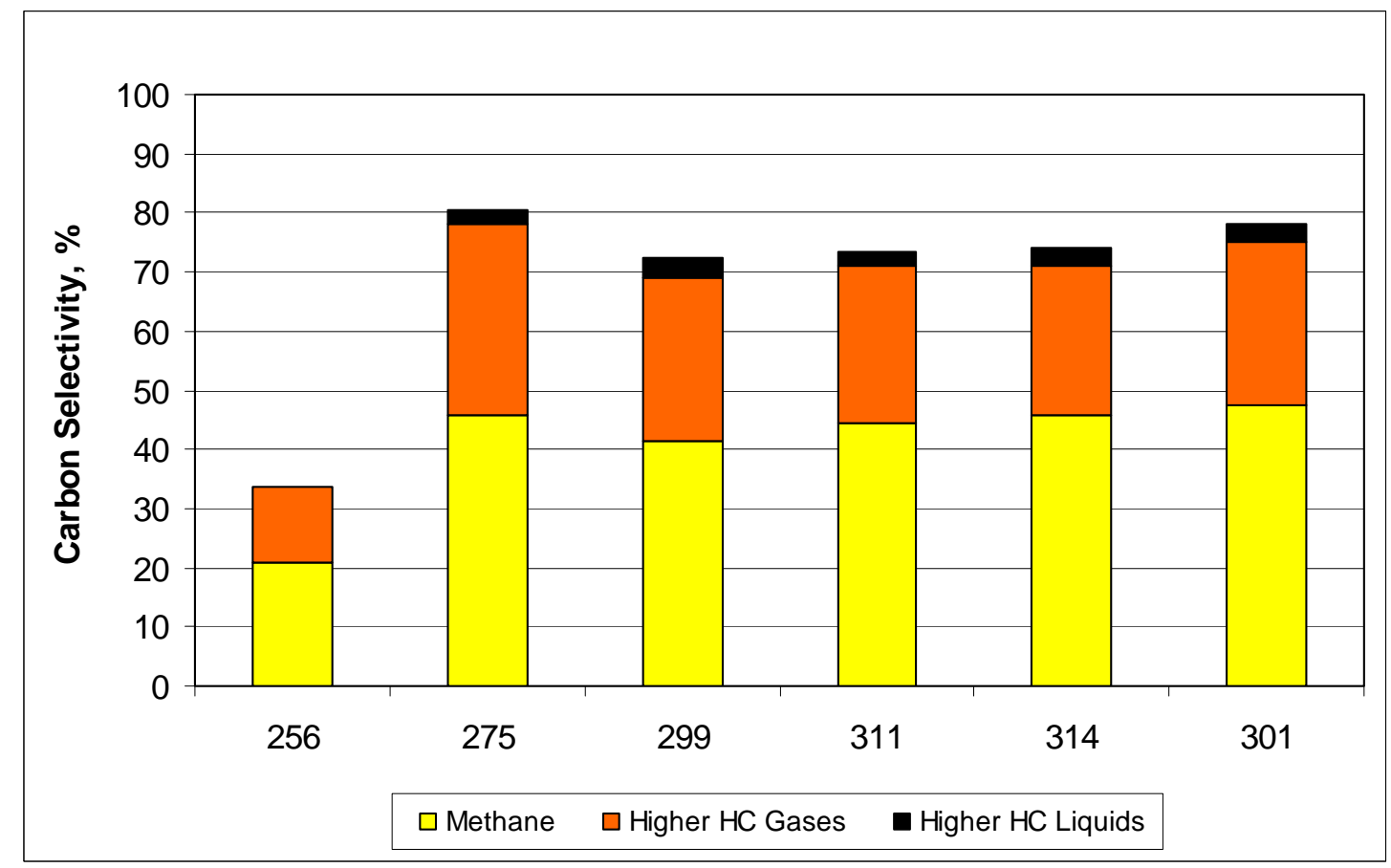

Figure B.45. Comparison of Hydrocarbon Selectivity for the W-Promoted Catalyst 




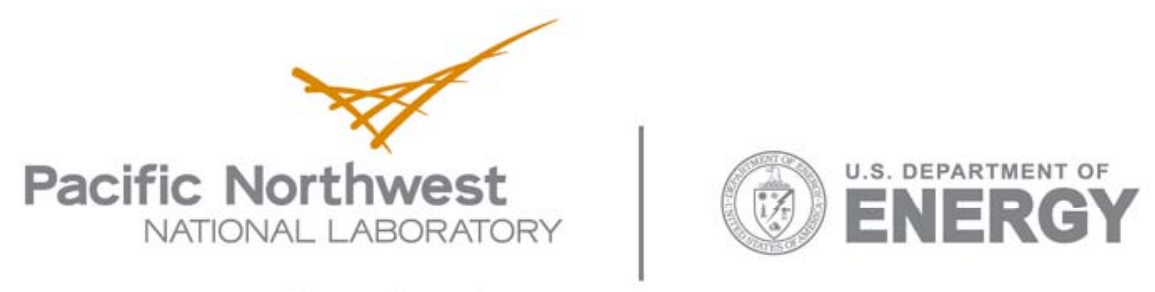

902 Battelle Boulevard

P.O. Box 999

Richland, WA 99352

1-888-375-PNNL (7665)

www.pnl.gov 